\title{
Pain-related fear in acute low back pain; towards understanding and prevention of chronicity
}

Citation for published version (APA):

Sieben, J. M. (2005). Pain-related fear in acute low back pain; towards understanding and prevention of chronicity. [Doctoral Thesis, Maastricht University]. Datawyse / Universitaire Pers Maastricht. https://doi.org/10.26481/dis.20051111js

Document status and date:

Published: 01/01/2005

DOI:

10.26481/dis.20051111js

Document Version:

Publisher's PDF, also known as Version of record

\section{Please check the document version of this publication:}

- A submitted manuscript is the version of the article upon submission and before peer-review. There can be important differences between the submitted version and the official published version of record.

People interested in the research are advised to contact the author for the final version of the publication, or visit the DOI to the publisher's website.

- The final author version and the galley proof are versions of the publication after peer review.

- The final published version features the final layout of the paper including the volume, issue and page numbers.

Link to publication

\footnotetext{
General rights rights.

- You may freely distribute the URL identifying the publication in the public portal. please follow below link for the End User Agreement:

www.umlib.nl/taverne-license

Take down policy

If you believe that this document breaches copyright please contact us at:

repository@maastrichtuniversity.nl

providing details and we will investigate your claim.
}

Copyright and moral rights for the publications made accessible in the public portal are retained by the authors and/or other copyright owners and it is a condition of accessing publications that users recognise and abide by the legal requirements associated with these

- Users may download and print one copy of any publication from the public portal for the purpose of private study or research.

- You may not further distribute the material or use it for any profit-making activity or commercial gain

If the publication is distributed under the terms of Article $25 \mathrm{fa}$ of the Dutch Copyright Act, indicated by the "Taverne" license above, 
Pain-related fear in acute low back pain: towards understanding and prevention of chronicity Judith Sicben - thesis Mastricht University - with references - with summary in Dutch.

All rights reserved. No part of this book may be reproduced, stored in at retrieval system or transmitted in any form or by any means, without written permission from the publisher.

\section{(1) 2005 J.M. Sieben, Mastricht, the Nerherlands.}

ISBN-10: $90-9020000-2$

ISBN-13: 978-90-9020000-2

Cover: "Hanna", sculpture by Noor van Nierop.

The studies presented in this thesis have been supported by the Dutch Council for Medical and Health Research (MW-NWO), grant nr. 904-65-090.

Financial support for the printing of this thesis has been kindly provided by Anna Fonds, Leiden and Nederlandse Vereniging van Rugpatiënten (NVVR) "de Wervelkolom".

Book preparation, cover design and printing: Datawyse / Universitaire Pers Maastricht. 


\title{
Pain-related fear in acute low back pain
} towards understanding and prevention of chronicity

\author{
PROEFSCHRIFT
}

ter verkrijging van de graad van doctor aan de Universiteit Maastricht, op gezag van de Rector Magnificus

Prof. mr. G.P.M.F. Mols, volgens het besluit van het College van Decanen,

in het openbaar te verdedigen op vrijdag 11 november 2005 om 14.00 uur

door

Judith Mirjam Sieben 


\section{Promotores}

Prof. dr. J.A. Knotmetus

Prof. dr. A. Antw:

\section{COPROMOTORES}

Dr. J.W.S. Vlaeyen

Dr. P.J.M. Portegujs

\section{BEOORDELINGSCOMMISSIE}

Prof. dr. R.A. De Bie (voorzitter)

Prof. dt. M. Van Kleef

Prof. dr. S.j. Linton (Örebro University, Sweden)

Prof. dr. J.F.M. Metsemakers

Mevt. dr. M.I. Peters 


\section{CONTENTS}

\section{Chapter 1}

Introduction

Chapter 2

Pain-related fear in musculoskeletal pain disorders

\section{Chapter 3}

Pain-related fear in acute low back pain: the first two weeks of a new episode

\section{Chapter 4}

Pain-related fear at the start of a new low back pain episode

\section{Chapter 5}

A longitudinal study on the predictive validity of the fear-avoidance model in low back pain

\section{Chapter 6}

Exposure in vivo treatment in acute low back pain patients with elevated levels of pain-related fear: a randomized controlled trial

\section{Chapter 7}

General practitioners' treatment orientations towards low back pain:

\section{Chapter 8}

General discussion

Summary

Samenvatting

Dankwoord 



\section{Chapter 1}

Introduction 
Tomnsman: "Doc, those pills, y' gave me for my backe? I'm not sure that they work" Doc WVilson: "Woll, I'm not sure either, but y' don't bear me complain..." (Opening scene of the movie "State and Main", 2000, director David Mamet)

These words well describe a familiar feeling both patients and doctors may recognize: what to do about low back pain? Together with the knowledge that most of you reading this thesis will likely have experienced back pain some time during adult life (or will, I'm sorry!), this may better illustrate the relevance of the work presented here than all figures on incidence rates and health care costs together.... 


\section{HISTORICAL PERSPECTIVE}

Low back pain (LBP) probably has been a problem since mankind started walking upright. The first known medical document in history, the Edwin Smith Papyrus (1700 B.C.), already reported on LBP (Breasted, 1930). This ancient text describes "a case of back strain", which the Egyptian surgeon who wrote it considered "an ailment which I will treat" (used throughout the document for injuties that most likely will be cured). Since then many more papers on LBP have been wittten, and many (experimental) studies have been conducted. In a nutshell, medical knowledge developed from Descartes' mechanical model of pain (17 th century) to modern biopsychosocial theoties (Waddell, 1998). However, nowadays LBP still is a major health problem, especially in industrialised societies.

More recently (during the last decade), pain-researchers focussed their work on finding factors that could help predict the course of LBP. For how can we explain that LBP is just a temporary and spontaneously resolving complaint in many patients, but at the same time often becomes a recurrent or chronic, highly interfering problem in others? It was found that cognitive and behavioural factors (reflecting the way people think about and deal with their pain) are much better predictors of future LBP outcome than physical diagnostics are.

\section{PAIN-RELATED FEAR: A CAUSAL FACTOR?}

The studies presented in this thesis are part of the FADIS ("Fear-avoidance beliefs, physical disuse and pain disability in low back pain') research program that aims at further refinement of knowledge on a specific cognitive-behavioural pathway to chronicity. The fear-avoidance model, developed by Johan Vlaeyen and his colleagues, postulates that LBP patients who are highly fearful of physical activity and movement (because they fear pain and/or reinjury), ate more vulnerable to become chronically disabled. "This concept of pain-related fear or "kinesiophobia" (as it is also called) originates from and was validated in (mainly cross-sectional) studies in chronic LBP patients. An important next step is to test its" validity as an explanation for the transition from acute to chronic LBB? conditions. If painrelated fear at an early stage turns out to be a predictor (rather than a consequence) of disability, this may offer new opportunities for screening and (secondary) preventive treatment.

\section{OUTLINE OF THIS THESIS}

The overall aim of the studies described in this thesis is to test the causal role of pain-related fear in the development of chronic L.BP. Chapter two provides an overview of theory, in which the fear-avoidance model and its backgrounds are described and the concept of pain-rellated fear is introduced. 
Before the start of this research only little was known about pain-related fear in acute stages of low back pain. Would pain-related fear really be detectable soon after the onset of back pain, as we expected? Are pain-related fear levels comparable to those in chronic patients? And what about its' stability over time? Clatpter three reports on a pilot study in acute low back patients. By using dairy methods, fear-avoidance processes were closely observed during the first two weeks of a LBP episode.

Furthermore it was assumed that early stage pain-related fear levels would predict long-term LBP outcome (in terms of pain and disability). We conducted a prognostic cohort study in general practice LBP patients who consulted their general practitioner (GP) because of a new LBP episode. In chapter four the crosssectional associations between fear-avoidance variables at baseline are described, and in the next one (chapter five) the results of longitudinal analyses are presented.

The strongest proof of a causal relationship is an experiment; we assumed that manipulation of pain-related fear in acute patients would influence LBP prognosis. Cbapter six reports on a tandomised controlled trial (RCT) in which the effects of a fear-reducing exposure in vivo treatment in addition to usual care are tested.

Up to this point, patients had been the subjects of our research and this thesis. However, it can be hypothesised that not only the patients' cognitions towards LBP are relevant, but also the LBP ideas of their health care providers. As health care providers are supposed to influence patients' beliefs and behaviour, their own treatment orientation towards LBP will be reflected in the way they educate and advice their patients. Chapter seven reports on a study that adds to the cohort study; we explored associations between GP treatment orientation, actual treatment behaviour and IBBP outcome in patients.

Finally, chapter eight provides a general discussion evaluating the methods, findings and conclusions of all these studies together. Clinical implications are discussed, and recommendations for future research are addressed.

\section{REFERENCES}

- Breasted, J.H. (1930). The Edwin Smith Surnizal Papyrus. Chicago: University of Chicago Press.

- Waddell, G. (1998). The Bace Pain Rewolution. Edinburgh: Churchill Livingstone. 


\section{Chapter 2}

\section{Pain-related fear in musculoskeletal pain disorders}

Judith M. Sieben, Jeanine A. Verbunt, Johan W.S. Vlaeyen

This chapter is a slightly edited version of:

Sieben, J.M., Verbunt, J.A., Vlaeyen, J.W.S. (in press) Pain-related fear in musculoskeletal pain disorders. In: Simmonds, M.). (ed.) Measuring and managing patients, practitioners and therapies in rehabilitation. Pain research and clinical management series. Elsevier, Edinbutgh. 


\section{INTRODUCTION}

The epidemically growing number of patients with chronic musculoskeletal pain syndromes is one of the most important medical and socio-economic problems in industrialised countries (Engel et al., 1996; Waddell, 1996). Besides hïgh health-care and societal costs, chronic musculoskeletal disorders also cause considerable suffering for individual patients. Chronic pain patients are generally faced with physical disability, wotk absenteeism and psychological problems (Dionne, 1.999).

Since a few decades it is widely recognised that a pure biomedical and mechanical approach to musculoskeletal pain is insufficient (Waddell, 1987) and that pain is not simply a sensory symptom. The gate-control theory (Melzack and Wall, 1965; Melzack and Casey, 1968) firstly distinguished sensory, affective and cognitive dimensions of pain. Later on, clinical psychologists have further explored cognitive and behavioural factors in chronic pain syndromes (Fordyce, 1976; Pincus et al., 2002). Within this biopsychosocial perspective, increased attention is being paid to the role of pain-related fear in the development and maintenance of disability. Several authors concluded that in patients with musculoskeletal disorders, pain-related fear may be more disabling than pain itself, and even may be the key factor in the development of pain disability (Waddell et al., 1993; Crombez et al., 1999b; Vlaeyen and Linton, 2000).

The purpose of this chapter is to provide an overview of concepts and mechanisms involved in pain-related fear in musculoskeletal pain problems. What is pain-related fear, why is it relevant, how can it be measured, and how can it be modified? In this contribution, the theoretical principles are discussed within a clinical perspective, with a special focus on assessment and treatment opportunities.

\section{THE FEAR-AVOIDANCE MODEL OF EXAGGERATED PAIN PERCEPTION}

The attempts of Lethem et al. (1983) to explain why some people develop a chronic pain syndrome resulted in the "fear-avoidance model of exaggerated pain perception". This model was developed from a multidisciplinary perspective on chronic low back pain. Lethem and his group defined exaggerated pain perception as: "Pain experience and/or pain behaviour (and/or physiological respanses to pain stimulation) which is out of all proportion to demonstrable organi patbology or awrent levels of nociceptive stimulation".

According to this model, the development of chronicity can be described as a process in which the emotional dimension of pain ("pain-experience") and the consequent pain behaviour become dissociated from the actual sensory pain stimulation and organic tissue damage. Key factor is fear of pain - which is 
believed to be the most important pain emotion - and consequent confrontation or awoidance responses:

Most people are highly motivated to resume their notmal activities as soon as the initial injury resolves. As a result, they constantly confront their pain. In a natural way expectations about pain are challenged and adjusted to the reality of sensory stimuli at every stage of recovery. This confrontation behaviour is tegarded as adaptive, because it maintains synchrony between pain sensation and pain emotion. In contrast, avoidance of new pain experiences due to fear is a maladaptive response. It strongly reduces the number of opportunities for calibration of pain behaviour against the actual level of nociception, which leads to desynchrony between pain components and to exaggerated pain perception.

It is suggested that confrontation and avoidance are both extremes of a continuum; most people will exhibit a mixture of both behaviours. The position of an individual on this continum is determined by the level of pain-related fear. "The degree to which a patient shows pain-related fear is in turn influenced by personal pain history, coping strategies and personality characteristics.

Empirical evidence supporting the general validity of this model is provided by several studies (Slade et al., 1983; Waddell et al., 1993). Rose et al. (1992) demonstrated this concept to be also applicable to chronic pain problems other than back pain.

\section{KINESIOPHOBIA}

The striking similarities between chtonic pain and phobia have often been noted in literature (Philips, 1987; Kori et al., 1990; Asmundson et al., 1999). First, like phobia, many cases of chronic pain start with a traumatic experience (injury). The resulting avoidance of potential painful actions in pain patients is similar to the avoidance of stimuli and situations, which are perceived to be equally dangerous ns the initial one, in phobic patients. Both types of avoidance behaviour tend to generalize to a growing number of situations, becoming persistent and excessive in nature. Also similar patterns of comorbidity are found in both phobic and chronic pain populations. In both groups anxiety and depression are common symptoms (Linton, 2000; Bienvenu et al., 2001). Furthermore, phobic patients mostly are aware of the irrational character of their fear. In chronic pain patients the presence of fear of pain is unreasonable too, when considering medical findings. Although, a difference is that in chronic pain, patients are convinced that their pain really indicates danger, despite lacking medical evidence.

Kori et al. (1990) argued that at least a substantial subgroup of chronic pain patients actually suffers from a specific type of phobic disorder, and introduced the term "kinesiophobia" (kinesis $=$ movement). Kinesiophobic patients are characterised by "an excessive, irrational and debilitating fear of physical thovement and 
ativity resulting frow a feeling of whlnerability to painful ingury or reinjwry". The concept of kinesiophobia had not been recognised as such before, but it did provide a useful framework for integration of current knowledge of cognitions, emotions and behaviout of chronic musculoskeletal pain patients.

\section{A COGNITIVE-BEHAVIOURAL MODEL OF FEAR OF MOVEMENT/ (RE) INJURY}

Efforts to join the previously described models and recent research findings concerning the role of fear and avoidance in musculoskeletal pain resulted in the cognitive-behavioural model of fear of movement/(re)injury as it is described by Vlaeyen et al. (1995a; 1995b) (see figure 2.1). Although the model of Lethem et al. already sufficiently predicted which subgtoup of patients is at risk of becoming a chronic pain patient, little was still known about the mechanisms involved in the development of musculoskeletal pain problems. Earlier research was largely crosssectional in nature, leaving the question whether fear of movement/reinjury should be interpreted as a causal factor tather than a consequence of chronic pain.

Figure 2.1 Cognitive-behavioural model of fear of movement/(re)injury

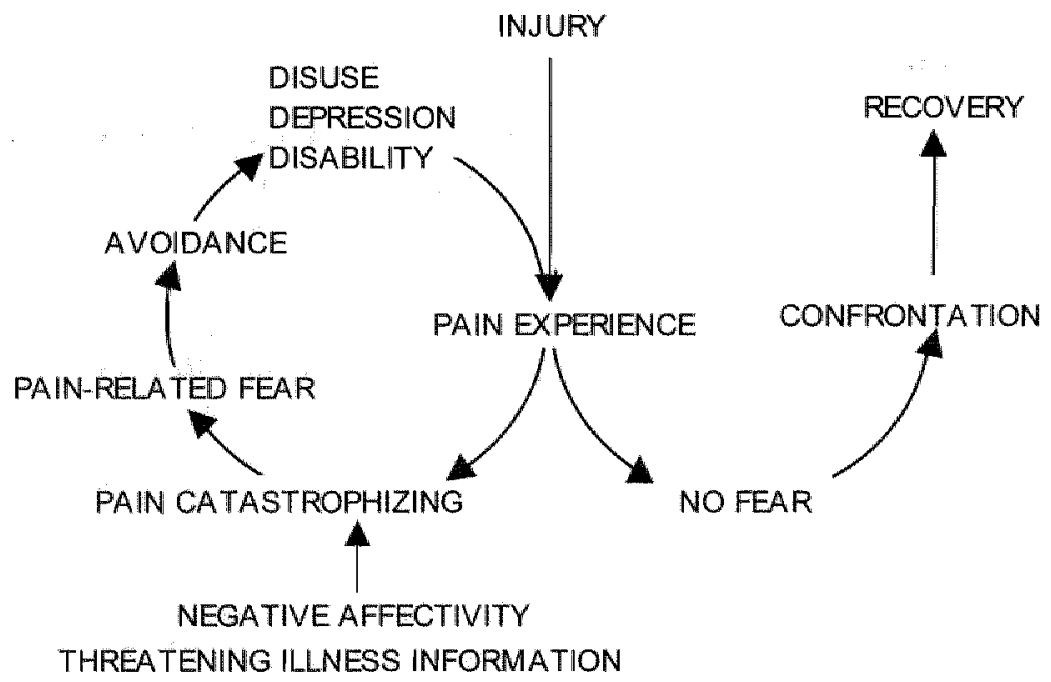

Reprinted from: Vlacyen, J.W.S. and Jinton, S.J. Fear-avoidance and its consequences in chronic musculoskeletal pain: a state of the art. Pastr, 2000; $85: 317-3332$. (Reproduced with permission) 
This model again shows two opposite responses to acute injury, that is confrontation and avoidance. Pain catastrophizing (attentional bias towards and overinterpretation of negative pain-related information) is found to be a precursor of fear of movement/reinjury (McCracken and Gross, 1993; Vlaeyen et al., 1995b; Crombez et al, 1998). During the acute stage after injury, physiological reactions like muscular reactivity (elevated muscle tension), and often-observed guarded movements (disrupted musculoskeletal coordination) can aggravate the pain experience in already fearful patients (Flor et al., 1992; Main and Watson, 1996). These patients are likely to become avoiders, who end up in a cycle of fear, physical inactivity (disuse) and consequent physical deconditioning, disability and depressive symptoms. This model suggests that fear can both play a crucial causal role in the process of acute pain becoming chronic, and be a maintaining factor once a patient has developed a chronic pain syndrome. Supporting evidence is accumulating. A longitudinal study done by Klenerman et al. (1995) showed fearavoidance variables to be better predictors of one-year outcome than pain history, and another study by Picavet et al. (2002) showed that pain-related fear and pain catastrophizing predicted disability at six months follow-up. Buner and Linton (2002) found fear-avoidance to be associated with activity levels in a sample of pain-free individuals. Linton et al. (2000) furthermore suggested pain-related fear to be related to the inception of LBP episodes.

\section{IMPACT OF AVOIDANCE BEHAVIOUR}

Structural avoidance of physical activities in daily life can have far-teaching physical as well as psychological consequences. Immediately following injury, escape and avoidance strategies (such as resting or limping) may be appropriate coping responses, because they reduce nociception and facilitate tissue healing (Wall, 1979). However, long-term adaptation of posture and avoidance of fear-eliciting daily activities may result in a combination of problems: disability, disuse (a decreased level of physical activity in daily life) and depression.

\section{DISABILITY}

Avoiding physical activities substantially affects one's personal life, as it also involves work, sports and leisure time activities. Besides physical impairments, the limited behavioural repertoire resulting from generalized and persistent avoidance strongly disables the patient (Waddell, 1991; Al-Obaidi et al., 2000; Van den Hout et al., 2001). The patient easily becomes "trapped" in a vicious cycle, and depression, as a result of deprivation of daily teinforcement, is likely to occur as well (Dionne et al., 1997). 


\section{DISUSE AND DECONDITIONING}

Disuse is considered to be another consequence of avoidance behaviour. It is assumed that fearful parients, who systematically avoid daily physical activities, have to deal with physical deconditioning: a decreasing level of physical fitness. And since physical fitness can be seen as a multidimensional phenomenon, which includes musculat strength, endurance and power, joint flexibility, cardiorespiratory endurance, speed, teaction time, balance and body composition (Protas, 1999), changes have to be expected on all these physical domains in patients reporting lower levels of physical activity. In pain literature, comparisons are even made with the disuse syndrome; a concept, which describes the physiological changes of the human body in a long term bedridden, immobilised situation (Bortz, 1984).

However, in contrast to the influence of pain-related fear on the perceived disability level, the presumed negative influence of pain-related fear on the actual level of physical activity in daily life and accompanying deconditioning has received less attention in pain literature. Evidence in this area is inconclusive. Regarding the domain of aerobic fitness, several researchers (Schmidt, 1985, 1986; Brennan et al., 1987; Van der Velde and Mietau, 2000) found a significant lower aetobic fitness in patients, while Battie et al. (1989), Hurrie et al. (1991), Kellet et al. (1991) and Wittink et al. (2000) found comparable levels for patients and controls. Moreover, in several studies (Hurri et al., 1991; Wittink et al., 2000; Verbunt et al., 2001) the association between disability and physical activity or physical fitness appeared to be weak of non-existing. Pain-related fear and disability seemed to better relate to a perreived decline in the level of physical activity since the onset of pain than to the actual activity level (Verbunt et al., in press).

Considering these results, the hypothesized influence of physical deconditioning as referred to a disuse syndrome in chronic low back pain can be questioned. About $50 \%$ of the Dutch adults and even more than $60 \%$ of the American adults show an inactive lifestyle (i.e. performing activities less than 30 minutes of moderate-intensity physical activity on five days of the week) (USDHHS, 1996; Hildebrandt et al., 1999). This may give rise to the question whether the deconditioning problem in chronic pain exceeds its presence in the general population. The extent of the problem of deconditioning in chronic pain and its specific perpetuating role in chronicity are still unclear.

Besides, physical performance testing in chronic pain patients can be complicated. Behavioural factors causally related to avoidance behaviour, such as fear of injury can lead to submaximal performance during the test, thus influencing test validity (Watson, 1999). Fearful patients will not end a test when maximum performance levels are reached, but when escape and avoidance win out. Also, 
tests that were supposed to measure fatigue or endurance of specific muscle groups, appeared to measure pain tolerance instead (Novy et al., 2002).

In summary, conclusions are diverse, depending on the physical domain studied and the tests used. In chronic pain patients disuse in terms of physical deconditioning has not been demonstrated, but rather some evidence indicating disordered muscular coordination is available (Lamoth et $\mathrm{al}_{1,}$ 2002). More research is needed to further explore the exact relationship between fear of morrement, pain and physical consequences.

\section{COGNITIVE ASPECTS}

Another issue in avoidance behaviour is that of its cognitive aspects. Fordyce (1976) described avoidance in terms of operant learning mechanisms. He argued that chronic pain patients persist in their avoidance behaviour because of external reinforcement. Pain behaviour may be positively reinforced by attention from a partner or health care provider, or negatively ireinforced by successful avaldance of undesirable activities and responsibilities. However, avoidance of physical activity has been shown to be related more to fear of pain than to actual reinforcement (Linton, 1985). A cognitive avoidance learning theory (Philips, 1987) explains avoidance as an anticipation of pain, instead of as a response to it. Fearful patients avoid physical activities because they expect pain or reinjuxy. However, by avoiding these activities, they deprive themselves of the opportunity to experience the inaccuracy of their beliefs. The avoidance response prevents them from learning that an alternative behaviour (becoming physically active) would have been harmless and more adaptive. Without external intervention, they will persist in their dysfunctional fear and avoidance.

\section{PAIN IN CHRONIC PAIN SYNDROMES}

As mentioned before, during the acute stage after injury nociceptive stimulation takes place, causing a reasonable pain experience. But latier on, when the pain problem becomes chronic, pain experience often becomes dissociated from the actual and initial sensory input. Although the initial tissue damage will soon be resolved in most cases, in the long term disuse-effects due to avoidance can result in lower pain-thresholds, causing increased pain experience. Furthermore, permanently elevated levels of muscular tension (due to both muscular reflexes and guarded movements) can aggravate the pain problem. As a result increasingly more movements become painful (and will thus be avoided).

On the other hand, several studies have shown pain-intensity to be a poor predictor of disability in chronic patients (Vacyen et al., 1995b), probably because of its' desynchrony with other variables. However, recent studies indicate pain- 
intensity to be a rather good predictor of disability in subacute patients (Fritz et al., 2001; Van den Hout et al, 2001). Although more research into the underlying mechanisms is needed, these findings suggest that desynchrony may develop gradually together with the increasing level of disability.

\section{ATTENTION TO PAIN}

In his cognitive theory of anxiety, Eysenk (1997) assumes that anxiety serves to facilitate early detection of potentially threatening situations. Fearful patients therefore tend to be easily distractible (general hypervigilance) and attend selectively to pain-related stimuli (specific hypervigilance). This attentional bias towards threat-related information may highly interfere with other tasks, such as usual everyday activities.

Chronic patients have been demonstrated to pay more attention to bodily sensations, being hypervigilant for pain stimuli (Asmundson et al., 1997; McCracken, 1997). More particularly, attention to pain has been shown to be associated with pain-related fear (Crombez et al., 1999a), and is hypothesized to mediate the relationship between pain-related fear and pain severity. There is evidence that patients reporting pain-related fear scan their body faster than low fearful patients, and that this scanning process amplifies the intensity of innocuous stimuli (Peters et al., 2000). Eccleston and Crombez (1999) furthermore argued that the attentional demand of pain is closely related to an urge to escape. It is suggested that pain-related fear facilitates and intensifies the activation of escape mechanisms and in this way aggravates the interruptive function of (threatening) pain.

\section{HOW CAN PAIN-RELATED FEAR BE MEASURED?}

Several questionnaires are developed to measure pain-telated fear (see table 2.1). Four well-known instruments are introduced in the following paragraph, but more are available. Although they are all frequently used, there are some small conceptual differences between them.

\section{Questionnaires - concepts and differences}

The Fear-Avoidance Beliefs Questionnaire (FABQ) was developed by Waddell et al. (1993) for routine clinical testing of subacute and early chronic low back pain patients. The 16-item FABQ measures fear-avoidance beliefs about work and physical activity. Each item is scored on a 7-point scale (strongly disagree to strongly agree) and two subscale scores (one for work and one for physical activity) are obtained. 
Table 2.1 Examples of pain-related fear questioninaires

\section{Fear Avoidance Beliefs Questionnaire (FABQ)}

My pain was caused by physical activity.

I should not do physical activities which (might) make my pain worse.

My work might harm my back.

I should not do my normal work with my present pain.

\section{Pain And Impairment Relationship Scale (PAIRS)}

An increase in pain is an indication that I should stop what I am doing until the pain decreases.

I have to be careful not to do anything that might make my pain worse.

I have come to accept that I am a disabled person, due to my chronic pain.

All of my problems would be solved if my pain would go away.

Pain Anxiety and Symptom Scale (PASS)

I can't think straight when in pain.

I go immediately to bed when I feel severe pain.

When I feel pain I am afraid that something terrible will happen.

Pain seems to cause my heart of pound or race.

\section{Tampa Scalle for Kinesiophobia (TSK)}

I'm afraid that I might irjure myself if $I$ exercise.

If I were to try to overcome it, my pain would increase.

My body is telling me I have something dangerously wrong.

My pain would probably be relieved if I were to exercise (reverse scored).

Another instrument is the Pain And Impairment Relationship Scale (PAIRS; (Riley et al., 1988)). 'This questionnaire more globally assesses patients' belliefs about the relationship between pain and functional limitations. It was developed to study attitudes towards activity and pain in chronic patients. The scale has 15 items with answers on a 7 -point scale (completely disagrae to completely agree).

The Pain Anxiety and Symptom Scale (PASS), developed by (McCracken et al.; 1992) is a 40-item questionnaire with four subscales. Items relate to cognitive anxiety symptoms, escape and avoidance responses, fearful appraisals of pain and physiological anxiety symptoms associated with pain. Patients rate a frequency for each item on a 6-point scale (never to alwayo).

Finaly, the Tampa Scale for Kinesiophobia (TSK) (Miller et al, 1991) specifically focuses on the concept of fear of movement/(re)injury, and consists of 17 items with 4 scoring alternatives (strongly agree to strongly disagree). T'wo subscales represent constructs of somatic focus and activity awoidance (Roelofs et al., 2004). This questionnaire is relatively short and easy to use for quick screening, for example in primary care settings (Swinkels-Meewisse et al., 2003). 
Table 2.2 Psychometric characteristics of pain-related fear questionnaires

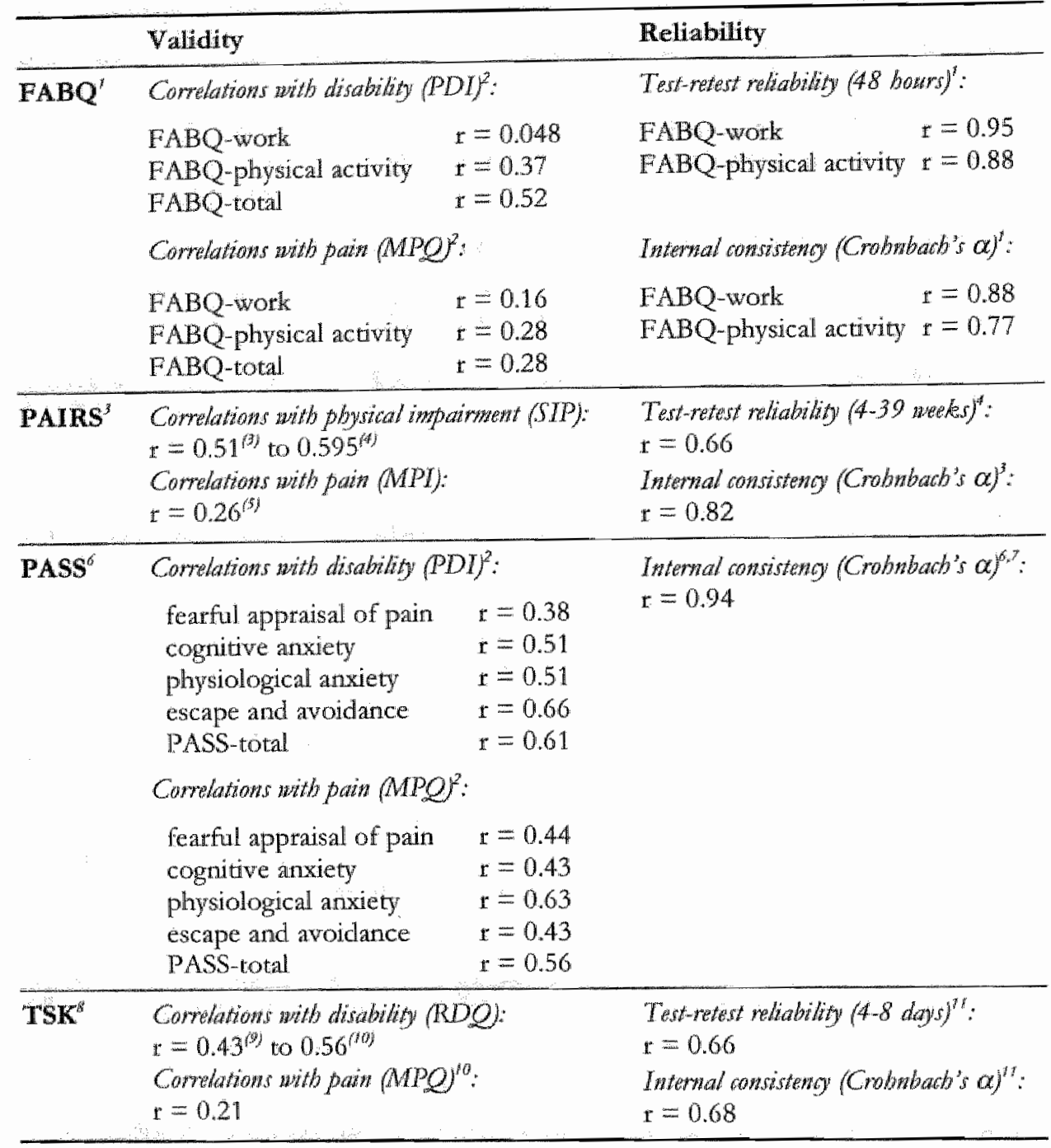

$P D I=$ Pain Disability Index, MPQ $=$ McGill Pain Questionnaire, SIP = Sickness Impact Profile, $\mathrm{RDQ}=\mathrm{Roland}$ Disability Questionnaire. 1 Waddell et al. (1993); ${ }^{2}$ Mccracken et al. (1996); ${ }^{3}$ Riley et at. (1988); "Slater et al. (1991); ${ }^{5}$ Guck et al. (1999); ${ }^{6}$ McCracken et all (1992); ${ }^{7}$ Osman et al. (1994); "Kori et al. (1990): "Vlaeyen et al. (1995a); "V Vaeyen et al. (1995b); "Goubert et al. (2000).

\section{Psychonstric characteristics}

Some psychometric characteristics of the pain-related fear questionnaires described above are summarized in table 2.2. Because a variety of strategies is used to evaluate validity and reliability of questionnaires, comparison of results is difficult. 
In chronic patient populations, all four instruments have shown to positively correlate with vatious measures of disability (Riley et al., 1988; Waddell et al., 1993; Vlaeyen et al., 1995b; McCracken et al., 1996; Crombez et al., 1999b). Although correlations are modest, they are statistically significant and often stronger than associations between pain and disability. Furthermore, FABQ, PAIRS and TSK showed good test-tetest reliability (Slater et al., 1991; Waddell et al., 1993; Goubert et al, 2000). Considering predictive validity, when controlling for pain characteristics (anatomical pattern, pain intensity, duration of pain), both $F A B Q-$ subscales turned out to be strong predictors for disability in activities of daily living. Additionally, FABQ-work was significantly related to work-loss (Waddell et al., 1993). Similarly, after controlling for pain intensity and pain duration, PAIRSscores correlated highly with scores on the Sickness Impact Profile (SIP, physical and psychosocial impairment) (Slater et all, 1991). With regard to the PASS, results show the escape/avoidlance subscale of this questionnaire to be highly related to measures of disability (after controlling for pain intensity) and help seeking (after controlling for FABQ-work) (McCracken et al., 1996). The PASS-physiological subscale showed to be a significant predictor for non-specific physical complaints (McCracken et al., 1998). Finally, the TSK was also found to be a good predictor of disability, after controlling for pain duration and gender (Vlaeyen et al,, 1995b).

In general, these four pain-related fear questionnaires all seem to be suitable for: screening patients in clinical settings. However, there is still a need for normative data to facilitate interpretation of individual test-results. Cut-off points will have to be determined with respect to clinically relevant subgroups of patients with high levels of fear and/or a negative prognosis.

\section{THE MANAGEMENT OF PAIN-RELATED FEAR}

\section{Exposure in vivo}

Recently, specific treatment methods have been developed for patients who show substantial pain-related fear and avoidance of plysical activities. As Philips (1987) already suggested, graded exposure in vivo to those movements the patient is most afraid of, can be effective in readjusting incorrect cognitions towards pain and movement. Since the persistent avoidance behaviour has deprived the patient of natural adjusting learning situations, exposute therapy offers the patient an imposed opportunity to testore synchrony between pain sensation and pain cognitions.

The idea of exposure treatment for pain patients results from the awrareness of the strong similarities between phobias and chronic pain. Exposure techniques are frequently used in the treatment of phobias (Brondolo et al., 1997) and might be analogously applicable in kinesiophobic pain patients. Recently, Vlaeyen et al. 
(2001) designed and applied an exposure therapy in chronic low back pain patients. This therapy consists of three components: screening, education and exposure.

\section{Screning}

High scores on pain-related fear questionnaires only indicate the presence of fear, but do not distinguish the exact contents of the fear-problem in the specific patient. Additional information is needed to establish a clear and complete picture of the patient's cognitions, behaviour and situation. During the screening session before the start of the treatment program, a structured interview is conducted to carefully map the patient's beliefs and expectations towards development, course and treatment of back pain (see table 2.3 for examples of questions).

Table 2.3 Structured interview topics (example)

\section{Description of the current back pain episode}

How exactly did it happen (when, where, what were you doing)?

How did you manage the pain (rest, medication use, exercise)?

What did your doctor (therapist, specialist) do? What did he/she advise you to do?

\section{Description of back pain history}

Have you ever had back pain before? (number, duration and course of episodes)

How did it happen?

How did you manage the pain?

How has your back pain been treated in the past?

\section{Cognitions}

What do you think is the cause of your back pain?

What are the things that make it better or worse?

What questions/worries do you have about your back pain?

\section{Avoidance}

What activities are you not doing because of your back pain?

In what situations do you act careful because of your back pain?

\section{Other people}

How do other people (spouse, family, colleagues) respond to your back pain?

Are you in touch with other back pain patients (Eamily, friends) with negative course

(specific causes)?

Are there any complicating social or economic circumstances?

The screening will be completed with a functional analysis, specificaily focussed on fear and avoidance of movements. In order to be able to apply effective exposure later on, it is important to determine which physical activities and movements the patient is most aftaid of. The Photograph Series of Daily Activities (PHODA; (Kugler et al., 1999)) can be used as a screening instrument to obtain a 
personal hierarchy of fear-eliciting movements. Patients are invited to judge the threat value of each of 98 various physical movements from daily life activities represented by photographs. Although kinesiophobic back pain patients tend to generally fear some typical movements in which the spine is involved (for example: reaching, bending, rotating, lifting), the exact object of fear varies between individuals. Depending on their normal repertoire of movements during work, household activities, leisure time and social (family) responsibilities, patients will report different situations to be fear eliciting.

Psychometric characteristics of the PHODA as a measurement tool (specificity, sensitivity) still have not been established, but exposure studies in which the instrument was firstly used, showed PHODA-scores to drop significantly after exposure treatment, while scores did not decrease after graded activity treatment in high-fearful patients (Vlaeyen et al., 2001, 2002).

\section{Education}

Subsequently, the patient receives education directed at his or her own specific situation and history. Previous studies (Burton et al., 1999; Moore et al., 2000) already demonstrated a positive effect of education on fear-aroidance beliefs in back pain patients. Main goal is to teach the patient to view back pain as a harmless, common condition rather than a serious disease. The importance of selfmanagement and resumption of activities instead of rest, protection and extensive medical examination and passive care is emphasised. In addition, the fearavoidance model is introduced and explained in relation to the patient's own narrative. Personal symptoms, behaviours and beliefs are used to illustrate the mechanisms maintaining and aggravating the pain problem. Of course the use of educational interventions in itself is not new, but in the context of this therapy the educational part of the treatment serves to facilitate exposure and self-exposure in the next stage.

\section{Graded exposure}

The third step consists of graded exposure to the situations the patient has identified as "dangerous" or "threatening". Individually tailored practice tasks are developed, based on the graded hierarchy of fear-eliciting situations. Each activity or movement is first modelled by the therapist. Furthermore, the general principles for exposure are followed. The patient agrees beforehand to perform certain activities or movements that he or she was used to avoid despite fear. The patient is encouraged to engage in a fearful activity as much as possible until the anxiety level is decreased. Then, a more threatening activity will be chosen for practice. This procedure will be repeated until the patient performs activities, which are 
often more fear-eliciting than usual daily life activities, and which go further than strictly necessary for reaching the aim of the treatment.

To enhance and to generalize the effects of the therapeutical practice sessions, patients are encouraged to engage themselves in activities of everyday life they tended to avoid. Positive reinforcement of adaptive behaviour helps to change the axoidance behaviour into more confronting habits.

\section{Bebavioural experiments}

Exposure in vivo exercises often take the form of a behavioural experiment. The essence of a behavioural experiment is that the patient performs an activity to challenge the validity of his or her catastrophic expectations and misinterpretations in an empirical design. These interpretations take the form of "if ... then ..."statements (for example: "if I jump down the stairs, then nerve injury will occur). During a behavioural experiment these statements can be empirically tested, in which three steps can be distinguished: formulation of a hypothesis, designing the personal experiment, carrying out and evaluating the experiment. Table 2.4 displays the elements commonly included in a behavioural experiment. Evidence on exposure

Table 2.4 Elements of the behavioutal experiment

The patient formulates a hypothesis

$\mathrm{Ms}, \mathrm{C}$. may expect that lifing a shopping box out of the car will inevitably cause a "crack" in her shoulder and excruciating pain.

\section{An experiment is designed}

If $\mathrm{Ms}_{\text {s. }} \mathrm{C}$. is convinced that lifting is harmful, the therapist can further inquire about the minimal weight that is needed to cause at "crack".

\section{The experiment is cartied out and evaluated}

The therapist invites Ms. C. to lift a shopping box out of the car. The consequences (the failure of injury to occur) are discussed. In this way the patient will experience that performing the feared movements will cause no harm, and the level of anxiety will dectease.

The practice of exposure treatment as described in paragraph 9 is part of an experimental program, and only few studies have been conducted to test its effectiveness. Vlaeyen et al. $(2001 ; 2002)$ and Boersma et al. (2004) found promising results in low back pain patients with an above median TSK-score (Vlaeyen et al., 1995a; Crombez et al., 1999b); suggesting that at least 50\% of patients with chronic non-specific low back pain might possibly benefit from exposure in vivo. Replication studies in the form of randomised controlled trials using latger samples and long-term follow-up measurements are warranted to 
devellop this treatment beyond the experimental stage and make it suitable for more extensive clinical application.

\section{EXPOSURE AS A PREVENTIVE STRATEGY}

Although exposure-treatment may be effective, it is still hard work to reverse processes once a patient has entered the subacute or chronic stages and disability has been developed. It seems reasonable to search for opportunities to prevent acute pain from becoming chronic (Linton, 1999). Recently, several attempts have been made to distinguish subgroups of patients at risk at a much earlier stage, before they become chronic pain patients (Klenerman et al., 1995; Kendall et al., 1997; Linton et al., 2000). Preventive cognitive-behavioural intervention during the acute stage might be easier to do and more cost-effective than rehabilitation of subacute or chronic patients (for example: Moore et al., 2000).

\section{WHERE DOES PAIN-RELATED FEAR COME FROM?}

Little is still known about the origin and development of pain-related fear. Anxiety sensitivity and catastrophizing are regarded to be precursors of fear (Vlaeyen et al,, 1995b; Asmundson et al, 1999), but it is still unclear whether these factors are trait-like dispositions that trigger pain-related fear whenever acute pain occurs, or whether they are merely part of the cognitive responses associated with painrelated fear. Although many questions remain about the exact role of the patient's underlying state and trait personality chatacteristics, it seems plausible that social and environmental influences also contribute to the development of pain-related fear.

According to Rachman (1990) three different pathways to fear can be distinguished. Firstly, fear can be acquired by a process of conditioning by exposure to traumatic experiences. When considering pain-related fear, an acute injury or a previous back pain episode with a negative course can provoke the development of kinesiophobia. The second pathway involves vicarious learning from, for example, modelling by relatives or stories told by other phobic patients. Although well intended, actions of social support often provided to back pain patients ("Take care of your back!" or "No, let me carry that box, you should not do it!") could be a source of vicatious transmission of fear. Finally, exchange of fear-inducing information is the third pathway. A patient's level of pain-related fear can unintentionally be negatively influenced by the information given by physician, specialist or therapist. Rainville et al. (2000) found that physicians' recommendations concerning physical activity to patients with low back pain may vary widely and often are restrictive, advocating avoidance of painful movements. It is very likely that such advice will enhance the patient's feelings of concern 
towards the influence of physical activity on pain and recovery. Therefore, paying attention to the way diagnostic information is communicated to a patient is very important. Fearful patients might benefit from unambiguous, fear-reducing information.

\section{SUMMARY AND CONCLUDING REMARKS}

Pain-related fear appears to be a powerful predictor of chronic disability and its importance is now widely recognised. Valid and reliable instrument are available to assess the level of pain-related fear in both clinical and tesearch settings. Painrelated fear not only is associated with avoidance behaviour, thereby influencing the level of disability, it is also shown to be associated with increased attention to bodily sensations amplifying existing pain. Preliminary data suggest that exposure in vivo - together with behavioutal experiments - is effective in reducing painrelated fear and associated disability levels in patients with chronic low back pain. Until now, most research has been done in chronic back pain patients, but it is likely that exposure-therapy may be a suitable approach for other musculoskeletal disorders and that it can be applied in primary care settings as well.

Despite these important developments, future research should focus on the development of adequate measures and norms to identify clinically relevant subgroups of patients with high levels of pain-related fear. Furthermore, the costeffectiveness and generalisability of exposure-therapy has to be tested in a variety of clinical populations and settings, and the opportunity for preventive use of fearreducing interventions needs to be further explored. Overall, the fear-avoidance model has proven to be a valuable tool that deserves further application and refinement in pain research and management. 


\section{REFERENCES}

- Al-Obaidi, S.M., Nelson, RM., Al-Awadhi, S. Alshuwale, N. (2000). The role of anticipation and fear of pain in the persistence of avoidance behaviour in patients with chronic low back pain. Spme, 25 (9), 1126-1131.

- Asmundson, G.], Kuperos, J.L., Norton, G.R. (1997). Do patients with chronic pain selectively attend to pain-related information? preliminary evidence for the mediating role of fear. Pain, $72(1-2), 27-32$ :

- Asmundson, G.J., Norton, P.J., Norton, G.R. (1999). Beyond pain the role of fear and avoidance in chronicity. Clin Pychol Res, 19 (1), 97-119.

- Battie, M.C., Bigos, S.l., Fisher, L.D., Hansson, T.H., Nachemson, A.L.s, Spengler, D.M., Wortley, M.D., Zeh, J. (1989). A prospective study of the role of cardiovasculat risk factors and fitness in industrial back pain complaints. Spine, 14 (2), 141-147.

- Bienvenu, O.J., Brown, C., Samuels, J.F., Luang, K. ., Costa, P.T., Eaton, W.W., Nestadt, G. (2001). Normal personality traits and comorbidity among phobic, panic and major depressive disorders. Psychiaty Res, $102(1), 73-85$.

- Boersma, K, Linton, S., Overmeer, T., Jansson, M., Vlaeyen, J., de Jong, J. (2004). Lowering fear-avoidance and enhancing function through exposure in vivo. A multiple baseline study actoss six patients with back pain. Pain, 108 (1-2), 8-16.

- Bottz, W.M., 2nd. (1984). The disuse syndrome. West J Med, 147 (5), 691-694.

- Brennan, G.P., Rubling, R.O., Hood, R.S., Shultz, B.B., Johnson, S.C., Andrews, B.C. (1987). Physical chanacteristics of patients with herniated intervertebral lumbar discs. Spine, $12(7), 699-702$.

- Brondolo, E., DiGiuseppe, R., Tafrate, R.C. (1997). Exposure-based treatment for anger problems: focus on the feeling. Cogntive and behaworal prattio, 4, 75-98.

- Buer, N., Linton, S.J. (2002). Fear-awoidance beliefs and catastrophizing occurrence and risk factor in back pain and ADL in the general population. Paxts, 99 (3), 485-491.

- Burton, A.K., Waddell, G., Tillotson, K.M., Summerton, N. (1999). Information and adwice to patients with back pain can have a positive effect. A randomized controlled trial of a novel educational booklet in primaty care. Spine, 24 (23), 24842491 .

- Crombez, G., Eccleston, C. Baeyens, F., Eelen, $\mathbb{P}$. (1998). Wheth somatic information threatens, catastrophic thinking enlances attentional interference Pain, $75(2-3), 187-198$.

- Crombez, G., Eccleston, C., Baeyens, $F_{\text {, }}$ van Houdenhove, B., van den Broeck, A. (1999a). Attention to chronic pain is dependent upon pain-related fear. J Psychosom Rots, 47 (5), 403-410.

- Crombez, G., Vlaeyen, J.W.S., Heuts, P.H., Lysens, R. (1999b). Pain-related fear is more disabling than pain itself: evidence on the role of pain related fear in chronic back pain disability. Pain, 80 (1-2), 329-339.

- Dionne, C.E. (1999). Low back pain. In I.K. Crombie (Ed.), Epidenzioloy of pain (pp. 283-297). Seattle: IASP Press.

- Dionne, C.E. Koepsell, T.D., Von Korf, M., Deyo, RA, Barlow, W.E., Checkoway, H. (1997). Predicting long-term functional limitations among back pain patients in primary care setrings. J Chn Espidmiol, $50(1), 31-43$. 
- Eccleston, C., Crombez, G. (1999). Pain demands attention: A cognitive-affective model of the interruptive function of pain. Pychologial Bulletin, 125, 356-366.

- Engel, C.C., won Kouff, M., Katon, W.J. (1996). Back pain in primary care: predictors of high health-care costs. Poin, 65 (2-3), 197-204.

- Eysenk, M.W. (1997). Anxity and rogwthon. A wnifred theom. Hove: Psychalogy Press.

- Flor, H, Birbaumer, N., Schugens, M.M, Lutzenberger, W. (1992). Symptom-specific psychophysiological responses in chronic pain patients. Psychopbysology, 29 (4), 452-460.

- Fordyce, W.E. (1976). Bebavioral methods for dorowic pain and illsess. St. Louis: Mosby.

- Frti, JM. George, S.Z., Delitto, A. (2001). The role of fear-avoidance beliefs in acute low back pain: relationships with current and future disability and work status. Pain, 24 (1), $7-15$.

- Goubert, L., Crombez, G., Vlaeyen, JWW.S, Van Damme, S, Van den Broeck, A., Van Houdenhove, B. (2000). De Tampa Schal voor Kinesiofobie. Psychometrische karakteristieken en normering [The Tampa Scale for Kinesiophobia: Psychometric characteristics and norms]. Gedrag en Gerondheid: Tijdschrift voom Psyobologie en Gezandheid, 28 (2), 54-62

- Hildebrandt, V.H., Lrlings, I.J.M., Proper, K.I., Ooijendijlk, W.T.M., Stiggelhout, M. (1999). Are the Dutch still sufficiently physically active? In V. H. Hildebrandt, W. T. M. Ooijendijk \& M. Stiggelhout (Eds.), Trendrappon Bewegen en Geqondhed 1998-1999. Lelystad: Koninklijke Vermande.

- Hurri, $H_{\text {, }}$ Mellin, G., Korhonen, O., Harjula, R., Harkapaa, K., Iuoma, J. (1991). Aerobic capacity among chronic low-back-pain patients. I Spinal Disord, 4 (1), 34-38.

- Kellett, K.M., Kellett, D.A., Nordholm, L.A. (1991). Effects of an exercise program on sick leave due to back pain. Pbys Ther, 71 (4), 283-291; discussion 291-283.

- Kendall, N.A.S., Linton, S.J., Main, C.J. (1997). Guide to assessing psychosocial yellow flags in acute low back pain: wisk factors for long term disability and work loss. Wellington, NZ.: Accident Rehabilitation \& Compensation Insurance Corporation of New Zealand and National Health Committee.

- Klenerman, L., Slade, P.D., Stanley, I.M, Pennie, B., Reilly, J.P., Atchison, L.E., Troup, J.D., Rose, M.J. (1995). The prediction of chronicity in patients with an acute attack of low back pain in a general practice setting. Spine, 20 (4), 478-484.

- Koti, S.H., Miller, R.P., Todd, D.D. (1990). Kinisophobia: a new view of chronic pain

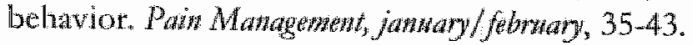

- Kugler, K., Wiju, J., Geilen, M., de Jong, J., Heuts, P.H.T.G., vlaeyen, J.W.S (1999), The Photograph Series of Daily Activities (PHODA). CD ROM version. Institute for Rehabilitation Research Hoensbroek, School for Physiotherapy Heetlen, and Maastricht University, The Netherlands.

- Lamoth, C.J., Meijer, O.G., Wuisman, P.I., van Dieen, J.H., Levin, M.F., Beek, P.J. (2002). Pelvis-thorax coordination in the transverse plane during walking in persons with nonspecific low back pain. Spine, 27 (4), E92-99.

- Lethem, J., Slade, P.D., Troup, J.D., Bentey, G. (1983). Outline of a Fear Avoidance Model of exaggerated pain perception--1. Bubaw Rer Tber, 21 (4), 401-408.

- Linton, S.J. (1985). The relationship between activity and chronic back pain. Paits, 21 (3), $289-294$. 
- Linton, S.J. (1999). Prevention with special reference to chronic musculloskeletal disorders. In R. J. Gatchel \& D. C. Turk (Eds.), Pyanasocial factors in path (pp. 374 389). New York, London: The Guilford Press.

- Linton, S.J. (2000). A rewien of psychological risk factors in back and neck pain. Sptwe, $25(9), 1148-1156$.

- Linton, S.J., Buer, N., Vaeyen, J.W.S., Hellsing, A.L. (2000). Are fear-aroidance bellefs related to the inception of an episode of back pain? A prospective study. Psybology and Health, 14, 1051-1059.

- Main, CJ., Watson, P.J. (1996). Guarded movements: development of chronicity. In M. E. Allen (Ed.), Muscalosketetal pain enanating from the bead and neck: current contepts in diagrowis, managewent and cost comtanment (pp. 163-170): The Haworth Medical Ptess.

- McCracken, L.M. (1997). "Attention" to pain in persons with chronic pain: a behavioral approach. Bebavior Tberapy, 28 (2), $271-284$.

- McCracken, L.M., Faber, S.D., Janeck, A.S. (1998). Pain-related anxiety predicts nonspecific physical complaints in persons with chronic pain. Bebav Res Ther, 36 (6), 621-630.

- McCracken, L.M., Gross, R.T. (1993). Does anxiety affect coping with chronic pain? Clin J Pain, 9(4), 253-259.

- McCracken, L.M., Gross, R.T., Aikens, J., Carnrike, C.L., Jr. (1996). The assessment of anxiety and fear in persons with chronic pain: a compatison of instruments. Behrov Res Thor, $34(11-12), 927-933$.

- McCracken, L.M., Zayfert, C., Gross, RT. (1992). The Pain Amxiety Symptoms Scale: development and validation of a scale to measure fear of pain. Paint, 50 (1),67-73.

- Melzack, R, Casey, K.J. (1968). Sensory, motivational and central control determinants of pain. In K. D.R. (Ed.), The stin senses (pp. 423-439). Springfield: Charles C. Thomas.

- Melzack, R., Wall, P.D. (1965). Pain mechanisms: a new theory. Sicknce, 150 (699), 971 979.

- Miller, R.P., Kori, S.H., Todd, D.D. (1991). The Tampa Scale Unpublished Report, Tampa; FL.

- Moore, J. E., Von Korff, M., Cherkin, D., Saunders, K., Lorig, K. (2000). A randomized trial of a cognitive-behavioral program for enhancing back pain self care in a primary care setting. Poin, 88 (2), 145-153.

- Novy, D.M., Sirnmonds, M.), Lee, C.E. (2002). Physical performanace tatsks: what are the underlying constructs? Arb Pbys Med Rehabil, 83 (1), 4447.

- Peters, M.L., Vlaeyen, J.W.S., van Dnunen, C. (2000). Do fibromyalgia patients display hypervigilance for innocuous somatosensory stimuli? Application of a body scanning reaction time paradigm. Pax, $86(3), 283-292$.

- Philips, H.C. (1987). Avoidance behaviour and its role in sustaining chronic pain. Behaw Res Ther, 25 (4), 273-279.

- Picavet, H.S., Vlaeyen, J.W.S., Schouten, J.S. (2002). Pain catastrophizing and. kinesiophobia: predictors of chronic low back pain. Am J Epidemiol, 156 (11), 1028-1034.

- Pincus, T., Burton, A.K, Vogel, S., Field, A.P. (2002). A systematic review of psychological factors as predictors of chronicity/disability in prospective cohorts of low back pain. Spine, 27 (5), E109-120. 
- Protas, EJ. (1999). Physical activity and low back pain. In M Max (Ed), Patin 1999 - A* Updated Rewew (Refresher Cowsed Syllabos) (pp. 145-152). Seattle: LASP-Press.

- Rachman, S. (1990). The determinants and treatment of simple phobias. Adwames Bebawiow Researth and Therapy, 12,1-30.

- Rainville, J., Carlson, N., Polatin, P., Gatchel, R.I. Indah, A. (2000). Exploration of physicians" tecommendations for actwities in chronic low back pain. Spine, 25 (17), 22102220 .

- Riley, JF., Ahem, D.K, Follick, MY. (1988). Chronic pain and functional impaiment: assessing beliefs about their relationship. Arth Pby Med Rehabil, 69 (8), 579-582.

- Roelofs, J., Goubert, L. Peters, ML., Vlaeyen, J.W.S., Crombez, G. (2004). The Tampa Scale for Kinesiophobia: further examination of psychometric properties in patients with chronic low back pain and fibromyalgia Eur J Paw, 8 (5), 495-502.

- Rose, M.J., Klenerman, L., Atchison, L., Slade, P.D. (1992). An application of the fear awoidance model to three chronic pain problems. Bebur Res Ther, 30 (4), 359-365.

- Schmidt, AJ. (1985). Cognitive factors in the performance level of chronic low back pain patients. I Psychorowy Res, 29 (2), 183-189.

- Schmidt, A.J. (1986). Persistewce bebaviour of chrowic low back pain patients in treadmill test mith fale and adeguate ferdbacks.

- Slade, P.D., Troup, J.D., Lethem, J., Bentley, G. (1983). The Fear-Avoidance Model of exaggetated pain perception-II. Bebav Res Ther, 21 (4), 409-416.

- Slater, M.A., Hall, H.F., Adkinson, J.H., Garfin, S.R. (1.991). Pain and impaiment beliefs in chronic low back pain: validation of the Pain and Impaiment Relationship Scale (PAIRS). Pain, $44(1), 51-56$.

- Swinkels-Meewisse, E.J., Swinkels, R.A., Verbeek, A.L., Vlaeyen, J.W.S., Oostendorp. R.A. (2003). Psychometic properties of the Tampa Scale for kinesiophobia and the fearavoidance beliefs questionnaire in acute low back pain. Mas Ther, 8 (1), 29-36.

- USDHHS. (1996). US Department of Health and Humav Services "Pbysical Activity and Health: A report of the Swrgeon General Atlanta: Department of Health and Human Services, Centers for Disense Control and Prevention, National Center for Chronic Disease Prevention and Health Promotion.

- Van den Hout, J.H.C., Vhaeyen, J. W.S. Heuts, P.H.T.G., Sillen, W.J.T., Willen, A.J.E.H.L. (2001). Functional disability in nonspecific low back pain. the role of pain-

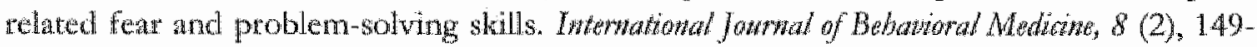
162.

- Van der Velde, G., Mierat, D. (2000). The effect of exercise on percentile rank aerobic capacity, pain, and self-rated disability in patients with chronic low-back pain: a retrospective chant review. Awt Pbys Med Rebabil, 81 (11), 1457-1463.

- Verbunt, ., Sieben, J.M., Seelen, H.A., Vheyen, JW.S, Bousema, E, Van der Heijden, $\mathrm{G}_{\mathrm{a},}$ Knotnerus, A. (2005). Decline in physical activity, disability and pain-related fear in sub-acute low back pain. Euty I Pain, 9, 417-425.

- Verbunt, J.A., Westerterp, K.R., van der Heijden, G.J., Seelen, H.A., Vaeyen, J.W.S., Knottnerus, J.A. (2001). Physical activity in daily life in patients with chtonic low back pain. And Pby Med Rubabs, 82 (6), 726-730. 
- Vaeyen, J.W.S., de Jong, J., Geilen, M., Heuts, P.H., van Breukelen, G. (2001). Graded exposure in vivo in the treament of pain-related fear: a replicated single-case experimental design in four patents with chronic low back pain. Bebay Res Ther, 39 (2), 151-166.

- Vaeyen, J.W.S., de Jong, J., Geilen, M., Heuts, P.H, van Breukelen, G. (2002). The treatment of fear of movement/(re)injury in chronic low back pain: further evidence on the effectiveness of exposure in vivo. Cin J Pain, 18 (4), $251-261$.

- Vlaeyen, J.W.S., Kolle-Snijders, A.M., Boeren, R.G., van Eek, H. (1995a). Fear of movement/(re)injury in chronic low back pain and its relation to behavioral performance. Pain, 62 (3), 363-372.

- Vlaeyen, J.W.S., Kole-Snijders, A.M.J, Rotteveel, A., Ruesink, R., Heuts, P.H.T.G. (1995b). The role of fear of movement/(re)injury in pain disability. Jownal of Ocappational Rehabilitation, 5 (4).

- Vlaeyen, JW.S., Linton, S.J. (2000). Fear-avoidance and its consequences in claronic musculoskeletal pain: a state of the art. Pain, 85 (3), 317-332.

- Waddell, G. (1987). 1987 Volvo award in clinical sciences. A new clinical model for the treatment of low-back pain. Spine, $12(7), 632-644$.

- Waddell, G. (1991). Low back disability. A syndrome of Western civilization. Newnowng Clin $N A m, 2(4), 719-738$.

- Waddell, G. (1996). Low back pain: a twentieth century health care enigma. Spime, 21 (24), $2820-2825$.

- Waddell, G., Newton, M., Henderson, I., Somerville, D., Main, C.J. (1993). A FearAvoidance Beliefs Questionnaire (FABQ) and the role of fear- avoidance beliefs in chronic low back pain and disability. Pain, 52 (2), 157-168.

- Wall, P.D. (1979). On the relation of injury to pain. The John J. Bonica lecture. Pain, 6 (3), $253-264$

- Watson, P. (1999). Non-physiological detetminants of physical petformance in musculoskeletal pain. In M. Max (Ed.), Pain 1999. An spdated rewew (refresber course syllabus) (pP. 153-158). Seattle: IASP-Press.

- Witunk, H., Hoskins Michel, T., Wagner, A., Sukiennik, A., Rogers, W. (2000). Deconditioning in patients with chronic low back pain: fact or fiction? Spowe, 25 (17), 22212228 . 


\section{CHAPTER 3}

\section{Pain-related fear in acute low back pain: the first two weeks of a new episode}

Judith M. Sieben, Johan W.S. Vlaeyen, Sandrine Tuerlinckx, Piet J.M. Portegijs

Published as:

Sieben, J.M., Vlaeyen, J.W.S., Tuerlinckx, S., Portegijs, P.J.M. (2002) Pain-related fear in acute low back pain: the first two weeks of a new episode. European Journal of Pain, 6, 229-237. 


\section{ABSTRACT}

The overall aim of this study was to explore the natural course of pain-related fear during the early stage of a new low back pain episode, using a prospective case series design. Specific reseatch questions addressed the existence of typical patterns in individual time seties of pain-related fear and sequential relationships between the occurrence of pain-related fear, pain and pain catastrophizing. Forty-four general practice patients who consulted their physician with a new episode of nonspecific low back pain were recruited. They completed diaries on pain-related fear, pain and pain catastrophizing for 14 days following the consultation. Follow-up questionnaires on disability were completed at 3 months and 12 months. Time series analyses produced subgroups of patients with descending, stable and rising levels of pain-related fear over the 2 -week period. These groups differed on baseline characteristics and outcome at follow-up. A time-shift between the occurrence of pain-events and pain-related fear or pain catastrophizing could not be demonstrated.

In summary, these results fit in with previous findings in chronic patients. A relevant subgtoup of patients who might benefit from early intervention could be identified. These findings support the need for further research into fear mechanisms in acute low back pain. 


\section{INTRODUCTION}

Chronic low back pain and its consequences account for important medical and socio-economic problems. Lifetime incidence of low back pain is high: $59 \%-70 \%$ of all adults will experience low back pain at some stage of their life (Picavet et al, 1996; Andersson, 1999). Non-specific low back pain by its nature appears to be a universal, benign, self-limiting condition, although residual symptoms and recurrences and are common (Waddell, 1998). Most patients recover within a few weeks, but those who do not, are at risk of developing a chronic pain syndrome. This relatively small group of chronic low back pain patients is faced with physical disability, work absenteeism and a range of psychological problems (Dionne, 1999). Given the serious consequences of chronic pain, and because sufficient evidence supporting primaty prevention of acute low back pain is still lacking, it seems to be more appropriate to look for possibilities to prevent acute pain from becoming chronic (Linton et al., 1993).

The easiest way to select patients at risk is to wait and see for some weeks. Most episodes of back pain resolve spontaneously within days or a few weeks, often without work loss or health care. Those patients who are still off work after a month have a $20 \%$ risk of chronic disability (Waddell, 1998). This 'self-selected' group requires special attention from health care providers to prevent long-term problems. This course of action is adopted for example by the Dutch General Practice Guideline for Low Back Pain (Faas et al., 1996). A drawback of this approach is however, that it may be difficult to reverse the negative consequences of back pain once it has already existed for several weeks.

Another option is early screening of all acute back pain patients, in order to identify high-tisk patients as soon as possible. Preventive intervention during the acute stage might be easier to do and more cost-effective than tehabilitation of subacute or chronic patients (Linton, 1999). For example screening on 'psychosocial yellow-flags' has been found to be an effective tool to early select patients, with a poor prognosis (Linton and Hallden, 1998; Hutley et al., 2000; Hurley et al., 2001).

A recently developed concept, that may be useful as a theoretical framework for early screening and intervention, is the fear-avoidance model (Lethem et al., 1983) (Asmundson et al., 1999; Vlaeyen and Linton, 2000). Several studies (Crombez et al., 1999; Vlaeyen et al., 2001) support this cognitive-behavioural model in explanation of the development of chronic musculoskeletal pain. Key variables in this model are the level of pain catastrophizing and associated pain-related feat a patient reports as a response to a back pain experience. In back pain patients, painrelated fear often shows as a specific fear of movement or reinjury. Some low back pain patients are highly fearful of typical movements in which the spine is involved (for example twisting, totating or bending) and accompanying pain signals (Kugler 
et al., 1999). Fearful patients strongly believe that these particular movements will cause serious damage to their backs. This fear of a possible negative influence of movement on pain and recovery can result in the patient avoiding specific activities or movements. When this avoidance behaviour persists beyond the acute stage of a low back pain episode, this can have detrimental consequences, such as increasing disability (both physically and socially), physical deconditioning (due to disuse) and a lower pain threshold (due to both psychological and physiological responses). The patient is likely to end up in a cycle of fear, inactivity, disability and pain.

Within the framework of this theory it is unclear whether pain-related fear plays a crucial role in the process of acute pain becoming chronic, at that it is merely a maintaining factor once a patient has developed a chromic pain syndrome. In order to obtain an answer to this question, research should focus on acute patient populations and longitudinal designs. For example, (Linton et al., 2000) studied the role of tear-avoidance beliefs in a general population in relation to the inception of back pain. Their results indicate that fear-avoidance beliefs may be important at a very early stage in the development of back pain and associated activity limitations. Another recent study showed feart-avoidance beliefs about work in acute patients to be significant predictors of disability and work status after 4 weeks (Fritz et al., 2001).

The overall aim of the study presented in this paper is to explore the characteristics of pain-telated fear during the acute stage of low back pain. Daily measurements and time series analysis techniques are used to create a detailed picture of the first two weeks of a back pain episode. Specific research questions are: (1) What is the course of pain-related fear and pain intensity during the first two weeks after consultation? (2) Within the first two weeks after consultation, are increases in pain preceded or followed by increases in pain-related fear and/or pain catastrophizing?

\section{METHODS}

\section{Subjects}

Subjects were patients of 16 general practices located in the southem part of the Netherlands and the Flemish-speaking region of eastern Belgium. Patients who consulted their physician (GP) between September 1999 and January 2000 with a new episode of low back pain were recruited. A new episode of low back pain is defined as: (1) pain localised below the scapulae and above the gluteal folds (following IASP taxonomy (Merskey and Bogduk, 1994)), (2) duration since time of pain onset no longer than two weeks, (3) after a period of at least three months without significant activity limitations due to back trouble. Additional selection criteria were (4) 18-65 years of age, (5) no specific cause or strong suspicion of 
specific cause (such as a tumour, inflammation or vertebral fracture), (6) no pregnancy, (7) sufficient knowledge of Dutch/Flemish language and (8) informed consent.

\section{Measures}

Following the GP-visit, patients completed a general questionnaire concerning back pain history and current back pain episode. They also completed a set of standardized questionnaires addressing concepts of pain-related fear, pain catastrophizing and back pain disability. Both pain-related fear and back pain disability were reassessed 2 weeks later. Back pain disability was measured again after 3 months and at 12 months. In between baseline and first follow-up measurement the patients kept a diary with items on pain-intensity, pain-related fear and pain catastrophizing for 14 days.

Pain-related fear: The Dutch version of the Tampa Scale for Kinesiophobia (TSK) (Miller et al., 1991; Vlaeyen et al., 1995) measures the level of fear related to pain. The term kinesiophobia refers more specifically to fear of movement or (re)injury due to movement. The TSK is a 17-item 4-point scale questionnaire designed for application in a back pain population. Reliability and validity of the TSK Dutch version are well established (Vlaeyen et al., 1995; Goubert et al., 2000).

Pain satastropbizing. A Dutch version of the Pain Catastrophizing Scale (PCS) (Sullivan et al., 1995) was used in this study to determine patients' thoughts and feelings about pain. This scale consists of 13 items. Patients indicate on a 5-point scale the extent to which they have catastrophic ideas about pain. The PCS has been shown to have good reliability and validity (Osman et al,, 1997; Van Damme et all., 2000).

Back pain disability: The Dutch translation of the Roland Disability Questionnaire (RDQ) (Roland and Morris, 1983; Gommans et al., 1997) was used in this study. The RDQ is designed to specifically determine the level of back pain related disability and consists of $24 \mathrm{yes} / \mathrm{no}$-items on the ability to perform common daily activities. The number of yes-answers indicates the level of difficulty to perform these activities without help. The $R D Q$ is known as a reliable and valid instrument (Deyo et al., 1998; Bombardier, 2000).

Diary: A diary consisting of several visual analogue scales (VAS) was completed every day for 14 days. A single VAS-item (a $10 \mathrm{~cm}$. horizontal line fixed left and right by the words 'no pain' and 'worst imaginable pain') was included to measure the current pain intensity. Other sets of VAS-items were derived. from the TSK (4 items) and the PCS ( 3 items). The diary has not yet been validated for this purpose, however this method was successfully applied in an intervention study that was aimed at reducing pain-related fear and associated disability levels (Vlaeyen et all, 2001). 


\section{Analysin}

Separate analyses were performed to answer both research questions.

(1) Costrse of paim-related fear over time: Individual patterns of pain, pain-related fear and pain catastrophizing were described using time series analysis (TSA). In TSA a regression equation is fitted for each subject's series of daily VAS-scores, including a correction factor for possible dependency between successive measurements (autocorrelation). In this study the AREG (AR1) autoregression-model was used to describe the time series data of each subject. Because of the limited number of measurements only complete datasets could be analysed. Individual lines were then clustered in subgroups of positive slopes (b1 $>=1 \mathrm{~mm} /$ day), negative slopes (b1 $<=-1 \mathrm{~mm} /$ day $)$ and stable slopes $(-1<\mathrm{b} 1<1 \mathrm{~mm} /$ day). Kruskal Wallis tests and Chi-square tests were performed to determine differences on baseline variables between groups with different patterns. Differences on follow-up outcome were tested by MANOVA-procedures.

(2) Sequential relationsbips: An SPSS-algorithm was developed to determine any possible sequential order (time-shift) in the occurrence of sudden increases in pain, pain-related fear and pain catastrophizing. The goal of this algorithm is to filter out peak-segments in individual pain graphs and corresponding sequences in time in pain-related fear and pain catastrophizing graphs. A pain-peak-day was defined as the first day in a subject's time series on which the VAS-value for pain intensity was $15 \mathrm{~mm}$. higher than two days before. Whenever the SPSS-algorithm detected such a sudden rise, all available data extending from 4 days before the peak-day to 4 days after the peak-day were extracted. All sequences originating from individual data sets were collected and mean levels for each day relative to the peak-day were calculated. Differences between the levels of pain-related fear and pain catastrophizing before, during and after the peak-day were determined by Wilcoxon signed ranks tests.

\section{RESULTS}

\section{Subject characteristics}

Forty-four patients met the selection criteria and completed baseline questionnaires. The sample consisted of 22 men and 22 women with a mean age of 42.7 years $(\mathrm{SD}=10.8)$. Twelve patients $(27.3 \%)$ reported no previous episodes; another 12 patients (27.3\%) experienced three or less episodes before. Mean RDQscore (level of disability) at baseline was $13.8(\mathrm{SD}=5.4)$. Of the total sample, 37 participants $(84.1 \%)$ were working at the time of the study, 4 individuals $(9.1 \%)$ were on long-term sick leave. According to data from our self-report questionnaire, thirty-five patients $(79.5 \%)$ consulted their physician within 14 days of the onset of their complaints. However, accurate determination and/or recall of 
the day of pain-onset seemed difficult for many patients. Plyysicians judgenents about episode length were used instead, and data from all subjects were used for furthet analyses.

At the two-week follow-up assessment, complete data sets with regard to the diaries were obtained of 34 subjects $(77.3 \%)$. After three months 33 patticipants (75.0\%) retumed completed questionnaires, and full one-year follow-up datn were gathered from 30 subjects $(68.2 \%)$. No statistical significant differences on baseline characteristics were found between respondents and non-responders $(p>0.208)$.

Figure 3.1 Mean-scores on daily VAS-measures of pain-related fear for subgroups with rising stable and descending time series

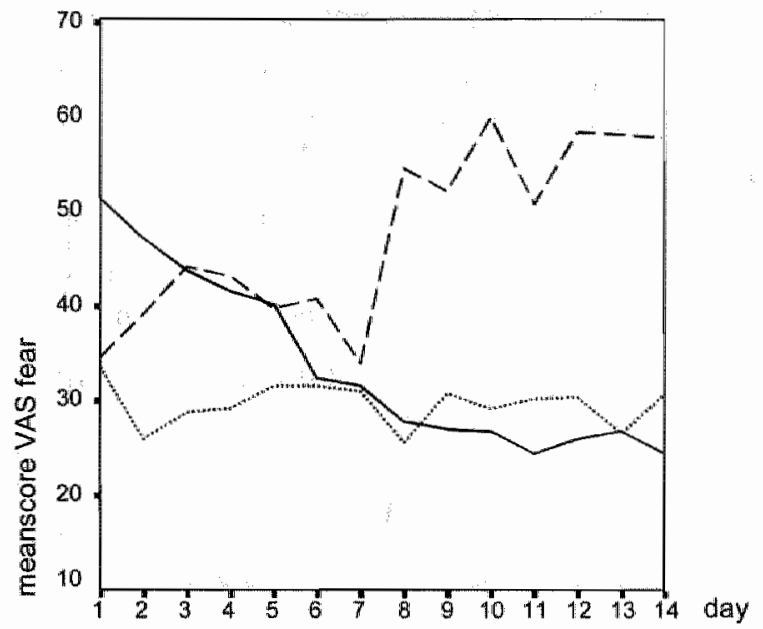

$\mathrm{N}$ analysed $=34$, missing $\mathrm{N}=9$ : only complete data sets could be analysed by Time Series Analysis. descending pain-related fear slope $b \leq-1 \mathrm{~mm} / \mathrm{day} ; \mathbb{N}=13$ stable pain-related fear: $1<$ slope $b<1 \mathrm{~mm} / \mathrm{day} ; \mathrm{N}=12$ rising pain-related fear: slope $b \geq 1 \mathrm{~mm} / \mathrm{day} ; \mathrm{N}=9$

\section{Pain-related fear, pain catastropbizing and pain}

(1) Course of pain-related forr ower time: Complete datasets from 34 subjects could be analysed. After time series analyses of the daily measures of pain-telated fear for each patient, 13 negative slopes $(38.2 \%), 12$ stable slopes $(35.3 \%)$ and 9 positive slopes (26.5\%) could be distinguished. Figure 3.1 shows a graph of mean levels of pain-related fear for each subgroup over the 14 consecutive days. The rising and descending time series could not be attributed to regression-to-mean alone (Mann Whitney Test for slope by intercept; $\mathrm{p}=0.248$ ). Simple regression analysis with slope as dependent and intercept as independent variables showed R-square to be 
0.293 , so only a minor part of the differences found could be attributed to a regression-to-mean effect. The subgroup of patients with a rising level of painrelated fear over time differed from the group with the descending pattern on one descriptive characteristic: the rising group reported a longer back pain history before the current episode $(\mathrm{p}=0.004)$.

Table 3.1 Mean values and standatd deviations on disability (RDQ) at baseline, day 14, 3-months follow-up and 12-months follow-up for all subjects and groups with (1) descending and (2) rising patterns of pain-related feat as measured by daily VASitems

\begin{tabular}{llllll}
\hline & & $\begin{array}{l}\text { RDQ } \\
\text { baseline }\end{array}$ & $\begin{array}{l}\text { RDQ } \\
\text { day 14 }\end{array}$ & $\begin{array}{l}\text { RDQ } \\
\text { 3 months }\end{array}$ & $\begin{array}{l}\text { RDQ } \\
\text { 12 months }\end{array}$ \\
\hline $\begin{array}{l}\text { Totall } \\
N=34\end{array}$ & Mean & 13.81 & 10.10 & 06.73 & 06.50 \\
\hline Group 1: descending fear Mean & 17.58 & 08.17 & 03.92 & 03.75 \\
$N=13$ & SD & 03.55 & 07.42 & 03.66 & 05.10 \\
\hline Group 2: rising fear & Mean & 12.38 & 14.00 & 09.38 & 09.13 \\
N=9 & SD & 05.07 & 04.44 & 03.58 & 04.49 \\
\hline MANOVA & p-value & 0.032 & 0.136 & 0.010 & 0.040 \\
Group 1 vs. group 2) & & & & & \\
\hline
\end{tabular}

p-values are from univariate post-hoc F-tests in MANOVA-procedure.

In table 3.1, differences in disability at follow-up between the descending painrelated fear group and the rising pain-related fear group are presented. MANOVA confirmed overall differences in follow-up outcome $(p=0.001$ for overall course of RDQ). Post-hoc tests indicated that the mean level of baseline RDQ is lower in the rising group, but at 3-months and 12-months follow-up this group reported higher perceived disability than patients with descending pain-related fear patterns.

Figure 3.2 presents a graph of mean levels of pain for each of the three subgtoups over the two-week period. For the subgroups with descending and stable levels of pain-related fear, pain rapidly diminished. In patients with a rising pattern of pain-related fear, course of pain was probably different (MANOVA $\mathrm{p}=0.08$ for overall course of pain; post-hoc $\mathrm{p}<0.05$ for differences on days 8 to 10 and 12 to 14 ). 
Figure 3.2 Mean scores on daly VAS-measures of pain for subgroups with descending, stable and rising time series on pain-related fear

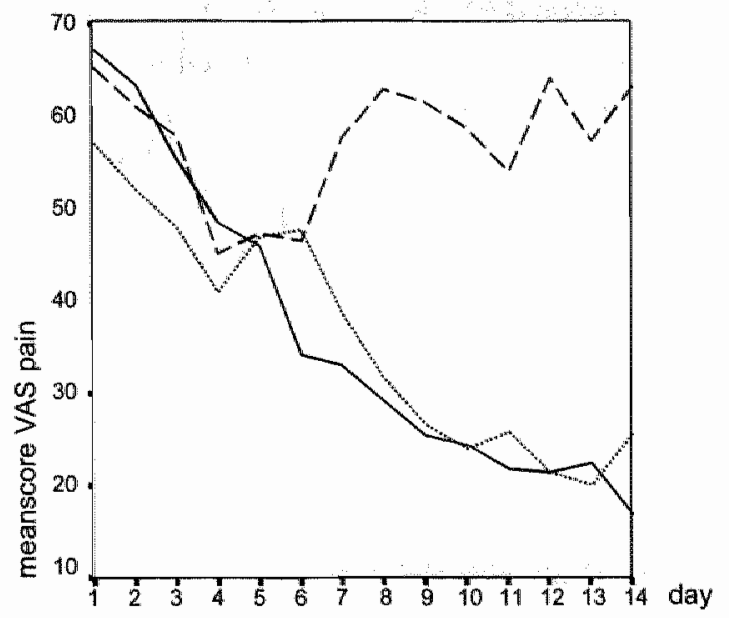

$\mathrm{N}$ analysed $=34$, missing $\mathrm{N}=9$; only complete data sets could be analysed by Time Series Analysis. descending pain-related fear: slope $b \leq-1 \mathrm{~mm} /$ day; $N=13$ stable pain related fear: $-1<$ slope $\mathrm{b}<1 \mathrm{~mm} . /$ day; $\mathrm{N}=12$ rising pain-telated fear: slope $b \geq 1 \mathrm{~mm} /$ day; $N=9$

Figure 3.3 Standardised mean scores of pain (peak by definition) and pain-related fear and pain catastrophizing in corresponding sequences in time

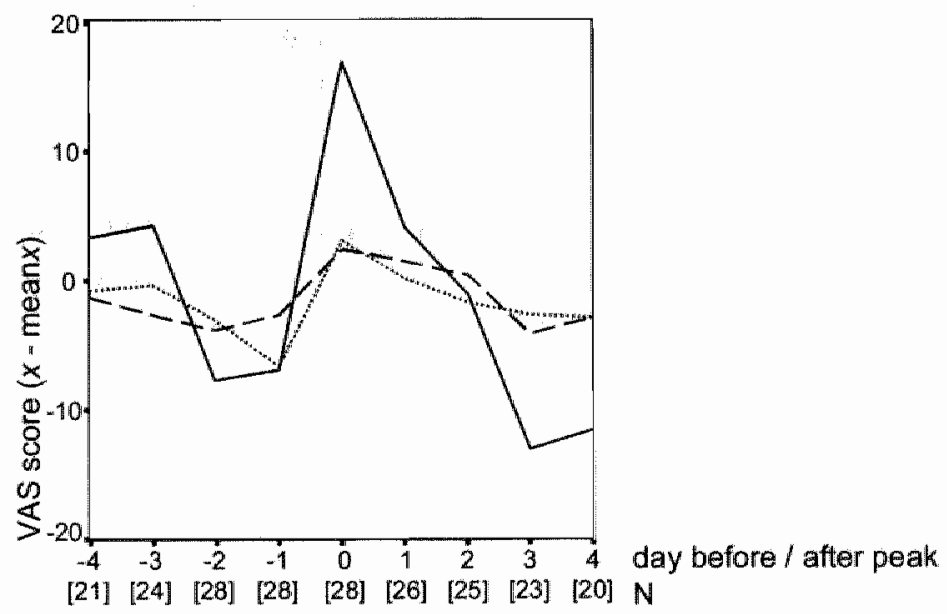

- pain (peak by definition); .... pain catastrophizing; - . pain-rellated fear.

$\mathrm{N}$ analysed $=42$. 
(2) Sequential relationshipts: In 42 inclividual sets of daily pain measures 28 peakdays were identified (maximum 1 peak-day per patient). Figure 3.3 shows the resulting mean graph, together with mean graphs of corresponding sequences in pain-related fear and pain catastrophizing. The defined increase in pain during the two days preceding the peak-day was accompanied by a tising level of pain-related fear $(p=0.022)$, and pain catastrophizing tended to rise during this two-day period $(\mathrm{p}=0.106)$. No time-shift between pain catastrophizing and pain or between painrelated fear and pain could be demonstrated; top-levels in pain-related fear and pain catastrophizing occurred on the same day as the peak in pain.

\section{DISCUSSION}

In recent years, several prospective cohort studies have been conducted to determine the predictive value of psychosocial factors as predictors of chronic lowback pain disability in primary care (Linton, 2000). Few studies, however, have specifically addressed the role of pain-related fear in the development of chronicity. The purpose of the present study was to extend previous research by investigating the short-term course of pain-related fear during the acute stage of a new low back pain episode. A prospective case series design with sequential measurements was used to explore possible underlying cognitive mechanisms.

\section{Summary of results}

With respect to the actual course of pain-related fear during the acute stage of a back pain episode, subgroups of patients with descending, stable and rising levels of pain-related fear over time could be identified. These groups differed on levels of disability at baseline and follow-up. Although starting with low levels of disability, patients with tising pain-related fear levels were more disabled after one year. Furthermore, analyses regarding sequential relationships showed that increases in pain intensity were accompanied by increases in pain-related fear and probably its precursor pain catastrophizing as well. However, no time-shift between the occurrence of increases in pain, pain-related fear and pain catastrophizing could be demonstrated.

When comparing the results of this study with recent publications, another indirect but remarkable finding is, that levels of pain-related fear in acute patients (mean $=39.1$ and $\mathrm{SD}=7.6$ at baseline) ate comparable (independent samples t-test not significant) to mean values found in subacute (mean $=37.0$ and $\mathrm{SD}=7.5$ (Swinkels, 1999)) and chronic patients (mean $=40.1$ and $\mathrm{SD}=6.6$ (van den Hout et al., 2001)), despite dissimilar clinical settings. 


\section{Patients with increasing fear: a subgroup at nisk?}

When discussing the interpretation and implications of the results, special attention must be paid to the TSA findings. In many patients pain-related tear showed a descending pattern over time, as could be expected as a result of natural recovery. A second substantial subgroup of patients showed stable patterns of pain-related fear, fluctuating around a rather low, not alarming, level. The most striking tesult was the number of patients with steadily rising levels of pain-related fear. A few rising patterns were to be expected by chance, but a $26.5 \%$ subgroup cannot be ignored. These patients might be at risk of developing chronic disability. Their one-year outcome on disability strongly suggests a negative prognosis.

But why the observed rising patterns of fear occur in people, who initially report surprisingly low levels of disability and fear, remains unclear. The sudden increase in pain at the beginning of the second week is an intriguing, but as yet inexplicable finding as well. In the past, several mechanisms have been put forward to explain the development of fear and these are worthwhile considering also in the context of pain-related fear:

(1) Match-mismatch processes (as proposed by Antz et al. (1991), in which the pain a patient experiences does not match pain expectations, can result in increasing pain-related fear. It is quite possible that patients with a low level of disability expect that pain will fade away within a couple of days. However, when pain persists beyond the expected time, they may start worrying about the seriousness of the pain felt. Worrying about pain is a normal process that can be triggered by situational factors (increase in pain, awareness of somatic sensations) (Eccleston et al, 2001). The fact that patients in the rising fear group reported a longer back history before the current episode might add to the worry.

(2) The aetiology of fear might be attributed to unconditioned stimulus (UCS) inflation (Davey, 1992; Hosoba et al., 2001). A UCS -in this case pain- is being reevaluated with new information about this stimulus, resulting in a stronger: response (fear). Pain-related information can originate from several sources such as media, telatives, other patients as well as health care providers. Noticeably, (Rainville et al., 1995) proposed that patients' attitudes and beliefs (and thereby patients' disability levels) may be derived from the projected attitudes and beliefs of health care providers" (page 288).

But, which of these mechanisms are of importance in the development of feat in acute low back pain patients remains unclear, as no data concerning the specific models are gathered in this study. 


\section{Demonstrating causal relationships witbin a circular model}

Another theoretical issue is that of causal relationships between pain catastrophizing; pain-related fear and pain. Because of the circular nature of the fear-awoidance model, a sudden pain-experience can as well be preceded or followed by an increase in pain-related fear. Close-up examination of graphs as performed in this study did not contribute to an answer to causality-questions. Although analysis of isolated peak-segments in pain graphs confirmed that an increase in pain indeed was accompanied by increases in pain-related fear and, probably, pain catastrophizing, sequential relationships could not be demonstrated, at least not within 24-hour intervals. This might be due to methodological shortcomings, but optimised methods might not reveal sequential differences either. Maybe any time-shift between pain and pain-related fear can only be demonstrated during the very first passage through the fear-avoidance cycle. After this first cycle, a cleat distinction between causes and consequences might no longer exist, fading to permanent presence of both fear and pain, increasing and decreasing together at the same pace.

\section{Methodological considerations}

In describing the natural course of pain-related fear, single case techniques reveal details that cannot be noticed by group level analyses with appropriate, large sample sizes. Critical remarks can be made with regard to the design of this study however.

Firstly, the results could have been more meaningful if additional qualitative data collection during the two-week period had been undertaken. In the present design, the patterns found in fear and pain cannot sufficiently be explained. It is likely that the time series are influenced by the occurrence of specific events (for example: return to work on resumption of sports activities). Replication of this study, including additional monitoring of the (co)incidence of such events, can provide more clear evidence about underlying mechanisms.

Furthermore, the sensitivity of the method used for sequential analysis can be questioned. It is possible that a demonstrable time-shift between the occurrence of pain, pain-related fear and catastrophizing is lacking, because diaries were completed retrospectively. Use of more sensitive measures and shorter intervals are needed to test sequential relationships. Hand-held computer diary-methods can probably be helpful, because of the ability to produce longer time series with shorter intervals and more accuracy.

Finally, another methodological consideration addresses the definition of a new low back pain episode. Although a new episode can be properly defined by its occurrence in time, a patient's cognitions accompanying this new episode will 
inevitably be influenced by any previous back pain experiences. The optimal, though very impractical, solution for this would be to identify and uniquely select patients with a very first back pain episode, who have never gone through the fearavoidance-cycle before.

\section{CONCLUSIONS}

After considering the interesting results together with the suggestions for improvement of the design, it seems worthwhile to replicate this study with optimised techniques of measurement and analysis, and to search for ways to further examine pain and pain-related fear mechanisms in acute low back pain patients. It might possibly lead to clues to improve strategies to prevent chronic disability. For example, a recent study with fearful chronic patients has shown that by gradual exposure to specific feared movements, the patient's incortect attributions can be readjusted (Vlaeyen et al., 2001), resulting in lower levels of pain-rellated fear. It is likely that fear-reducing treatment can also be effective to prevent chronic back pain disability in acute patients (e.g. (Moore et al., 2000)). More knowledge about the exact object of a patient's pain-related fear and its origin and development, might contribute to the success of fear and disability reducing therapies.

\section{ACKNOWLEDGEMENTS}

Parts of this study were previously presented as a poster at the EFIC-congress "Pain in Europe", Nice (France), 26-29 September 2000. The authors like to thank Stephen Morley for his valuable suggestions, and Anja van den Hout and Ilse Swinkels for their permission to use their data on chronic and subacute patients for comparison. 


\section{RETERENCES}

- Andersson, GB. (1999). Epidemiological features of chronic low-back pain. Lanet, 354 (9178), 581-585.

- Antz, A., van den Hout, M.A., van den Berg, G., Meijboom, A. (1991). The effects of incorrect pain expectations on acquired fear and pain responses: Bebaw Res Ther, 29 (6), 547 560 .

- Asmundson, G.J. Norton, P.J., Norton, G.R. (1999). Beyond pain: the role of fear and avoidance in chronicity. Cha Psychol Rev, 19 (1), 97-119.

- Bombardier, C. (2000). Outcome assessments in the evaluation of treatment of spinal disorders: summary and general tecommendations. Spine, 25 (24), 3100-3103.

- Crombez, G., Eccleston, C., Bayens, F., van Houdenhove, B., van den Broeck, A. (1999). Attenton to chronic pain is dependent upon pain-related fear. J Psychoson Res, 47 (5), $403-410$.

- Davey, G.C.I. (1992). Classical conditioning and the acquisition of human fears and phobias: a teview and synthesis of the literature. Adwantes in Bebaviour Research and Theratpy, $14,29-66$.

- Deyo, R.A., Battie, M., Beurskens, A.J., Bombardier, C., Croft, P., Koes, B., Malmivaara, A, Roland, M., Von Korff, M., Waddell, G. (1998). Outcome measures for low back pain research. A proposal for standardized use. Spin, 23 (18), 2003-2013.

- Dionne, CE. (1999). Low back pain. In I. K Crombie (Ed.), Epideniology of pain (pp. 283-297). Seatte: IASP Press.

- Eccleston, C., Crombez, G., Aldrich, S., Stannard, C. (2001). Worty and chronic pain patients: a description and analysis of individual differences. Exar J Pain, 5 (3), 309-318.

- Faas, A., Chavannes, A.W., Koes, A.W., Van den Hoogen, J.M.M., Mens, J.M.A., Smeele, I.J.M., Romeijnders, A.C.M., Van der Laan, J.R. (1996). Practice Guideline 'Low Back Pain" [translation], Utrecht.

- Fritz, J.M., George, S.Z., Delitto, A. (2001). The role of fear-avoidance beliefs in acute low back pain: relationships with current and future disability and work status. Pain, 94 (1), $7 \times 15$.

- Gommans, IH.B., Koes, B.W., Van Tulder, M.W. (1997). Validiteit en responsiviteit: Nedertandstalige Roland Disability Questionnaire. Walidity and responsiveness: Dutch version Roland Disability Questionnaire.]. Nederlands Tyidschrift wow Fysiatherapie, 2, 28-33.

- Goubert, L., Crombez, G., Vlaeyen, J.W.S., Van Damme, S., Van den Broeck, A., Van Houdenhove, B. (2000). De Tampa Schaal voor Kinesiofobie. Psychometrische karakteristicken en normering. [The Tampa Scale for Kinesiophobia: Psychometric chatacteristics and noms.]. Gedrag Gezowdheth Tydshrift voor Pyobologie en Gezondhetd, 28 (2), 54-62.

- Hosoba, T., Iwanaga, M., Sewa, H. (2001). The effect of UCS inflation and deflation procedures on 'fear' conditioning. Bebay Res Ther; 39 (4), 465-475.

- Hurley, D.A., Dusoir, T.E., McDonough, S.M., Moore, A.P., Baxter, G.D. (2001). How effective is the acute low back pain screening questionnaire for predicting 1-year follow-up in patients with low back pain? Cin J Pain, 17(3), 256-263. 
- Hurley, D.A., Dusoir, T.E., McDonough, S.M., Moore, A.P. Linton, S.J., Baxter, G.D. (2000). Biopsychosocial screening questionmaire for patients with low back pain: preliminary report of utility in physiotherapy practice in Northern Ireland. Clim $J$ Paim, 16 (3), 214-228.

- Kugler, K., Wijn, J., Geilen, M., de Jong, J., Heuts, P.H.T.G., Vaeyen, J.W.S. (1999). The Photograph Series of Daby Antivites (PHODA). CD-ROM version. Institute for Rehabilitation Research Hoensbroek, School for Physiotherapy Heetlen, and Mastricht University, The Netherlands.

- Lethem, J, Slade, P.D., Troup, J.D., Bentley, G. (1983). Outline of a Fear-Avoidance Model of exaggerated pain perception-1. Bebay Rer Tber, 21 (4), 401-408.

- Linton, S.J. (1999). Prevention with special teference to chronic musculoskeletal disorders. In R. J. Gatchel \& D. C. Turk (Eds.), Psobosarial fartors in pan (pp. 374-389). New York: The Guilford Press.

- Linton, S.J. (2000). A review of psychological tisk factors in back and neck pain. Spino, $25(9), 1148-1156$.

- Linton, S.J., Buer, N., Vlaeyen, J.W.S., Hellsing, A.L. (2000). Are fear-avoidance beliefs related to the inception of an episode of back pain? A prospective stady: Psyctology and Health, 14, 1051-1059.

- Linton, S.I., Hallden, K. (1998). Can we screen for problematic back pain? A screening questionnaire for predicting outcome in acute and subacute back pain. Clin J Pakn, 14 (3), $209-215$.

- Linton, S.J., Hellsing, A.L., Andersson, D. (1993). A controlled study of the effects of an early intervention on acute musculoskeletal pain problems, Pain, 54 (3), 353-359.

- Merskey, H., Bogduk, N. (1994). Classyfication of thronic pain. Second Edition, IASP "Taks Force on Taxonomy. Seattle: IASP Press.

- Miller, R.P., Kori, S.H., Todd, D.D. (1991). The Tampa Sale (Unpublished Report). Tampa, Fil.

- Moore, J.E., Von Korff, M., Cherkin, D., Saunders, K., Lorig, K. (2000). A randomized trial of a cognitive-behavioral program for enhancing back pain self care in a primary care setting. $P_{a n n} 88(2), 145-153$.

- Osman, A., Barrios, F.X., Kopper, B.A., Hauptmann, W., Jones, J., ONeill, E. (1997). Factor structure, reliability, and validity of the Pain Catastrophizing Scale. J Bebow Med, 20 (6), 589-605.

- Picavet, H.S.J., Schouten, J.S.A.G., Smit, H.A. (1996). Prevalenties en consequevthis waw lage raghkachten in bet MORGEN-projed 1993-1995. [Prevalences and consequences of low back pain in the MORGEN-project 1993-1995.] (263200004). Bilthoven, The Netherlands: Rijksinstituut voor volksgezondheid en milieu (RIVM).

- Rainville, J., Bagnall, D., Phalen, L. (1995). Health care providers" attitudes and beliefis about functional impaiments and chronic back pain. Clin j Pain, 11 (4), 287-295.

- Roland, M., Morris, R. (1983). A study of the natural history of back pain. Part I: development of a reliable and sensitive measure of disability in low-back pain. Spine, 8 (2), $141-144$.

- Sullivan, M.J.L., Bishop, S.R., Pivik, J. (1995). The Pain Catastrophizing Scale: development and validation. Psybological Asserment, 7 (4), 524-532. 
- Swinkels, E.J.CM. (1999). Kinesicfabie en fear-awoidante bellefs bij arute bage rugbiju. [Kinesiophobia and fear-awoidance beliefs in acute low back pain]. Vrije Universiteit, Brussel.

- Van Datnme, S., Crombez, G., Vlaeyen, J.W.S., Goubert, L., Van den Broeck, A., Van Houdenhove, B. (2000). De Pain Catastrophizing Scale: Psychometrische karakteristieken en normering. [The Pain Catastrophizing Scale: Psychometric characteristics and norms:] Couragstherapie, $33(3), 209-220$.

- van den Hout, J.H., Vlaeyen, J.W.S., Houben, R.M., Soeters, A.P.y Peters, M.L. (2001). The effects of failure feedback and pain-related fear on pain report, pain tolerance, and pain avoidance in chronic low back pain patients. Pain, 92 (1-2), $247-257$.

- Vlaeyen, J.W.S, de Jong, J., Geilen, M., Heuts, P. H., van Breukelen, G. (2001). Graded exposure in wiwo in the treatment of pain-telated fear: a replicated single-case experimental design in four patients with chronic low back pain. Behav Res Ther, 39 (2), 151-166.

- Vlaeyen, J.W.S., Kole-Snijders, A.M.J., Rotteveel, A., Ruesink, R., Heuts, P.H.T.G. (1995). The role of feat of movement/(re)injury in pain disability. joumal of Ocaupational Rethabilitation; $5(4), 235-252$.

- Vlaeyen, J.W.S., Linton, S.J. (2000). Fear-avoidance and its consequences in chronic musculoskeletal pain: a state of the art. Paint, 85 (3), 317-332.

- Waddell, G. (1998). The Back Pain Revolution. Edinbungh: Churchill Livingstone. 


\section{CHAPTER 4}

\section{Pain-related fear at the start of a new low back pain episode}

Judith M. Sieben, Piet J.M. Portegiis, Johan W.S. Vlaeyen, J. André Knottnerus

Published as:

Sieben, J.M., Portegijs, P.J.M., Vlaeyen, J.W.S., Knottnerus, J.A. (in press) Painrelated fear at the start of a new low back pain episode. European Journal of Pain. 


\begin{abstract}
Previous research supports the fear-avoidance model in explaining chronic low back pain (LBP) disability. The aims of the present study were to determine (1) whether fear-avoidance model variables are associated already during acute stages of LBP and (2) whether (increases in) pain-related fear are associated with other patient characteristics routinely assessed by the General Practitioner (GP).

General practice patients consulting because of a new episode of LBP completed questionnaires on pain-related fear, avoidance, pain and disability. A sample of 247 acute LBP patients (median duration of current episode was 5 days) was collected. Significant associations were found between pain intensity, painrelated fear, avoidance behaviour and disability, but most correlations were genterally modest. A strong association was found between pain and disability. Pain-related fear was slightly higher in patients reporting low job satisfaction and in those taking bedrest.

These results suggest that the fear-avoidance model as it was developed and tested in chronic IBP, might not entirely apply to acute LBP patients. Future research should focus on the transition from acute to chronic LBP and the shifts that take place between fear-avoidance model associations.
\end{abstract}




\section{INTRODUCTION}

Non-specific low back pain (LBP) by its nature appears to be a benign and selflimiting condition. Many patients recover within a few weeks, but residual symptoms and recurrences are common (Waddell, 1987; Von Korff and Saunders, 1996). Chronic LBP accounts for important personal problems (Dionne, 1999) and medical and socio-economic costs (Waddell, 1996).

During the last decade, a cognitive-behavioural fear-avoidance model explaining disability in chronic back pain has been formulated (Vlaeyen and Linton, 2000). The basic tenet of this model is, that if back pain is being (mis)interpreted as a signal of (re)injury and/or tissue damage, fear emerges and movements that typically increase pain are systematically avoided. Persisting avoidance behaviour will then lead to increasing disability, physical deconditioning and lower pain thresholds. The fearful patient is likely to end up in a cycle of fear, inactivity, disability, depression and pain.

Accumulating evidence has been found supporting this fear-avoidance model. Pain-related fear appeared to be associated with impaired physical performance Vlaeyen et al., 1995a; Crombez et al., 1999; Al-Obaidi et al., 2000; van den Hout et al., 2001) and increased self-reported disability (Vlaeyen et all., 1995b; Asmundson et al., 1997; Crombez et al., 1999). Furthermore, it has been shown that educational interventions aimed at reducing negative attitudes and beliefs that mediate avoidance behaviour result in lower LBP related absence from work (Symonds et al., 1995; Moore et al., 2000; Buchbinder et al., 2001). The reduction of painrelated fear as a result of cognitive-behavioural treatment is associated with increased activity tolerance and improved functional abilities (Vlaeyen et al., 2001; Boersma et al., 2004).

Although most research on pain-related fear is performed in patients with chronic LBP, a small number of recent studies showed that pain-related fear can be identified in acute back pain patients as well. For example, (Fritz et al., 2001) focussed on subjects with work-related IJBP of less than three weeks duration. Patterns of correlations between fear-avoidance beliefs and other concurtently measured variables (disability, among others) were similar to those found in chronic LBP patients. Another study by our group (Sieben et al., 2002), using daily measures during the first two weeks of a new LBP episode, identified subgroups of patients with descending, stable and rising levels of pain-related fear. "These groups with different acute stage courses of pain-related fear differed on levels of disability at baseline and follow-up (patients with rising pain-related fear levels were more disabled after one year). Furthermore, Buer and Linton (2002) demonstrated painrelated fear to be detectable even in pain-free individuals. Linton et al. (2000) showed fear-avoidance beliefs to be related to the inception of new I.BP episodes. 
If fearful patients can be identifed in chinical practice at an early stage, they become dighble for (secondary) preventive intervention. In the Netherlands, acute LBP patients will initially consult a general practitioner (GP) for treatment, advice and, if needed, refertal to oher specialists. Therefore, the general practice context sectiss to provide an ideal opportunity for early screening (Von Korff and Moore, 2001). Usually, a number of pain characteristics are routinely assessed by the GP, including wpe of pain onset, tadiating symptoms, LBP history (previous episodes), taking bedrest, perceived causes of back pain and job satisfaction. If high-risk patients could be (even roughly) identified by these charactetistics, this would facilitate efficient eatly screening.

The aim of the ptesent study is twofold. First we will examine whether association between pain, (increases in) pain-related fear, avoidance and disability at the start of a new $L B P$ episode are comparable to those reported in chronic LBP patients. Secondly, we want to further explore associations between (increases in) pain-related fear and other LBP characteristics easily assessed by the GP.

\section{METHODS}

\section{Participants}

Participants were recruited between January 2001 and April 2003 from 35 general practices located in the southern part of the Netherlands. Patients who consulted their GP with a new episode of non-specific LBP were invited to participate in the study. A new episode of LBP was defined as: (1) pain localised below the scapulae and above the gluteal folds (following IASP taxonomy (Merskey and Bogduk, 1994)), (2) duration since time of pain onset no longer than three weeks, (3) after a period of at least three months without significant activity limitations due to back trouble. Additional selection criteria were (4) 18-60 yeats of age, (5) no specific cause or strong suspicion of speciffe cause (such as a fumout, inflammation or vertebral fracure), (6) no pregnancy. (7) sufficient knowledge of Dutch language. Selection critetia wete checked by the $G P_{s}$.

Eligible patents teceived full written information about the study to tead at hone: the invitation involved participation in a longitudinal study (the prospective part of which is beyond the scope of this paper). The next day a phone call was made by one of the researchers. Any questions about the study were answered, the patient was requested to verbally consent on participation and selection criteria were checked again. Consenting patients were instructed to retum the baseline questionnaite together with their writen informed consent. The study protocol was approved by the medical ethics review committees of Mastricht Unwersity Hospital \& Mastricht University (Maastricht, the Netherlands) and the Institute for Rehabiltation Research (Hoensbroek, the Netherlands). 


\section{Merasures}

Following the GP visit patients completed a questionnaire on (a) a set of descriptives: back pain history, characteristics of the current episode, work status, and (b) variables concerning the fear-avoidance model: pain-related fear, back pain disability and (avoidance of) physical activity.

Back pain biston: Information was gathered about previous back pain episodes (number of episodes in the past, age at which first episode occurred) and history of back pain treatment.

Current episade: The current episode was characterised by (a) pain intensity as measured by a $10 \mathrm{~cm}$. Visual Analogue Scale (VAS) anchored with extremes of 0 ("no pain') and 100 ("unbearable pain'), (b) type of pain onset (sudden or gradual) and (c) radiating symptoms (yes/no). These items were derived from the McGill Pain Questionnaire, Dutch Version (Verkes et al., 1989). Additionally acute pain duration (number of days since pain onset) was recorded.

Work status: To explore the occupational context, information was gathered about occupation, employment status, sick leave and job satisfaction.

Pain-related fear: The Dutch version of the Tampa Scale for Kinesiophobia (TSK) (Miller et al., 1991; Vlaeyen et al., 1995b) measures cognitions concerning somatic focus and activity avoidance. The TSK consists of 17 statements with answers on a 4-point scale ( $1=$ 'strongly disagree' to $4=$ 'strongly agree'). Reliability and validity of the TSK Dutch version ate well established (Vlaeyen et al., 1995b; Roelofs et al., 2004). In this study participants completed the TSK once at the GP practice (consultation) and again a few days later as a part of the baseline questionnaire set. Changes between both measurements were calculated (TSKscore baseline minus TSK-score consultation; positive change values reflect increasing TSK-scores).

Back pain disability: LBP disability was assessed using the Quebec Back Pain Disability Scale (QBPDS) (Kopec et al, 1996). This questionnaire is specifically developed for use in LBP populations. Patients rate on a 6-point Likert scale $(0=$ "no difficulty" to $5=$ "not able to do') to what extent they experience difficulty in performing 20 daily life activities. Both the original English QBPDS scale and the Dutch Vetsion are teliable and walid (Schoppink et al., 1996).

(Avoidawe of) physical activity: The Physical Activity Rating Scale (PARS) was used to determine the extent to which patients engage in a selection of 20 specific daily activities (e.g. one hour walking, climbing two stairs, shopping). Patients were asked to indicate on a 5-point scale ("never' to "vety often") whether they had performed each activity over the last 2 weeks. The PARS was initially developed for use in chronic fatigue syndrome and was found to be an acceptable alternative for assessment of physical activity with an accelerometer (Vercoulen et al., 1997). The PARS was previously applied in LBP research by Verbunt et al. (in press). 
A new question designed for this study was added to the PARS scale. After having rated activity frequencies, parients were asked for each item whether they would have performed the activity more often if they would not have taken their back pain into account. The sum of all 20 dichotomous answers (yes $=1 /$ no $=0$ ) was used as a measure of avoidance, with higher scores depicting more avoidance behaviour.

\section{Arialysis}

SPSS 11.0 was used for all statistical analyses. Because variables showed nonnormal distributions, nonparametric statistics were used. Unless reported otherwise, statistical tests are two-sided and p-values $\leq 0.05$ were judged significant.

Bivariate associations between variables within the fear-avoidance model (painrelated fear, pain intensity, avoidance and disability) were examined by Spearman rank correlation coefficients. Furthermore, in a circular model each variable serves both as a predictor and an outcome. By regarding the variables in the model as mediators in between two other variables, roles are shifted from effects to causes. The theoretical model is supported if each variable is a mediator of the association between the variables immediately preceding and following it. Partial (rank) correlations were used as a nonparametric alternative for the regression analyses as proposed by Baton and Kenny (1986) to test for mediation. Given significant bivariate correlations between independent variable $A$ and mediator variable $B$ and between independent variable $A$ and dependent variable $C$, variable $B$ is an essential mediator of the $\mathrm{AC}$-relation, if the partial correlation of $\mathrm{AC}$ corrected for $B$ is low.

To explore the association between pain-related fear and other LBP characteristics, subgroups of patients were created based on several dichotomous episode characteristics, LBP history and behavioural factors. Mann-Whitney U tests were then performed to test for differences in (increases in) pain-related fear between these subgtoups.

\section{RESULTS}

\section{Participant characteristics}

The GPs invited 464 patients to participate in the study. Of this total, 71 patients reported LBP for more than 3 weeks and were invited to participate in another study focussing on physical consequences of LBP (excluded from present analyses). Another 146 did not meet the selection criteria $(N=65)$ or refused participation $(N=81)$ after reading the information package. Ultimately, selection 
criteria were met and questionnaires were returned by 247 patients (144 male and 103 female). Mean age of this sample was 42.9 years (SD 10.3). Baseline levels of pain intensity, LBP disability and pain-related fear are shown in table 4.14, For these variables no differences were found between men and women. In table 4:1b characteristics of the current episode and LBP history are presented. Median duration of the current pain episode at consultation was 5 days (range $0-21$ ), which suggests that this is an acute back pain sample. Of all participants $75.7 \%$ were employed in a paid job. Eight individuals were on long-term sick leave ( $>12$ weeks) and another 13 were receiving disability benefits at the time of consultation (both not necessarily due to LBP, because other illness and associated sick leave were no exclusion criteria). There were no significant differences (age, gender) between participants and non-participants (excluded/refusal categories; data avallable from $\mathrm{N}=89$ ).

Table 4.1a \& 4.1b Baseline characteristics: acute low back pain in general practice, $\mathrm{N}=247$

\begin{tabular}{lll}
\hline A & Median & (Q1-Q3) \\
\hline Pain intensity (VAS; score 0-100) & 47.0 & $(25-64)$ \\
LBP disability (QBPDS; score 0-100) & 42.0 & $(29-55)$ \\
Pain-related fear (TSK; score 17-68) & 37.0 & $(32-41)$ \\
\hline
\end{tabular}

\begin{tabular}{lrl}
\hline B & $\mathbf{N}$ & $(\%)$ \\
\hline Previous episodes & 186 & $(75.3 \%)$ \\
$1-2$ previous episodes & 71 & $(28.7 \%)$ \\
$3-5$ previous episodes & 42 & $(17.0 \%)$ \\
$>5$ previous episodes & 73 & $(29.6 \%)$ \\
Onset of pain & & \\
$\quad$ sudden & 161 & $(65.2 \%)$ \\
gradual & 81 & $(32.8 \%)$ \\
Radiating symptoms & & \\
yes & 156 & $(63.2 \%)$ \\
no & 86 & $(34.8 \%)$ \\
\hline
\end{tabular}

Q1-Q3 = interquartile range.

\section{Associations between fear-avoidance model variables}

Spearman rank correlation coefficients of relevant associations within the fearavoidance model are presented in figure 4.1 (solid arrows). Although fear- 
awoidance theory implies unidirectional arrows between variables, two-sided arrows are displayed because no inferences concerning causality can be made based on cross-sectional data. Bivariate cortelations for all links showed to be significant. The strongest association was found between disability and pain intensity. Correlations between variables adjacent in the model were about as strong as the more distant cotrelations. Acute stage increase in pain-related fear was only weakly associated with increased disability (tho $=0.198, \mathrm{p}=0.002$ ) and pain intensity (tho $=0.160, \mathrm{p}=0.014)$

Figure 4.1 Associations and mediation within the fear avoidance model

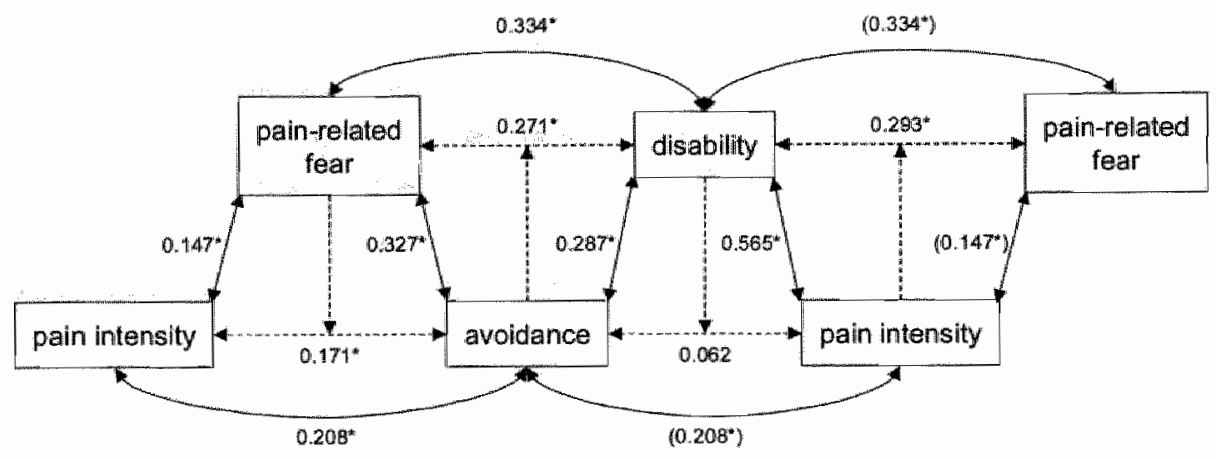

Explanation: The chain in this illustration represents the fear-avoidance model. By starting at the lower left side and by following the sollid arrows, one car navigate through the subsequent steps of the model (pain intensity, pain-related fear, avoidance, disability). Sold arwow: Spearman's rank correlation coefficients for associations between two variables. Dashed awon:s: tanked partial correlation coefficients for associations between two variables corrected for mediating influence of third variable. p-Walueg $\leq 0.05$ are marked *

\section{Mediation mithin the fear-avoidance model}

Results with respect to the mediating contribution of each variable within the model are shown in figure 4.1 (dashed arrows). Bivariate correlations and partial correlations involving sets of three variables are presented. Differences between correlations and partial correlations are mostly modest. Results show disability to be a mediator in between pain intensity and avoidance, because the correlation between pain intensity and avoidance drops considerably (from 0.208 to 0.062) and even looses significance when controlling for disability. As the partial correlation between pain-related fear and avoidance controlled for pain intensity is only slightly lower than the simple correlation between pain-related fear and avoidance (0.298 compared to 0.327 ; not shown in figure 4.1$)$, pain-related fear seems to be 
an independent predictor of avoidance rather than a mediator of the painavoidance relation. Similarly, disability and pain intensity are strongly related to each other apart from the influence of pain-telated fear and avoidance (simple correlation between disability and pain $=0.565$; controlled for fear $=0.552$; controlled for avoidance $=0.542$ ).

Table 4.2 Differences on pain-related fear between groups based on episode characteristics, LBP history and behavioural factors

\begin{tabular}{|c|c|c|}
\hline Groups (N) & TSK median (Q1-Q3) & MW-U p-value \\
\hline $\begin{aligned} & \text { Onset of pain } \\
& \text { sudden }(161) \\
& \text { gradual }(81)\end{aligned}$ & $\begin{array}{l}36(32-40) \\
37(32-42)\end{array}$ & 0.393 \\
\hline $\begin{array}{l}\text { Radiating symptoms } \\
\text { yes }(156) \\
\text { no }(86)\end{array}$ & $\begin{array}{l}36(32-41) \\
37(32-41)\end{array}$ & 0.763 \\
\hline $\begin{array}{l}\text { Nwmber of previous episades } \\
\begin{array}{ll}1-2 & (71) \\
>5 & (73)\end{array}\end{array}$ & $\begin{array}{l}36(31-40) \\
37(32-42)\end{array}$ & 0.197 \\
\hline $\begin{array}{l}\text { Bedrest because LBP } \\
\text { yes }(77) \\
\text { no }(164)\end{array}$ & $\begin{array}{l}38(33-44) \\
36(32-40)\end{array}$ & $0.015^{*}$ \\
\hline $\begin{array}{l}\text { Atribution cause } L B P \\
\text { muscular }(71) \\
\text { other }(149)\end{array}$ & $\begin{array}{l}36(31-41) \\
37(32-41)\end{array}$ & 0.644 \\
\hline $\begin{array}{l}\text { Job satisfantion } \\
\qquad \begin{array}{l}0-6=\operatorname{low} \quad(73) \\
7-10=\text { high }\end{array}\end{array}$ & $\begin{array}{l}38(34-44) \\
35(31-40)\end{array}$ & 0.004 . \\
\hline
\end{tabular}

TSK = Tampa Scale of Kinesiophobia scote as measured at consultation (score 17-68), Q1-Q3 = interquartile range. MW-U $=$ Mann-Whitney $\mathrm{U}$ test. $\mathrm{p}$-values $\leq 0.05$ are marked *

\section{Associations between pain-related fear and other back pain related variables}

Results of Mann-Whitney $U$ tests for differences on pain-related fear between groups divided by several LBP characteristics are presented in table 4.2. Patients with low scores on job satisfaction reported higher pain-related fear than patients who were satisfied with their jobs. Participants who took bedrest because of their LBP also showed higher levels of pain-related fear than those who did not. Although these differences are significant, they are not very large (2 to 3 TSK 
points). No differences were found on changes in TSK-scores (increase or decrease) for any of the LBP-related variables. However, it should be noted that changes in TSK-scores during the few days in between measurements are small in general (overall median $=-1$; interquartile range -6 to +2 ).

\section{DISCUSSION}

During the last decade a number of studies have focussed on the role of painrelated fear in LBP. Its importance as a perpetuating factor in chronic LBP has been well established (Vlaeyen and Linton, 2000), but the role of pain-related fear and avoidance during the acute stage of a low back pain episode is still unclear.

The sample of general practice acute LBP patients in this study was characterised by considerable pain, high acute LBP disability and pain-related fear levels comparable to those in chronic patients. Associations among fear-avoidance model variables were significant but rather modest. The strongest association was found between pain intensity and disability; these two variables appeared to be independently related and not mediated by pain-related fear. Slightly higher levels of pain-related fear at consultation wete found in patients with low job satisfaction and those who took bedrest; no clear differences were found for other LBP characteristics.

\section{The fear-avoidance model in ante $L B P$}

These results provide some, but rather weak, support for the feat-avoidance model in acute stages of LBP. The strong association found between pain intensity and disability replicates findings by van den Hout et al. (2001) and seems to reflect obvious differences between acute and chronic LBP.

The most common, suddenly emerging acute back pain may be related to mechanical strain or dysfunction with minor muscular tissue damage and physiological responses (Waddell, 1998). Therefore acute back injury can be quite painful and disabling during the first few days. This is in contrast with the situation in chronic patients, where the initial injury has long been resolved and disability is no longer related to pain intensity (Crombez et al., 1999).

Subsequently, as a strong association between pain and disability appatently makes sense, it is not surptrising that acute LBP patients are fearful of the pain and tend to avoid activities during the very early stages of a LBP episode. This avoidance behaviour may often be temporary; because many patients will be aware of the self-limiting nature of LBP, (possibly) painful or impaired activities will just be postponed. After a few days, pain-related fear and disability will resolve naturally along with the pain in most patients. This might explain why a mediating role of pain-related fear was not found as expected. 
This argumentation casts doubt on the value of measuring pain-related fear at a very early stage of an episode. As we showed in our previous study (Sieben et al, 2002), changes in pain-related fear over a longer period (for instance 2 weeks) may instead better predict disability at follow-up. Those patients who do not show a spontaneous decrease of pain-related fear as described above, should be made eligible for targeted intervention. From this study we could not derive an easy to apply altemative for the existing screening instrument (TSK) to do so.

The current paper is based on cross-sectional data, which impairs the ability to draw causal inferences. Preliminary analyses of our follow-up data both support and contradict fear-avoidance theory (details beyond the scope of this paper). More thorough analysis is warranted to further clarify the role of pain-related fear in the transition from acute to chronic LBP.

\section{Methodological considerations}

Some critical remarks can be made with regard to the methods used in this study. Testing early processes within a circular model involves design problems. Choosing a cross-sectional design limits the options for analysing causal relationships within the model. However, a longitudinal study design does not solve this problem, since in a circular model both causal factors and consequences may exist simultaneously. It can be hypothesized that causal relations between pain, pain-related fear and disability can only be demonstrated during the first few times a patient passes through the feat-avoidance cycle. Later, all variables present at the same time as an invariable complex, in which details of the chain and mutual processes can no longer be isolated.

This issue might be further confounded by the tecurrent nature of LBP. Even if a new episode can properly be defined by its occurrence in time (when clearly linked to an event or acute injury), the accompanying cognitions and expectations will not be uniquely related to this particular episode. In recurrent cases the patient's ideas will inevitably be influenced by previous LBP experiences. For these methodological reasons it could be recommended to only recruit patients with "first-time ever episodes", but such patients are very difficult to find. Besides, because LBP is very common, even patients without LBP history will have cognitions based on information from media and relevant others.

The number of patients in this study is also a reason for concern. Based on incidence rates and data on prevalence in primary care, the number of participants was expected to be higher. Recruiting acute patients for research appeared to highly interfere with daily practice. Furthermore, implementation of a new Dutch general practice guideline on treatment of LBP in recent years might have influenced the number of patients consulting with acute LBP. According to this new guideline, acute LBP patients can be initially advised to await natural recovery 
before seeing a doctor. The number of patients eligible for this study may have been reduced for this reason.

Finally, another issue involves the interval in between TSK measurements. We used a short time interval (a few days) to calculate changes in TSK-scores compared to the 2-week interval used in the previous study (Sieben et al., 2002). This might explain why we found only small changes and weak associations. A longer period of time will reflect a tendency (rising, stable, decreasing) more accurately:

\section{CONCLUSIONS}

Despite limitations, the present study reveals new information about pain-related fear in very acute LBP that may add to the knowledge already gained by research in chronic patient populations. The fear-avoidance model is often presented as a causal model of the development of chronic J.BP, while research in chronic LBP patients can only prove its worth as a perpetuating factor once chronicity is established. Our findings suggest that alteady in acute stages of $L B P_{s}$ significant associations between pain-related fear, avoidance, pain and disability exist. On the other hand, the fear-avoidance model as developed in chronic patients may not completely apply to acute low back pain conditions. Jongitudinal research can show what changes take place during the transition from acute to chronic LBP, and in which subgroups of patients pain-related fear is relevant to treat.

\section{ACKNOWLEDGEMENTS}

The authors like to thank the staff of the general practices participating in this study for their help in recruiting patients. We are allso grateful to Sita van Riet, Jeanine Verbunt and Eric Bousema for their help and support in conducting this study. 


\section{REFERENCES}

- Al-Obaidi, S.M., Nelson, R.M., Al-Awadhi, S., Al-Shuwwaie, N. (2000). The role of anticipation and fear of pain in the persistence of avoidance behavior in patients with chronic low back pain. Spine, 25 (9), 1126-1131.

- Asmundson, G.J, Norton, G.R., Alerdings, M.D. (1997). Fear and awoidance in dysfunctional chronic back pain patients. Paim, 69 (3), 231-236.

- Baron, R.M., Kenny, D.A. (1986). The moderator-mediator variable distinction in social psychological research: conceptual, strategic, and statistical considerations. J Pers Soc Psychol, 51 (6), 1173-1182.

- Boersma, K., Linton, S., Overmeer, T., Jansson, M., Vlaeyen, J., de Jong, J. (2004). Lowering fear-avoidance and enhancing function through exposure in vivo. A multiple baseline study across six patients with back pain. Paim, 108 (1-2), 8-16.

- Buchbinder, R., Jolley, D., W/yatt, M. (2001). Population based intervention to change back pain beliefs and disability: three part evaluation. Bmj, 322 (7301), 1516-1520.

- Buer, N., Linton, S.J. (2002). Fear-avoidance beliefs and catastrophizing: occurrence and risk factor in back pain and ADL in the general population. Pain, 99 (3), 485-491.

- Crombez, G., Vlaeyen, J.W.S., Heuts, P.H., Lysens, R. (1999). Pain-related fear is more disabling than pain itself: evidence on the role of pain-related fear in chronic back pain disability. Pain, 80 (1-2), 329-339.

- Dionne, C.E. (1999). Iow back pain. In I. K. Crombie (Ed.), Epidemintogy of pain (pp. 283-297). Seattle: IASP Press.

- Fritz, J.M., George, S.Z., Delitto, A. (2001). The role of fear-avoidance beliefs in acute low back pain: relationships with current and future disability and work status. Pain, 94 (1), $7-15$.

- Kopec, J.A., Esdaile, J.M., Abrahamowicz, M., Abenhaim, L., Wood-Dauphinee, S., Lamping, D.L., Williams, J.I. (1996). The Quebec Back Pain Disability Scale: conceptualization and development. J Clin Epidemiol, 49 (2), 151-161.

- Linton, S.J., Buer, N., Vlaeyen, J.W.S., Hellsing, A.L. (2000). Are féar-avoidance beliefs related to the inception of an episode of back pain? A prospective study. Psychology and Heallth, 14, 1051-1059.

- Merskey, H., Bogduk, N. (1994). Classification of dbronic pain. Second Edition, IASP Taks Force on Taxonomy. Seattle: IASP Press.

- Miller, R.P., Kori, S.H., Todd, D.D. (1991). The Tampa Scate for Kinesiopbobia. Unpublished report.

- Moore, J.E., Von Korff, M., Cherkin, D., Saunders, K., Lorig, K. (2000). A randomized trial of a cognitive-behavioral program for enhancing back pain self care in a primary care setting. Pain, 88 (2), 145-153.

- Roelofs, J., Goubert, L., Peters, M.L., Vlaeyen, J.W.S., Crombez, G. (2004). The Tampa Scale for Kinesiophobia: further examination of psychometric properties in patients with chronic low back pain and fibromyalgia. Exr I Paim, 8 (5), 495-502.

- Schoppink, L.E., van Tulder, M.W., Koes, B.W., Beurskens, S.A., de Bie, R.A. (1996). Reliability and validity of the Dutch adaptation of the Quebec Back Pain Disability Scale. Pbys Ther, 76 (3), 268-275. 
- Sieben, J.M., Vaeyen, J.W.S., Tuerlinckx, S., Portegijs, P.J.M. (2002). Parin-related fear in acute low back pain: the first two weeks of a new episode. Eur J Pain, 6 (3), 229-237.

- Symonds, T.L, Burton, A.K. Tillotson, K.M., Main, C.J. (1995). Absence resulting from low back trouble can be teduced by psychosocial intervention at the work place. Spine, $20(24), 2738-2745$.

- var den Hout, J.HC, Vheyen, JW.S., Heuts; P.H.T.G., Sillen, W.J.H., Willen, AJ.H.T. (2001). Functional disability in nonspecific low back pain: the tole of painrelated fear and problem-solving skills. Twtenational Jounal of Bebanoral Medicine, 8 (2), 149162.

- Verbunt, J.A., Seelen, H.A., Vlaeyen, J.W.S., Bousema, E.J., Van der Heijden, G.J., Heuts, P.H., Knottnerus, J.A. (2005). Pain-felated factors contributing to muscle inhibition in patients with chronic low back pain an experimental investigation based on superimposed electrical stimulation. Clin J Pain, 21(3), 232-240.

- Vercoulcn, J.H., Bazelmans, E., Swanink, C.M., Galama, J.M., Jongen, P.J., Hommes, O, Van der Meer, J.W., Bleijenberg, G. (1997). Physical activity in chronic fatigue syndrome: assessment and its role in fatigue. J Pyichiatr Res, 31 (6), 661-673.

- Verkes, R. J, Vanderiet, K., Vertommen, H, van der Kloot, W.A., van der Meij, J. (1989). De MPQ-DLV: een standaard Wederlandstalige wersie van de McGil]. Pain Questionnaire voor België en Nederland. In W. A. van der Kloot \& H. Vertommen (Eds.), De MPQDLV: een standard Nederlandstalige wersie van de MoGill Pain Qutestionnative. Adbtergronden en bandleiding. Lisse: Swets \& Zeitlinger.

- Vlaeyen, J.W.S., de Jong, J., Geilen, M., Heuts, P. H., van Breukelen, G. (2001). Graded exposure in vivo in the treatment of pain-related fear: a replicated single-case experimental design in four patients with chronic low back pain. Behav Res Ther, 39 (2), 151-166.

- Vlaeyen, J.W.S., Kole-Snijders, A.M., Boeren, R.G., van Eek, H. (1995a). Fear of movement/(re)injury in chronic low back pain and its relation to behavional performance. Pain, 62 (3), 363-372.

- Vlaeyen, JW.S., Kole-Snijders, A.M.J., Rotteveel, A., Ruesink, R. Heuts, P.H.T.G. (1995b). The role of fear of movement/(re)injury in pain disability. Joumal of Oncomational Rubaluititation, $5(4), 235-252$

- Vacyen, J.W.S., Linton, S. J. (2000). Fear-avoidance and its consequences in chronic musculoskeletal pain: a state of the art. Pain, 85 (3), 317-332.

- Von Korff, M., Moore, J.C. (2001). Stepped cate for back pain: activating approaches for primary care. Ann lotern Med, 134 (9 Pt 2), $911-917$.

- Von Korff, M., Saunders, K. (1996). The course of back pain in primary care. Spune, 21 (24), $2833-2839$.

- Waddell, G. (1987). 1987 Volvo award in clinical sciences. A new clinical model for the treatment of low-brick pain Spize, $12(7), 632-644$.

- Waddell, G. (1996). Low back pain: a twentieth century health care enigma. Spine, 21 (24), $2820-2825$.

- Waddell, G. (1998). The Back Pain Rewathion. Edinburgh: Churchill Livingstone 


\section{Chapter 5}

\section{A longitudinal study on the predictive validity of the fear-avoidance model in low back pain}

Judith M. Sieben, Johan W.S. Vlaeyen, Piet J.M. Portegijs, Jeanine A. Verbunt, Sita van Riet - Rutgers, Arnold D.M. Kester, Michael Von Korff, Arnoud Arntz, J. André Knottnerus

Published as:

Sieben, J.M., Vlaeyen, J.W.S., Portegijs, P.J.M., Verbunt, J.A., van Riet - Rutgers, S., Kester, A.D.M., Von Korff, M., Arntz, A., Knottnerus, J.A. (2005) A longitudinal study on the predictive validity of the fear-avoidance model in low back pain. Pain, $117,162-170$. 


\begin{abstract}
Recently, fear-avoidance models have been quite influential in understanding the transition from acute to chronic low back pain (LBP). Not only has pain-related fear been found to be associated with disability and increased pain severity, treatment focused at reducing pain-related fear has shown to successfully reduce disability levels. In spite of these developments, there still is a lack in well-designed prospective studies examining the role of pain-related fear in acute back pain. The aim of the current study was to prospectively test the assumption that pain-related fear in acute stages successfully predicts future disability.

Subjects were primary care acute LBP patients consulting because of a new episode of LBP ( $\leq 3$ weeks). They completed questionnaires on background variables, feat-avoidance model variables and LBP outcome (Graded Chronic Pain Scale, GCPS) at baseline, 3 months, 6 months and 12 months follow-up and at the end of the study.

Two hundred twenty-two acute LBP patients were included, of whom 174 provided full follow-up information $(78.4 \%)$. A backward ordinal regression analysis showed previous L.BP history and pain intensity to be the most important predictors of end of study GCPS. Of the fear-avoidance model variables, only negative affect added to this model. Our results do not really support the longitudinal validity of the fear-avoidance model, but they do feed the discussion on the role of pain-related fear in early stages of LBP.
\end{abstract}




\section{INTRODUCTION}

Back in 1996, Gordon Waddell called non-specific low back pain (LBP) "a twentieth century health care enigma" (Waddell, 1996). Now we have come to the twenty-first century, and still the puzzle has not been solved. With lifetime incidence rates as high as 70-85\% (Andersson, 1999), LBP is one of the most important medical problems in western societies. Although self-limiting in most cases, many face recurrences and some even develop a chronic condition, with severe consequences for both patients and society.

As Pincus et al. (2002) pointed out in their review, the importance of psychosocial factors in LBP is well accepted, and evidence-based clinical guidelines on LBP are consistent in adopting a biopsychosocial perspective (Faas et al., 1996; Kendall et al., 1997; Bekkering et al., 2001). A specific theoretical concept developed over the last decade in chronic LBP patients is the fear-avoidance model Wlaeyen and Linton, 2000). The basic tenet of the fear-avoidance model is, that when LBP is being misinterpreted as a sign of serious injury, patients (especially those in negative mood who tend to catastrophize about their pain) might develop pain-related fear and subsequent avoidance of movements that are believed to be harmful. Persisting avoidance behaviour will cause increasing disability and physical deconditioning as a result of inactivity. Fearful parients are at risk of becoming trapped in a cycle of pain, fear, disability and depressive symptoms.

Several studies addressed the predictive value of acute stage fear-avoidance variables in explaining LBP prognosis. Research done by Fritz et al. (2001) showed fear-avoidance beliefs to predict disability and work status four weeks later, even after controlling for initial levels of pain and impairment. Klenerman et al. (1995) reported fear-avoidance variables to be the strongest predictors for 12-month course of LBP. In the general population, pain-related fear and pain catastrophizing predicted LBP and disability 6 months later (Picavet et al., 2002). Similar results were found by Buer and Linton (2002), showing a relationship between fear-avoidance and activities of daily living in a sample of pain-free individuals and patients with non-chronic spinal pain. Linton et al. (2000) suggested that fear-avoidance beliefs are related to the inception of LBP. Finally, previous research by our group (Sieben et al., 2002) showed that rising fear during the first two weeks of a new LBP episode was associated with higher disability at 1 year follow-up. In contrast, only one study was traced in which fear-avoidance beliefs were not retained in a multivariate model including several psychological predictors in a mixed sample of acute and subacute LBP patients (Burton et al., 1995).

The methods used in these ptevious studies are very diverse with respect to sample selection, follow-up time, outcome measures, predictor variables and analyses. Although the results are important, generalisation is difficult and more 
rigorous prospective studies are needed. Aim of the present study is to test the longitudinal validity of the fear-avoidance model; the research question to be answeted is whether acute stage pain-related fear predicts long-term LBP outcome after adjustment for known risk factors.

\section{METHODS}

\section{Subjects}

Patient recruitment was carried out from January 2001 to April 2003 by 35 Dutch general practices joined in the Coordination Centre Primary Care (CEL) and/or the Registration Network of Family Practices (RNH)(Metsemakers et al., 1992). Both CEL and RNH are primary care research networks affiliated to the department of General Practice of Maastricht University.

The general practitioners (GPs) invited primary care patients who consulted because of a new episode of non-specific LBP to participate in this study. A new episode of LBP was defined as: (1) pain localised below the scapulae and above the gluteal folds (following IASP taxonomy (Merskey and Bogduk, 1994)), (2) time since pain onset no longer than three weeks, (3) after at least three months without relevant activity limitations due to LBP.

Exclusion criteria were (1) age younger than 18 or older than 60 years, (2) (suspected) specific cause of LBP (such as lumbar disc hemiation with neurological. complaints, tumor or vertebral fracture), (3) other major disease or psychiatric disorder (as far as known to the GP), (4) pregnancy, (5) insufficient knowledge of Dutch language to complete a questionnaire. Selection criteria were initially checked by the GPs and later rechecked by the researchers.

After the GP-consultation, eligible patients received full written information about the study to read at home. Within the next days, potential participants were contacted by phone. Any questions about the study were answered, and when agreeing on participation the patient was asked to return the bascline questionnaire together with the signed informed consent form.

\section{Eithics}

The study protocol was approved by the medical ethics review committees of Maastricht University Hospital \& Maastricht University (Maastricht, the Netherlands) and the Institute for Rehabilitation Research (Hoensbroek, the Netherlands). 


\section{Baseline questionnaire}

Within a few days after the GP visit participants completed the baseline questionnaire. This questionnaire consisted of (a) a set of descriptives such as work status, back pain history and characteristics of the current episode and (b) measures concerning the fear-avoidance model.

Work status: To explore the occupational context, items covering employment status, occupation, sick leave and job satisfaction were included in the questionnaite.

Back pain history: The patient's back pain history was characterised by the number of episodes in the past, age at which the first episode occurred and history of back pain treatment. Both work status and back pain history items were designed for this study (but based on previous questionnaires).

Cayrent LBP episode: The current LBP episode was described by (a) type of pain onset (sudden/gradual) and (b) presence of radiating symptoms (yes/no). Both these items are derived from the McGill Pain Questionnaire, Dutch Version (Verkes et al., 1989). An additional item covered acute pain duration (number of days since LBP onset).

Pain intensity: Pain intensity was measured by a $10 \mathrm{~cm}$. Visual Analogue Scale (VAS) with extremes of 0 ("no pain') and 100 ("unbearable pain') Jensen and Karoly, 1992).

Negative affect: Negative affect was assessed by the Dutch Version of the Negative Emotionality Scale (NEM), which contains 14 dichotomous items derived from the Multidimensional Personality Questionnaire (Stegen et al., 1998). The NEM does not contain any items concerning somatic complaints. The Dutch version NEM scale is known for good reliability and validity (Stegen et al., 1998; Crombez et al., 1999).

Pain catastropbizing: A Dutch version of the Pain Catastrophizing Scale (PCS) (Sullivan et al., 1995) was used in this study to determine patients' thoughts and feelings about pain. This scale consists of 13 iterns. Patients indicate on a 5 -point scale the extent to which they have an exaggerated negative view of their pain. The PCS has been shown to have good reliability and validity (Osman et al., 1997; Van Damme et al., 2002).

Pain-related fear: The level of pain-related fear was measured by the Tampa Scale for Kinesiophobia (Dutch Version) (Miller et al., 1991; Vlaeyen et al., 1995). This 17-item 4-point scale questionnaire was designed for use in back pain populations. Two subscales represent constructs of somatic focus (5 items) and activity avoidance ( 8 items). Reliability and validity of the TSK Dutch version and its subscales are good (Vlaeyen et al., 1995; Roelofs et al., 2004).

Physical disability: To assess LBP related physical disability the Quebec Back Pain Disability Scale (QBPDS) (Kopec et al., 1996) was used, which was developed 
specifically for LBP populations. To express the level of difficulty experienced in performing activities in daily life, patients rate a 6 -point Likert scale $0=$ 'no difficulty' to $5=$ 'not able to do') for 20 selected activities such as getting dressed, climbing the stairs and making the bed. The Dutch version is both reliable and valid (Schoppink et al., 1996).

Sowal interference: As recommended by Deyo et al. (1998), interference of LBP with social functioning is measured by a set of items covering absence from work and/or other normal daily activities, sports, leisure time activities and time spent in bed because of LBP. These items are derived from the National Health Interview Survey, have been vallidated for use in LBP patients by Patrick et al. (1995), and were successfully applied before in the Maine Lumbar Spine Study (Patrick et al., 1995; Atlas et al., 1996). For use in the present study the questions have been translated into Dutch.

(Avoidance of) pbysical activity: The Physical Activity Rating Scale (PARS) (Vercoulen et al., 1997) was used to determine to what extent subjects engage in daily life activities (e.g. shopping, one hour walking). Patients were asked to indicate on a 5-point scale ('never' to 'very often') whether they had performed each of 20 activities over the previous 2 weeks. The PARS was initially developed for application in chronic fatigue syndrome and was previously used in low back pain research by Verbunt et al. (in press). For this study a newly designed question was added to the PARS scale to measure physical avoidance behaviour. After having rated activity frequencies, patients were asked for each item whether they would have performed the activity more often if they would not have taken their back pain into account. The sum of all 20 dichotomous answers (yes $=1$, no $=0$ ), with higher scores indicating more avoidance behaviour, was used as a measure of avoidance in our analysis.

Depression: The level of depression was assessed using the Beck Depression Inventory (BDD)(Beck et al., 1961). The BDI consists of 21 items and is a widely used self-report measure of depressive symptoms in clinical and non-clinical populations. Answers are on a 4-point scale, and two subscales reflect a negative view of self (6 items) and a somatic factor ( 7 items)(Morley et al., 2002). The somatic factor was not evaluated in this study because of its conceptual overlay with orher measures (TSK, PCS); only the 'negative view of self' subscale was used in analysis. Validity and reliability of the Dutch version of the BDI are well established (Bosscher et al., 1986).

\section{Follows}

Follow-up questionnaires containing all measures related to the fear-avoidance model (pain intensity, negative affect, pain catastrophizing, pain-telated fear, physical disability, social interference, avoidance of activities, depression) were sent 
by mail to the participants at 3 months, 6 months and 12 months after the index GP visit. Non-responders were first reminded by telephone, and if necessary, received a written reminder together with another copy of the questionnaire.

At the end of the project (April 2004), when 12-months' follow-up for all participants were complete, a brief questionnaire assessing LBP outcome was sent to all participants at the same time (thus achieving a maximum follow-up of 40 months for those patients first enrolled in January 2001). A maximum of one reminder was sent to enhance response to this final cross-sectional measurement.

\section{Outconne}

As a primary outcome the Graded Chronic Pain Scale (GCPS) Von Korff et al., 1992) was used. This instrument was developed from the point of view that primary care $\mathrm{LBP}$ should not be regarded as either acute or chronic depending on the duration of the complaints, but rather as recurrent episodes characterised by variable severity. The GCPS consists of 7 items measuring aspects of pain, physical disability and social interference resulting in a 5 -class hierarchical scale: $0=$ no pain problem; I = low disability $/$ low pain intensity, II $=$ low disability $/$ high pain intensity, III = high disability/moderately limiting, IV = high disability $/$ severely limiting. The low range of this pain grading is typically characterised by pain intensity levels, while the high tange of the scale is described by differences in clisability levels. Differences between grades were shown to be clinically relevant (Von Korff et al., 1992). Higher GCPS grades were found to be associated with higher levels of pain, disability and depression, poor self-reported quality of health, more doctor visits and higher health care costs (Von Korff et al., 1992; Engel et al., 1996; Smith et al., 1997; Penny et al., 1999). Its responsiveness to changes over time was shown to be good (Elliott et al., 2000).

In the present study, the Graded Chronic Pain Scale was applied at the crosssectional end of study measurement. For all other measurements, an adaptation of the GCPS classification was derived from scores on pain, physical disability and social interference measures (details available from corresponding author). Calculation methods were refined by expert opinion and validated by comparison with data from similar samples (Von Korff et al., 1993; Von Korff, 2001).

\section{Analysis}

SPSS 11.5 (SPSS, Chicago, USA) was used for all statistical analyses. Because most variables showed non-normal distributions, nonparametric statistics were applied. Unless reported otherwise, statistical tests are two-sided and $\mathrm{p}$-values $\leq 0.05$ are judged significant. 
Bivatiate associations between fear-avoidance model variables as assessed at baseline and LBP outcome (GCPS) at each of the follow-up moments were examined by Spearman rank correlation coefficients.

Primary andlysis: Eight known or presumed "standard" risk factors (age, gender, number of days since pain onset, number of previous episodes, radiating symptoms (yes/no), type of onset (sudden/gradual), level of education, pain intensity) were evaluated for their contribution in explaining outcome (GCPS at end of study). Because of distinct non-normality of the outcome scores, an ordinal regression model (available through SPSS procedure PLUM (Polytomous Logit Universal Models)) was used. First, a backward regression analysis was applied to determine a restricted subset of these variables for use in subsequent analyses. Next, the additional predictive value of baseline pain-related fear variables was tested. The standard risk factors resulting from the previous analysis were forced into the model and were kept. Then baseline TSK-somatic focus, TSK-activity avoidance, disability (QBPDS), follow-up time and interaction effects (fearavoidance variables by follow-up time) were added and possibly deleted as part of the backward strategy. For each removal step likelihood-ratio tests were used to test the significance of the change in -2 loglikelihood. Steps were repeated until all remaining variables were significant contributors to the model or until no variables were left to delete. For each variable in the final model parameter estimates, odds ratios and $95 \%$ confidence intervals were calculated.

Secondary anabysis: Similar analyses were performed using 3 months', 6 months" and 12 months' chronic pain grades (GCPS) scores as a dependent variable successively (without testing for interaction effects as follow-up intervals were constant). Furthermore, the value of 3 months ${ }^{x}$ and 6 months' fear-avoidance variables in predicting end of study GCPS was tested using the same strategy as in primary analysis. Finally, analyses were repeated once more entering all baseline fear-avoidance variables together as independent variables to determine the predictive value of the entire fear-avoidance model.

\section{RESULTS}

\section{Subject characteristics}

The GPs invited 464 of their patients to participate. Of them, 81 refused to participare, 136 did not meet the selection criteria (mostly because of pain duration $>3$ weeks) and 25 with TSK scores $\geq 42$ were excluded because they participated in the intervention group of a trial study (RCT) that was conducted within the cohort. Selection criteria were met and informed consent was given by 222 general practice acute LBP patients. General characteristics of this sample are presented in table 5.1. The majority of patients consulted their GP within one week from LBP 
Table 5.1 Subject characteristics at baseline $(\mathrm{N}=222)$

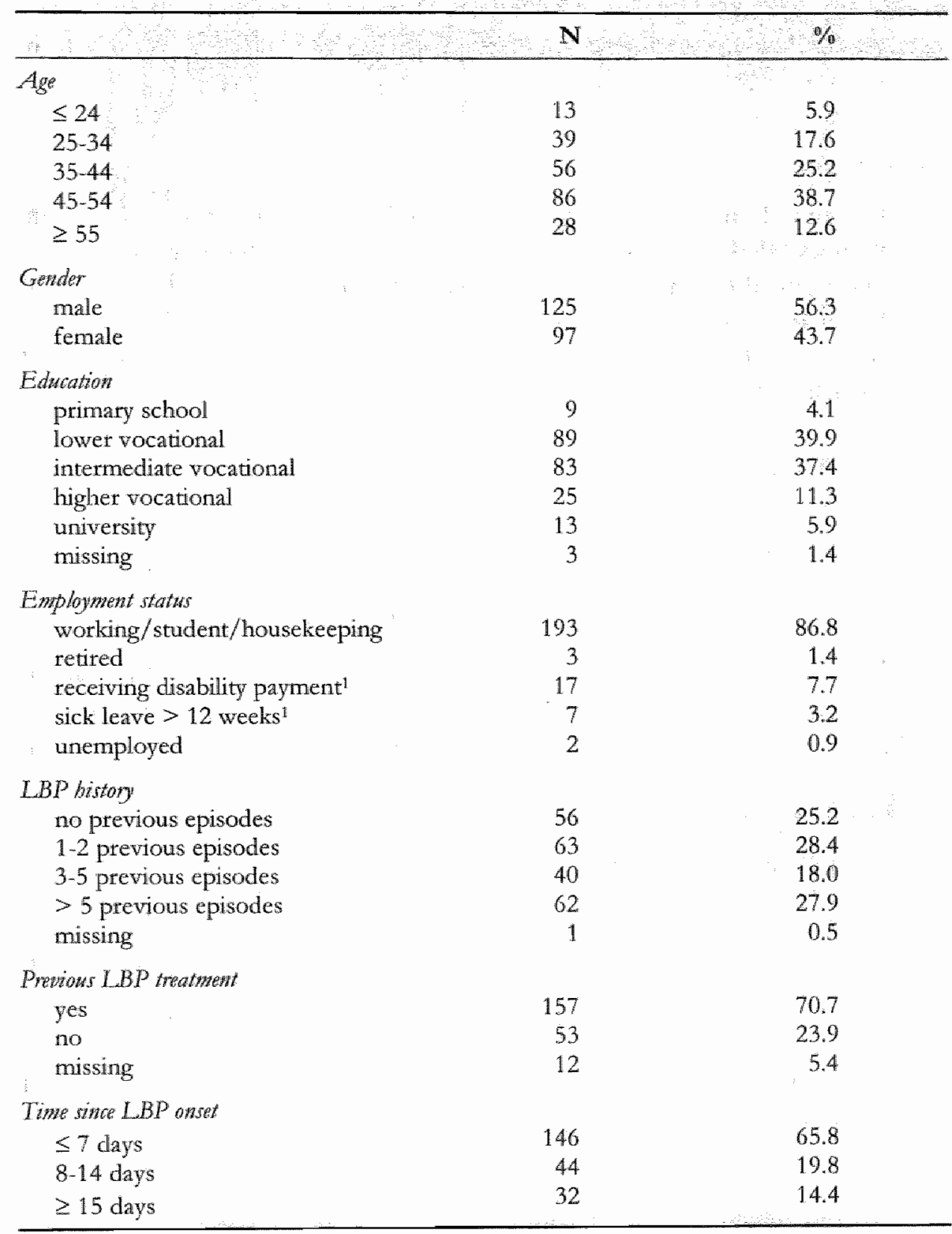

1 disability retirement/ sick leave not necessarily due to LBP. 
onset (median $=5$ days; interquartile range 2-10). About three-quarters of the participants reported a history of back pain. There were no significant differences (age, gender) between participants and non-participants (data were available from 89 non-participants).

\section{Follow-wp}

Response rates during follow-up are shown in table 5.2. No differences were found between responders and non-tesponders, except for age; non-tesponders tended to be younger (significant at 12 months and end of study). The end of study crosssectional data collection resulted in a median follow-up time of 1.9 years (minimum $=1 . \|$; maximum $=3.1$ years $)$. Follow-up data covered a total amount of 327.7 patient years.

Table 5.2 Response rates

\begin{tabular}{lcc}
\hline & N & $\%$ \\
\hline Selection criteria \& informed consent & & $\%$ \\
Baseline $^{2}$ & 222 & 100.0 \\
3 months $^{2}$ & 220 & 99.1 \\
6 months $^{2}$ & 180 & 81.1 \\
12 months $^{2}$ & 168 & 75.7 \\
End of study & 171 & 77.0 \\
\hline
\end{tabular}

1 number of participants included, 2 number of questionnaires returned.

\section{Outione}

Frequencies of Graded Chronic Pain Scale scores are reported in figure 5.1. Although many participants reported to be free of pain during follow-up, the largest group was categorized at grade I (low disability - low pain). About 15\% of all patients showed poor outcome (grades III and IV). Spearman's correlation between GCPS-scores as measured with the original instrument (end of study) and the adapted GCPS-scotes at 12 months was 0.701 for those who completed both questionnaires within a 3 months' time span. 'This sufficient consistency suggests that the adaptation of the GCPS instrument was performed successfully. 
Figure 5.1 Graded Chronic Pain Scale scotes during follow-up
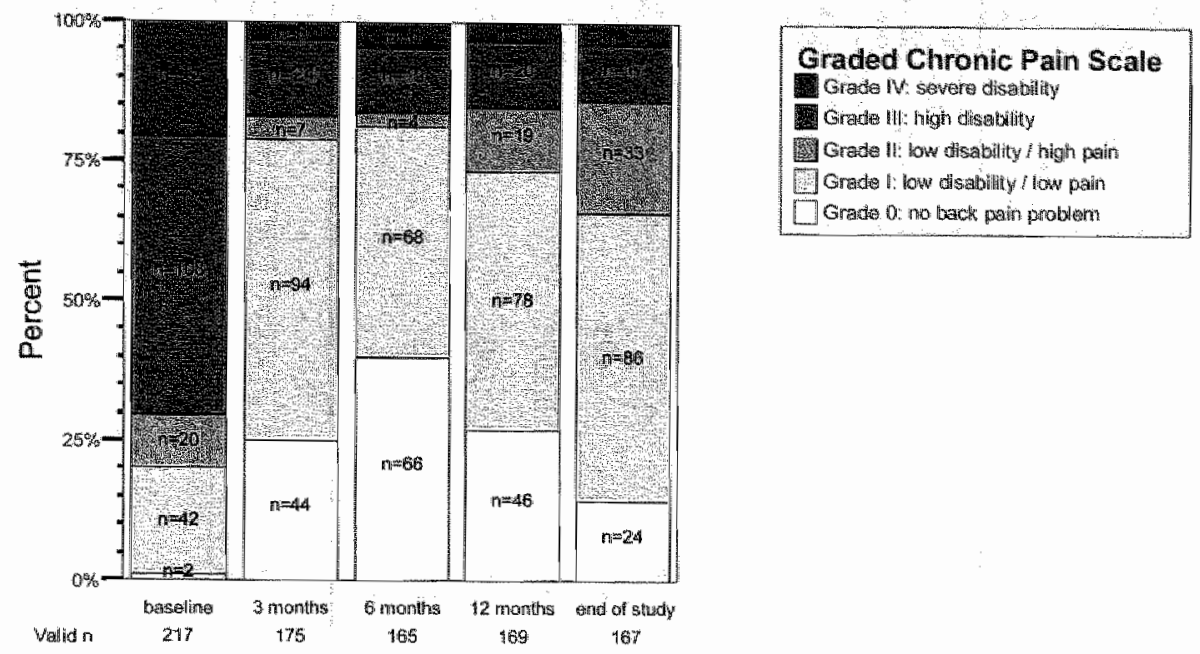

\section{Associations between fear-avoidance variables and $L B P$ owtione}

Table 5.3 shows descriptives of fear-avoidance model variables at baseline and correlations with follow-up chronic pain grades (GCPS). Significant but weak associations were found between end of study GCPS and all fear-avoidance variables except TSK-somatic focus. For shorter follow-up intervals only pain catastrophizing and avoidance of activity appeared to be associated with chronic pain grade. The BDI subscale "negative view of self was only significantly related to outcome at 6 and $\mathbb{2}$ months. Both TSK subscales were associated to baseline GCPS scores but not to follow-up. Note that the correlations found for pain intensity and disability with GCPS are inherent to the way GCPS scores are calculated from pain and disability items.

\section{Ordinal regression anabysis results}

Of the standard risk factors, age, level of education, number of previous episodes and pain intensity contributed to the prediction of outcome (results consistent for all follow-up measurements) and were selected for use in further analyses.

A backward procedure was carried out to determine the additional predictive value of pain-related fear in explaining end of study chronic pain grade (table 5.4). According to the backward elimination approach, all pain-related fear variables and interaction effects with follow-up time were removed from the modd. Details for the final model are presented in table 5.5. 


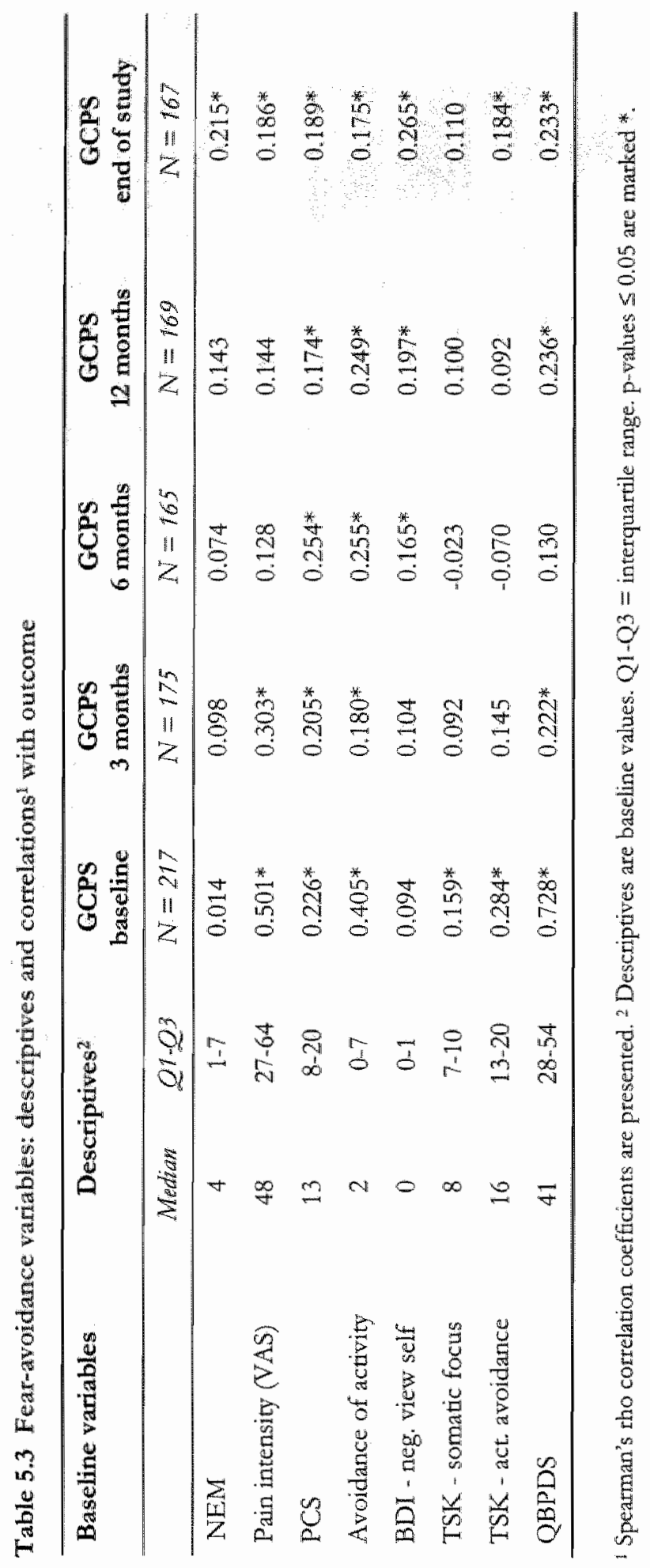


है

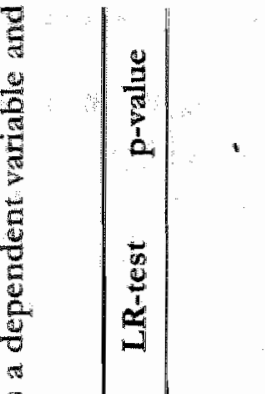

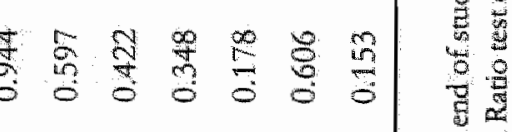

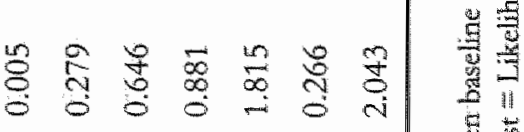

马

$\infty \quad \infty \quad \infty \quad \infty \quad \infty \quad 0$

8

웡

000 o in 4

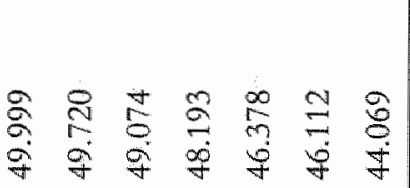

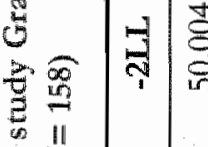

32

E

$=$

3

놀

.

3

2

5

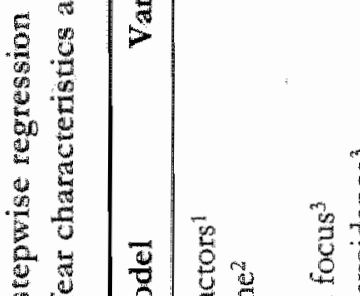

马ै

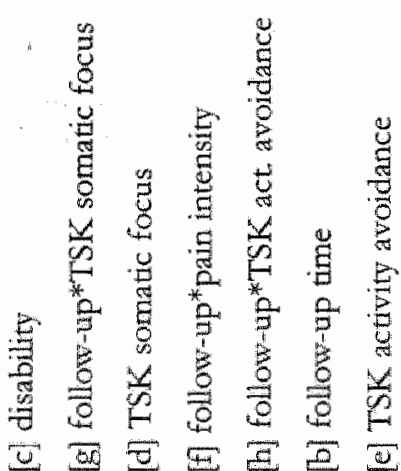

$\mathcal{H} \cdot \overline{0}$

sil

5

t

造

है

管

15.8

这地

焉

욜

की

8

$\frac{5}{5}$

要

क.

ㄴ.

o

贾

है ते

हैं

(3)

है:

可

siv

so

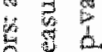

다 4 in

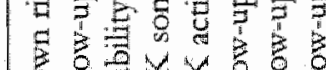

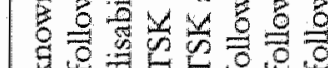

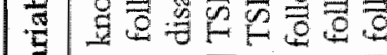

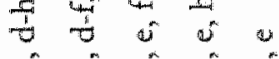

$z$

if

施

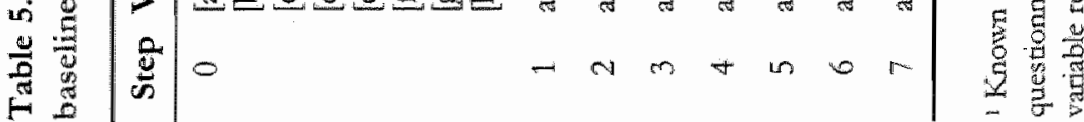

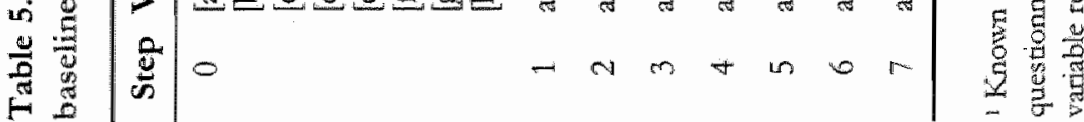


Odds tatios and confidence intervals showed number of previous episodes and baseline pain intensity to be signiffcant risk factors.

Another backward procedure was carried out to determine the predictive value of several fear-avoidance model variables together. Pain catastrophizing (PCS) was kept out of the model because of its conceptual overlay and correlation with painrelated fear (TSK) and negative affect (NEM). The remaining six fear-avoidance variables (negative affect, TSK-somatic focus, TSK-activity avoidance, avoidance of activities; BDI negative view of self and disability) were subject to stepwise removal; age, pain intensity, number of previous episodes and level of education were intially entered and not to be removed. The final model explaining end of study Graded Chronic Pain Scale scores included age, pain intensity, number of previous episodes, level of education and negative affect.

Similar results were found for the prediction of 3 months', 6 months' and 12 months" chronic pain grades; pain-related fear variables were removed from the model each time. Secondary analyses in which 3 months' and 6 months" variables were respectively used as predictors of end of study GCPS did not confirm painrelated fear to be relevant at a later stage during follow-up either (disability was only significant predictor).

Table 5.5 Prediction of end of study Graded Chronic Pain Scale: final model details

\begin{tabular}{lccc}
\hline \multicolumn{1}{c}{ Predictor variable } & $\begin{array}{c}\text { Parameter } \\
\text { estimate }\end{array}$ & Odds ratio $^{1}$ & $\begin{array}{c}\mathbf{9 5 \%} \text { confidence } \\
\text { interval }\end{array}$ \\
\hline Age & 0.020 & 1.020 & $0.989-1.051$ \\
Number of previous episodes & 0.773 & 2.166 & $1.629-2.881$ \\
Level of education & -0.204 & 0.815 & $0.593-1.121$ \\
Baseline pain intensity & 0.017 & 1.017 & $1.004-1.030$ \\
\hline
\end{tabular}

1 Ordinal regression odds tatio compares the odds of outcome being above vs. below each of the possible cut points (grade J-IV vs, gradle 0, gracte II-TV vs, grade 0 or I, etc.) when the independent variable increases with 1 unit.

\section{Post boc awatyses}

After interpreting and discussing these results, some post hoc analyses have been performed on alternative models. As the backgrounds of these analyses are best explained within the context of the discussion, they are presented in the next section. 


\section{Discussion}

The aim of the present study was to test the longitudinal validity of the featavoidance model using rigorous methodological, psychological and statistical methods. The results did not clearly support the fear-avoidance model in explaining the transition from acute LBP to long-term outcome.

\section{Methodological strengths and weatenesses}

In the present study in- en exclusion criteria were set to explicitly select acute patients consulting with LBP as a primaty problem. However, since LBP is known for high comorbidity with other functional disorders and psychiatric symptoms, some degree of 'contamination' may have occurred. On the other hand, it can be argued that this 'contamination' is an inevitable part of the real life situation health care providers have to deal with, and as such should not be eliminated for research validity reasons.

Furthermore, a strict approach was taken with regard to analysis. As recommended by Pincus et al. (2002), we chose to measure multiple fear-avoidance variables, but also considered correlations and conceptual overlay. Adjustment for known risk factors was performed by entering these variables into the model before fear-avoidance variables were considered. The outcome variable used (Graded Chronic Pain Scale) properly reflected the aspect of transition in that it is categorical with proven relevant changes between categories. A critical remark can be made about using an adapted version instead of the original instrument for the secondary measurements in this study. It is unlikely however that this has significantly influenced the results.

Another critical comment can be made with respect to sample size and statistical power. Based on incidence rates and data on prevalence of LBP in primary care, the number of participants in this study was expected to be higher. Furthermore, highly fearful patients are underrepresented in our analyses, because we excluded the intervention group or our concurrent trial. This will thave reduced statistical power, but probably did not bias results. Still, this is one of the larger studies to date, and a dropout rate of $21.6 \%$ is relatively low compared to similat studies, for example by Klenerman et al. (1995). Nevertheless, recruiting acute patients and following them for more than a year seems to highly interfere with daily GP practice (tecruitment) and patient interest and motivation (dropout).

An important topic not addressed by Pincus et al. (2002) is the length of follow-up. A long follow-up period is necessary in prospective cohort studies on LBP outcome. As Von Korff et al. (1993) and Wahlgten et al. (1997) pointed out, LBP runs a capricious course with many patients tecovering soon, a few becoming trapped in a chronic pain syndrome, and most dealing with recurrent pain of 
variable severity. In our opinion, a follow-up time of at least one year is required to capture the recurrent nature of L.BP. By adding a cross-sectional end of study outcome measurement, the number of patient years covered was almost doubled.

\section{Post boc considerations}

A rather basic and conceptual point of discussion we encountered during this study concerns the definition of LBP outcome and the choice of endpoints. Traditionally, and for theoretical reasons, researchers in chronic pain usually define negative outcome in terms of prolonged disability resulting from an isolated LBP episode. As with this study attention is shifted towards acute/recurrent LBP in primary care patients, we alternatively chose to interpret the Graded Chronic Pain Scale score at end of study as a status report of a patient's LBP career as a wholle (including pain and disability, relapses and periods of recovery). In our opinion, this approach more closely resembles reality in general practice; GPs do not follow-up on many distinctly chronic cases, most patients consult periodically with intermittent complaints of both pain and dysfunction. This operationalisation of primary outcome may, however, be criticised for being vulnetable to not finding existing associations between pain-related fear and disability as found in chronic patients, because the lower end of the GCPS-spectrum is determined by pain intensity instead of disability. Indeed, we did not find these relations - so do they not exist in acute stages of LBP, or did we fail to detect them? We reanalysed our data along the "chronic disability" line of investigation. A logistic regression analysis was performed with chronic disability (yes/no) as a dichotomous outcome. Chronic disability was defined as a GCPS score of III or IV at both 6 months and 12 months follow-up. The results were similar to those of our primary strategy; no associations were found between baseline fear-avoidance and outcome (disability). However, a drawback of this latter strategy is low power, as not many cases qualified as chronic. On the whole it seems that, whatever approach one may prefer, the only conclusion possible from this set of data is that the fear-avoidance model cannot be confirmed.

Along with the discussion about whether to investigate isolated LBP episodes or entire patient careers, the circularity of the fear-avoidance model further complicates analysis. Although our sample was selected to contain new acute LBP episodes, patients brought their previous LBP experience with them. It must be assumed that the effects of the fear-avoidance variables acting in the index episode is visible in our analyses, while earlier influences (that is: in previous episodes) may appear as an influence of fear-avoidance variables, of previous episodes, or both. Therefore, in our primary analysis (including the effect of previous episodes) the true influence of fear-avoidance may be underestimated. We compared this model post hoc to an alternative model not containing the influence of previous episodes. 
This latter model will result in an overestimation of the effect of fear-avoldance; the truth may be somewhere in between both estimates. However, the results show that fear-avoidance was not a significant predictor in either model. From this it can be concluded that, whether or not corrected for previous LBP experiences, within the present sample fear-avoidance variables do not add to the prediction of LBP outcome - not within the light of the indexed episode, nor within the perspective of the development of LBP career.

\section{Theoretical and dinical implications}

'The results of this study together with that of Burton et al. (1995) do not favour: the fear-aroidance model. Opposite evidence is provided by six studies in support of the theory (Klenerman et al., 1995; Linton et al., 2000; Fritz et al., 2001; Buer and Linton, 2002; Picavet et al, 2002; Sieben et al., 2002). However, comparing results and explaining differences found between studies is difficult, as study populations, measures used, follow-up periods and analyses vary highly, thus limiting possibilities to generalize. The current study may add to evidence in that it does not invalidate fear-avoidance theory, but at least raises doubt about its role early in a LBP episode. It is beyond dispute that the fear-avoidance model is well established as a perpetuating factor once chronicity has developed, but we could not confirm its significance in non-chronic cases.

In an attempt to explain this discrepancy it can be argued that at baseline we captured very early processes, since negative affect turned out to be the only predictive fear-aroidance variable at baseline. Negative affect is regarded to be a valnerability factor and potential precursor of pain-related fear. However, painrelated fear did not become a relevant factor at later stages during follow-up.

Of course it is also possible that no long-term effect of pain-related fear exists at all in this sample. In contrast with many chronic patients, the majority of general practice LBP patients will have learned how to cope with their LBP. Although a recurrent problem, they may have found a way to deal with it and take flare ups for granted to some extent. Only when an episode is experienced as "different" from previous ones, pain-related fear may raise to pathological levels. In other circumstances, some degree of fear and avoidance may even benefit acute stage recovery, as it teduces nociception and facilitates tissue healing during the first few days (Wall, 1979). The more "dangerous" aspect of prolonged avoidance in that it deprives the patient from correcting learning experiences may be less important because these patients are mostly active, working people who nevertheless will (be forced to) resume their normal activities as soon as possible. In this way their painrelated fear will naturally be confronted and reduced before it becomes problematic. 
Another option is that the fear-avoidance model alone may be insufficient to explain the transition to chronic LBP. Pain-telated fear will only show to be predictive of outcome, if it is the most prevalent pathway to chronicity. A general influence of, for instance, negative affect/depressive mood as a vulnerability factor for chronic pain may be more prevalent and obscure the effect of fear-avoidance at the group level. Future prospective studies might benefit from broadening the scope and including possible co-existing models.

\section{ACKNOWLEDGMENT'S}

The authors are grateful to the staff of the general practices participating in this study for rectuiting patients. Special thanks to Eric Bousema who played and essential role in study management. 


\section{REFERENCES}

- Atlas, S.J., Deyo, RA., Keller, RB., Chapin, A.M., Patrick, D.I, Long, J.M., Singer; D.E. (1996). The Maine Lumbar Spine Study, Part II. 1-year outcomes of surgical and honsurgical management of sciatica. Spme, 21 (15), 1777-1786.

- Beck, A.T., Ward, C.H., Mendelson, M., Mock, J., Erbaugh, J. (1961). An inventory for measuring depression. Arb Gen Psybiatry, 4, 561-571.

- Belkering, G.E., Hendriks, H.J.M., Koes, B.W., Oostendorp, R.A.B., Ostelo, R.W.J.G., Thomassen, J., van Tulder, M.W. (2001). KNGF-richtijn lage-rugpijn. Nederlands Tydswhift woor Fysotherapie, 111 (3), suppl. 1-24.

- Bosscher, R.J., Koning, H., Van Meurs, R. (1986). Reliability and validity of the Beck Depression Inventory in a Dutch college population. Psychol Rep, 58 (3), 696-698.

- Buer, N., Linton, S.J. (2002). Feat-avoidance beliefs and catastrophizing: occurrence and risk factor in back pain and ADL in the general population. Pain, 99 (3), 485-491.

- Burton, A.K., Tillotson, K.M., Main, C.J., Hollis, S. (1995). Psychosocial predictors of outcome in acute and subchronic low back trouble. Spine, $20(6), 722-728$.

- Crombez, G, Vaeyen, J.W.S., Heuts, P.H., Lysens, R. (1999). Pain-related fear is more disabling than pain itself: evidence on the role of pairn-related fear in chronic back pain disability, Pain, 80 (1-2), 329-339.

- Deyo, R.A., Battie, M., Beurskens, A.J., Bombardier, C., Croft, P., Koes, B., Malmivaara, A.; Roland, M., Von Korff, M., Waddell, G. (1998). Outcome measures for low back pain research. A proposal for standaidized use. Spine, 23 (18), 2003-2013.

- Elliott, A.M., Smith, B.H., Smith, W.C., Chambers, W.A. (2000). Changes in chronic pain severity over time: the Chronic Pain Grade as a valid measure. Pain, 88 (3), 303-308.

- Engel, C.C., von Korff, M., Katon, W.J. (1996). Back pain in primary care: predictors of high health-care costs. Pain, 65 (2-3), 197-204.

- Fars, A., Chavannes, A.W., Koes, A.W., Van den Hoogen, J.M.M., Mens, J.M.A., Smeele, I.J.M., Romeijnders, A.C.M., Van der Laan, J.R. (1996). Prantice Gwideline 'Lan Back Pain" [translation]. Utrecht Dutch College of General Practitioners (NHG).

- Fritz, J.M., George, S.Z., Delitto, A. (2001). The role of fear-avoidance beliefs in acute low back pain: relationships with current and future disability and work status, $p_{a i m}, 94(1)$, $7-15$.

- Jensen, M.P. Karoly, P. (1992). Self-report scales and procedures for assessing pain in adults. In D. C. Turk \& R. Melzack (Eds.), Hondbook of pain assessment (Pp. 135-151). New York: Guilford Press.

- Kendall, N.A.S., Linton, S.J., Main, C.J. (1997). Guide to assersing psychosocial yellow flags, in acute low bak paw: nisk factors for long term disability and work bas. Wellington, NZ.: Accident Rehabilitation \& Compensation Insurance Corporation of New Zealand and National Health Committee.

- Klenerman, L., Slade, P.D., Stanley, IM., Pennie, B., Reilly, J.P., Atchison, L.E., Troup, J.D., Rose, M.J. (1995). The prediction of chronicity in patients with an acute attack of low back pain in a general practice setting. Spine, 20 (4), 478-484. 
- Kopec, JA, Esdaile, J.M., Abrahamowicz, M., Abenhaim, L., Wood-Dauphinee, S., Lamping, D.L. Williams, J.I. (1996). The Quebec Back Pain Disability Scalem conceptualization and development. J Chin Epideryiol, 49 (2), 151-161.

- Linton, S. J, Buer, N., Vlacyen, J.W.S., Hellsing, A.L (2000). Are fear-awoidance beliets related to the inception of an episode of back pain? A prospective study. Psyobology and Heatho, 14, 1051-1059.

- Merskey, H. Bogduk, N. (1994). Classification of chronic pazin. Second Edition, MASP Taks Force on Taxonomy, Seatle: IASP Press.

- Metsemakers, J.F, Hoppener, P., Knottnerus, J.A., Kocken, R.J., Limonard, C.B. (1992). Computerized health information in The Nethedlands: a registration network of family practices. BrJ Gro Pran, 42 (356), 102-106.

- Miller, R.P., Kori, S.H., Todd, D.D. (1991). The Tampa Scale for Kineriophobia. Unpublished report.

- Morley, S., Williams, A.C., Black, S. (2002). A confirmatory factor analysis of the Beck Depression Inventory in chronic pain. Pain, 99 (1-2), $289-298$.

- Osman, A., Barrios, F.X., Kopper, B.A., Hauptmann, W., Jones, J., O'Neill, E. (1997). Factor structure, reliability, and validity of the Pain Catastrophizing Scale. f Behow Med, 20 (6), 589-605.

- Patrick, D.L., Deyo, R.A., Atlas, SJ., Singer, D.E., Chapin, A., Kellet, R.B. (1995). Assessing health-related quality of life in patients with sciatica. Spine, 20 (17), 1899-1909.

- Penny, K.I., Purves, A.M., Smith, B.H., Chambers, W.A., Smith, W.C. (1999). Relationship between the chronic pain grade and measures of physical, social and psychological well-being. Pain, 79 (2-3), 275-279.

- Picavet, H.S., Vlaeyen, J.W.S., Schouten, J.S. (2002). Pain catastrophizing and kinesiophobia: predlictors of chronic low back pain. Am J Epidemol, 156 (11), 1028-1034.

- Pincus, T., Burton, A.K., Vogel, S., Field, A.P. (2002). A systematic review of psychological factors as predictors of chronicity/disability in prospective cohorts of low back pain. Spine, 27 (5), E109-120.

- Roelofs, J., Goubert, L., Peters, M.L., Vlaeyen, J.W.S., Crombez, G. (2004). The Tampa Scale for Kinesiophobia: further examination of psychometric properties in partents with chronic low back pain and fibronyalgia. Eur / Pam, 8 (5), 495-502.

- Schoppink, L.E., van Tulder, M.W., Koes, B.W., Beurskens, S.A., de Bie, R.A. (1996). Reliability and validity of the Dutch adaptation of the Quebec Back Pain Disability Scalle. Ploys Ther; 76 (3), 268-275.

- Sieben, J.M., Vhaeyen, J.W.S., Tuerlinckx, S., Portegijs, P.J.M. (2002). Pain-related fear in acute low back pann the first two weeks of a new episode. Eur J Pain, 6 (3), 229-237.

- Smith, B.H., Penny, K.I., Purves, A.M., Munro, C., Wilson, B., Grimshaw, J., Chambers, W.A., Smitli, W.C. (1997). The Chronic Pain Grade questionnaire: validation and reliability in postal research. Pain, $71(2), 141-147$.

- Stegen, K., Neujens, A., Crombez, G., Hermans, D., Van de Woestijne, K.P., Van den Bergh, $\mathrm{O}$. (1998). Negative affect, respiratory reactivity, and somatic complaints in a CO2 enriched air inhalation paradigm. Biol Psychol, 49 (1-2), 109-122.

- Sullivan, M.J.L., Bishop, S.R., Pivik, J. (1995). The Pain Catastrophizing Scale: development and validation. Pyobological Assersment, 7 (4), 524-532. 
- Van Damme, S., Crombez, G., Bijttebier, P., Goubert, L., Van Houdeahove, B. (2002). A confirmatory factor analysis of the Pain Catastrophizing Scalle inwariant factor structure across clinical and non clinical populations. $P_{a n_{3}} 96(3), 319-324$.

- Verbunt, J.A., Seelen, H.A., Vlaeyen, JW.S., Bousema, E.J., Van der Heijden, G.J., Heuts, P.H., Knottnerus, J.A. (2005). Pain-related factors contributing to muscle inhibition in patients with chronic low back pain: an experimental investigation based on superimposed electrical stimulation. Clon I Pazm, 21 (3), 232-240.

- Vercoulen, J.H., Bazelmans, E., Swanink, C.M., Galama, J.M., Jongen, P.J., Hommes, O., Van der Meer, J.W., Bleijenberg, G. (1997). Physical activity in chronic fatigue syndrome: assessment and its role in fatigue. J Psychiatr Res, 31 (6), 661-673.

- Verkes, R.J., Vanderiet, K., Vertommen, H., van der Kloot, W.A., van der Meij, J. (1989). De MPQ-DLV: een standaard Nederlandstalige versie van de McGill Pain Questionnaire voor België en Nederland. In W. A. van der Kloot \& H. Vertommen (Eds.), De MPQDLV: een standaard Nederlawdstalige werse wan de MaGill Pain Qwestionnatre. Achtergronden en bandleiding. Lisse: Swets \& Zeitinger.

- Vlaeyen, J.W.S., Kole-Snijders, A.M.J., Rotteveel, A., Ruesink, R., Heuts, P.H.T.G. (1995). The role of fear of movement/(re)injury in pain disability. Jownal of Ocapational Rebabilitation, 5 (4), 235-252.

- Vaeyen, J.W.S., Linton, S.J. (2000). Fear-avoidance and its consequences in chronic musculoskeletal pain: a state of the art. Pain, 85 (3), 317-332.

- Vlaeyen, J.W.S., Morley, S. (2004). Active despite pain: the putative role of stop-rules and current mood. Pain, 110 (3), 512-516.

- Von Korff, M. (2001). Epidemiologic and survey methods; chronic pain assessment. In D. C. Turk \& R. Melzack (Eds.), Handbowk of pain astessments serond edition (pp. 603-618). New York: Guilford Press.

- Von Korff, M., Deyo, R.A., Cherkin, D., Barlow, W. (1993). Back pain in primary care. Outcomes at 1 year. Spine, $18(7), 855-862$.

- Von Kotff, M., Ormel, J., Keefe, F.J., Dworkin, S.F. (1992). Grading the severity of chronic pain. Pain, 50 (2), 133-149.

- Waddell, G. (1996). Low back pain. at twentieth century health care enigma. Spine, 21 (24), 2820-2825.

- Waltgren, D.R., Atkinson, J.H, Epping-Jordan, J.E., Williams, R.A., Pruite, S.D., Klapow, J.C., Patterson, T.L., Grant, I, Webster, J.S., Slater, M.A. (1997). One-year followup of first onset low back pain. Paint, 73 (2), $213-221$.

- Wall, P.D. (1979). On the relation of injury to pain. The John J. Bonica lecture. Pain, 6 (3), 253-264. 


\section{Chapter 6}

Exposure in vivo treatment in acute low back pain patients with elevated levels of pain-related fear: a randomised controlled trial

Judith M. Sieben, Piet J.M. Portegijs, Johan W.S. Vlaeyen, Paul Knipschild, Arnold D.M. Kester, J. André Knottnerus, Arnoud Arntz 


\section{ABSTRACT}

Recent literature emphasizes the role of pain-related fear in the development of chitonic low back pain (LBP) and suggests that fear-reduction in acute stages might prevent long-term disability. We performed a non-blind randomised controlled trial to test the effectiveness of an exposure in vivo treatment in addition to usual care for acute LBP patients with elevated levels of pain-related fear (kinesiophobia").

General practice patients who consulted their doctors because of a new episode of LBP were scteened for their levels of pain-related fear. Eligible patients with Tampa Scale of Kinesiophobia scores $\geq 42$ (upper quartile) were randomised to either a fear-reducing exposure in vivo intervention in addition to usual care ( $\mathrm{EV})$ or to usual care only (UC). Questionnaires on primary outcome (Graded Chronic Pain Scale) and secondary outcome variables (pain related fear, pain catastrophizing, disability, pain intensity, depression, avoidance of activity) were completed at baseline and at 3 months, 6 months and 12 months follow-up and at end of study (primary outcome only).

The study was severely hampered by tecruitment problems; only 48 patients could be included, of whom 34 (17 in EV and 17 in UC) provided full follow-up information at 12 months. The primary analysis (Mann-Whitney test) demonstrated no differences. However, despite randomisation the EV group showed considerably higher baseline levels of pain-related fear than the UC group. A secondary ordinal regression analysis showed a significant interaction between pain-related fear and treatment allocation ( $\mathrm{p}=0.05$ two-sided). The results suggest that in a subgroup of persistently highly fearful patients fear-reducing treatment might be indicated to reduce the risk of chronicity to develop. However, these latter findings are based on secondary analyses, so replication by new studies is needed.

Our findings must be interpreted with great caution. Nevertheless they do support fear-awoidance theory and suggest refinements. We urgently advise replication of this experiment and we have recommendations for design improvements. 


\section{INTRODUCTION}

It is now widely accepted that psychological factors play an important role in the actiology and prognosis of low back pain (LBP). Many treatments are aimed at decreasing the risk of developing long-term chronic pain by addressing cognitive and behavioural risk factors (Linton, 2002; Pincus et al., 2002). One specific factor that has been extensively studied over the last decade is pain-telated fear (also known as "kinesiophobia". (Kori et al., 1990)). The fear-avoidance model (Crombez et al., 1999; Vlaeyen and Linton, 2000) postulates two opposite responses to a LBP pain experience. If LBP is interpreted as a threatening sign of serious damage, pain-related fear may evolve. A highly fearful patient is likely to avoid specific physical activities that he or she expects to be harmful. This avoidance behaviour will result in increased disability, social interference, depressive symptoms and prolonged pain. In contrast, low fearful patients will spontaneously resume daily activities soon, thereby facilitating natural recovery of symptoms.

The fear-avoidance model offers a valid explanation for the maintenance of disability in chronic LBP patients (Vlaeyen et al., 1995a, 1995b; Asmundson et al., 1997; Crombez et al., 1999; Al-Obaidi et al., 2000), and pain-related fear has also shown to be predictive of LBP outcome in several studies on acute and subacute patients (Fritz et al., 2001; Buer and Linton, 2002; Picavet et al., 2002). Furthermore, pain-related fear was successfully treated in highly fearful chronic patients; their physical functioning improved and disability levels decreased (Vlaeyen et al, 2001, 2002a; Boersma et al., 2004).

A logical next step is to test the effectiveness of pain-related fear reducing treatment as a secondary preventive strategy to stop the development of chronicity at an early stage. It is assumed that long-term outcome will improve if pain-related fear can be successfully manipulated during acute stages of LBP. Moore et al. (2000) tested a cognitive-behavioural self-management program in primary care and showed positive effects on pain-related fear. Burton et al. (1999) found a reduction of fear-avoidance beliefs in patients who received an evidence based educational booklet. Buchbinder et al. (2001) evaluated a media campaign addressing back pain beliefs in the general population and showed a decrease in LBP disability and health care costs. While these earlier studies have targeted multiple aspects of general self-management and back pain beliefs at the level of a group or entire population, the present study might add to our current knowledge because it systematically focuses on the reduction of pain-related fear at an individual level.

The aim of this study is to test the effectiveness of an exposure in vivo treatment in acute stage LBP patients with elevated levels of pain-related fear. The rationale of exposure in vivo treatment is based on the treatment of phobia. Philips 
(1987) was one of the first to argue that avoidance behaviour in fearful patients emerges as an anticipation of pain (and not as a response). Sustained and systematic avoidance behaviour deprives the patient of the opportunity to spontaneously experience that physical activity is harmless. In exposure in wivo treatment, the patient is forcedly exposed to specific fear-eliciting movements or activities in order to produce disconfirmations between the irrational expectations of pain and harm, and the actual consequences of the activity. Such a feat-reducing treatment was successfully applied in patients with chronic LBP (Vlaeyen et all, $2001,2002 a$; Boersma et al., 2004), but is not yet tested as a secondary preventive strategy in acute patients.

We hypothesize that an exposure in vivo treatment in addition to usuall care will (a) improve long-term LBP outcome as measured by 12 months chronic pain grade by (b) decreasing the levels of pain catastrophizing, pain-related feat and avoidance of activities: According to fear-avoidance theory, it can be expected that as a consequence (c) also levels of disability, pain intensity and depression will be reduced. This experiment may contribute to the development of effective treatment that is useful in clinical practice and may also provide an additional and prospective test of the validity of fear-avoidance theory in back pain.

\section{METHODS}

\section{Setting}

Volunteers for this RCT were recruited from 35 Dutch general practices joined in the Coordination Centre Primary Care (CEL) and the Registration Network of Family Practices (RNH)(Metsemakers et al, 1992). Both CEL and RNH are primary care research networks affiliated to the department of General Practice of Masastricht University.

\section{In- and exchusion criteria}

The general practitioners (GPs) invited acute LBP patients to participate in this research. Patients consulting their GP because of a new episode of non-specific LBP were eligible for invitation if (1) they were between 18 and 60 years of age, (2) their pain was localized below the scapulae and above the gluteal folds, (3) time since pain onset was no longer than three weeks, (4) after at least three months without relevant activity limitations due to LBP. They were not admitted to the study if one or more of the following exclusion criteria were present: (1) specific causes of LBP or strong suspicion of such a cause (2) other major pathologies or psychiatric disorders more important than LBP, (3) pregnancy, (4) insufficient knowledge of Dutch language to be able to complete a questionnaire. Selection criteria were initially checked by the GPs and rechecked by the researchers. 


\section{Recruitment}

All potential participants who met the selection criteria completed a screening on pain-related fear immediately after the GP-visit, prior to leaving the primary care practice. We used the Tampa Scale of Kinesiophobia (TSK) (Miller et al., 1991; Vlaeyen et al., 1995b) to measure the level of fear related to pain (see paragraph on secondary outcome measures for details). Patients with low levels of pain-related fear (TSK total score < 42) were excluded for the present research; they were invited to participate in a longitudinal cohort study (Sieben et al., in press) instead. Fearful patients (TSK total score $\geq 42$ ) received full written information about the RCT to read at home. Within the next few days, they were contacted by one of the researchers by telephone. When the patient agreed to participate, he/she was asked to return the baseline questionnaire together with the signed informed consent form. The patient was then randomly assigned to either exposure in vivo in addition to usual care (EV) or usual care only (UC).

\section{Randomisation details}

A random allocation list was generated beforehand by the research supervisor using the random number generator in SPSS. Stratified random permuted block procedures (Schouten, 1995) were performed with the general practices as strata and a block length of 20 . Results of the random assignment wete unknown to the researchers and were contained on cards in sealed envelopes that were onlly marked on the outside by stratum and number. After the patient gave verbal consent during the telephone call, the appropriate envelope was opened and the content of the card (EV or UC) was told to the participant. Used envelopes and cards were archived by the study administration office.

\section{Intervention: exposure in wito}

The treatment was provided by a specially trained researcher (JS). A strict protocol was developed following exposure in vivo guidelines (Butlex, 1989; Vlaeyen et al., $2002 \mathrm{~b}$ ). The intervention consisted of three subsequent stages: screening, education and exposure.

Screening: First, the patient's symptoms and beliefs about LBP were explored during a structured interview, with special focus on any catastrophic cognitions the patient might have concerning his/her LBP. In addition, a structured analysis was performed of specific physical activities that were avoided. We made a hierarchy of fear-eliciting movements and activities using the Photograph Series of Daily Activities (PHODA) (Kugler et al., 1999). 
Education: Next, the patient received individually tailored education that was aimed at correcting the catastrophic ideas revealed during the screening interview: Each patient was unambiguously educated to view $L B P$ as a hatmless condition that can be self-rmanaged rather than as a serious disease that requires rest, special medical attention and protection. Furthermore, we introduced the fear-avoidance model, using the patient's own symptoms and medical history as an illustration. The risk associated with prolonged avoidance behayiour and the need to break the vicious cycle of pain, avoidance and impaiment were carefully explained.

Exposure: After understanding and acceptance of the tationale for exposure to the avoided movements was reached, we carried out the actual exposure. Relevant activities for practice were selected based on hierarchy ratings and personal importance. Individually tailored exposure tasks took the form of behavioural experiments, in which irrational expectations about the influence of movement on pain and recovery were explicitly being challenged. The patient was asked to formulate a statement of what would happen if he/she had to perform the specific activity he/she tended to avoid ("If I carry this heavy shopping-bag, my nevves will be damaged and I can not wallk anymore"). Subsecquently, an experiment was designed in which the statement was empirically tested by performing the "dangerous" activity. The patient was encouraged to engage in the fear-eliciting activity as much as possible. Each experiment was repeated and evaluated until the participant could no longer maintain the incorrect idea(s). Tasks used in exposure treatment were normal daily life activities and the researcher first modelled each task. Patients were also advised to resume their normal routine activities (household, work, sports, leisure time). Homework plans were made to perform self-exposure exercises in between treatment sessions.

The intervention sessions took place at the patient's home. Initially, two sessions (60-90 minutes each) were carried out; the first one as soon as possible after recruitment, and the second one about one week later. In the third week, progress was evaluated. Treatment was ended if the patient showed sufficient selfexposure (he or she successfully carried out the agreements about self-exposure and tesumption of activities); if not, two additional sessions were scheduled in week 4 and 5 .

During the entire intervention and follow-up period, care as usual was provided by the GP. No limitations were set to the care given, but all medication prescriptions, follow-up visits and referrals were to be recorded in the report that the GPs completed on each participant.

\section{Control condition: care as msual}

Patients who were assigned to the control condition received only care as usual. The $G P_{S}$ were expected (but not explicitly instructed) to treat their patients 
conform the Dutch general practice guideline on LBP (Faas et al, 1996). All follow-up visits, referrals to therapists or medical specialists and medication prescriptions were to be recorded in the patient report fle for this study.

\section{Blinding}

Study personnel, participants and treatment providers were not blinded for group assignment because of the dissimilarity of the intervention and control condition.

\section{Measures}

Participants completed questionnaires at baseline and at 3 months, 6 months and 12 months after the initial GP-visit. A final assessment of primary outcome was done for all patients at the same time at the end of the study (April 2004). In this way a maximum follow-up of 40 months was achieved for those who wete first recruited in January 2001. All questionnaires were sent by mail and could be returned postage free. Non-responders were reminded by telephone and/or by mail (with a maximum of two reminder copies of the questionnaire for each measurement).

\section{Descriptives}

At baseline a set of characteristics was collected describing the occupational context (employment status, occupation, sick leave, job satisfaction), LBP history (number of previous episodes, history of LBP treatment) and the current LBP episode (type of pain onset, tadiating symptoms, number of days since pain onset).

\section{Prinaty outcome}

In orcler to capture the typical multi-faceted character of many LBP problems the Graded Chronic Pain Scale (GCPS) (Von Korff et al., 1992) was used as a primary outcome. The GCPS consists of 7 items measuring several aspects of pain, physical disability and social interference. As a result patients are ranked on a 5-class hierarchical scale: $0=$ no pair problem, $1=$ low disability $/$ low pain intensity, $2=$ low disability $/$ high pain intensity, $3=$ high disability $/$ moderately limiting, $4=$ high disability/severely limiting. In previous research GCPS showed to be responsive to changes over time (Elliot et al., 2000) and differences between grades were found to be clinically relevant; higher grades were associated with lower self-reported quality of health and higher medical consumption (Engel et al., 1996; Smith et al., 1997; Penny et al., 1999). We used the 12 months scote for our main analysis. 


\section{Secondary outcome and intermediate variables}

Measures concerning the fear-avoidance model were assessed at baseline, 3 months, 6 months and 12 months follow-up.

Pain intensity: Pain intensity was measured using a Visual Analogue Scale item (length $10 \mathrm{~cm}$ ) with anchors 'no pain' $(=0)$ and 'unbearable pain' $(=100)$ (Jensen and Karoly, 1992).

Pain catastrophizing: The 13-item Pain Catastrophizing Scale (PCS; Dutch version) (Sullivan et al., 1995) was used to determine patients' thoughts and feelings about pain. Questions are on a 5-point scale and are related to catastrophic thinking about pain. Reliability and validity have been evaluated as good (Osman et al., 1997; Van Damme et al., 2002).

Pain-related fear: The level of fear related to pain (fear of harm, fear of movement). was measured with the Dutch version of the Tampa Scale for Kinesiophobia (TSK) (Miller et al., 1991; Vlaeyen et al., 1995b). This 17-item 4point scale wras designed and extensively tested in LBP populations (reliability and validity are adequate). 'Two subscales represent constructs of 'somatic focus' and 'activity avoidance' (Goubert et al., 2004; Roelofs et al., 2004). Note that painrelated fear was measured twice before randomisation: immediately after the GPconsultation as part of the selection procedure (TSK-1) and again a few days later as part of the baseline questionnaire (TSK-2).

Avoidance behaviour: Subjects rated on the Physical Activity Rating Scale (PARS) (Vercoulen et al., 1997) to what extent ('never' to 'very often') they engaged in each of 20 activities of daily life. For this study, patients were additionally asked for each item whether they would have performed the activity more often if they would not have taken their back pain into account. The sum of all dichotomous answers (yes $=1$, no $=0$ ) was interpreted as a measure of avoidance behaviour.

Depression: The presence of depressive symptoms was assessed using the 21 item 4-point scale Beck Depression Inventory (BDI) (Beck et al., 1961), which is widely used in both clinical and non-patient populations. Validity and reliability of the Dutch version are well established (Bosscher et all., 1986).

Disability: The Quebec Back Pain Disability Scale (QBPDS) (Kopec et al., 1996) was developed to specifically measure the level of physical disability related to LBP. The QBPDS lists 20 selected daily life activities; patients have to express on a 6-point scale $(0=$ "no difficulty' to $5=$ "not able to do") the level of difficulty they experience in performing each activity. The Dutch version of the QBPDS was found to be both reliable and valid (Schoppink et al., 1996). 


\section{Sample size}

Lacking a validated cut-off point above which fear-reducing treatment is indicated, we arbitrarily chose to target the highest quartile of pain-related fear in consulting general practice LBP patients. A pilot study (Sieben et al., 2002) showed that the upper quartile matched with a TSK total score of $\geq 42$.

We expected that it would be feasible to enrol 100 patients in each group. When accounting for loss to follow-up, these numbers would allow $80 \%$ power to detect a difference of 0.4 standard deviation between both groups ( $\alpha=0.05$, twosided). With 200 patients representing the top $25 \%$ of the TSK scale, a total of 800-1000 patients had to be referred to the study by the GPs. We planned a twoyear period for patient enrolment, and with the cooperation of 30 general practices, this implied a referral rate of 1.4 patients per practice per month. With a mean of 2350 patients per practice and a LBP incidence of $4 \%(=1-2 \mathrm{LBP}$ patients per practice per week) (Faas et al., 1996), the numbers estimated were considered realistic and achievable.

\section{Etbics}

In compliance with the Dutch regulations on medical tesearch, the study protocol was approved by the medical ethics review committees of Maastricht University Hospital \& Maastricht University (Maastricht, the Netherlands) and the Institute for Rehabilitation Research (Hoensbroek, the Netherlands).

\section{Analysis}

All statistical analyses were performed using SPSS 11.5 (SPSS, Chicago, USA). Nonparametric statistics were used because of ordinal scales and skewed distributions. Primary outcome measures were compared for experimental (EV) and control (UC) groups using Mann-Whitney U tests. As a supplementary analysis, comparison of EV and UC groups with baseline pain-related fear as an additional covariate to correct for baseline imbalances on this variable was done with ordinal regression. (SPSS-procedure Polytomous Logit Universal Models (PLUM), an extension of logistic regression to the ordinal level). For the secondary outcome variables, change scores were calculated by subtraction of follow-up from baseline values (so positive changes teflect symptom improvement); medians and interquartile ranges are presented. In addition, treatment effects controlled for baseline pain-related fear were tested using ordinal logistic regression analysis as described above. Two-sided significance tests $(\alpha=0.05)$ were used throughourt. According to intention-to-treat rules all randomised patients with available followup data were analysed in their allocated group. 
Figure 6.1 Chat of patients flow through the randomised controlled trial

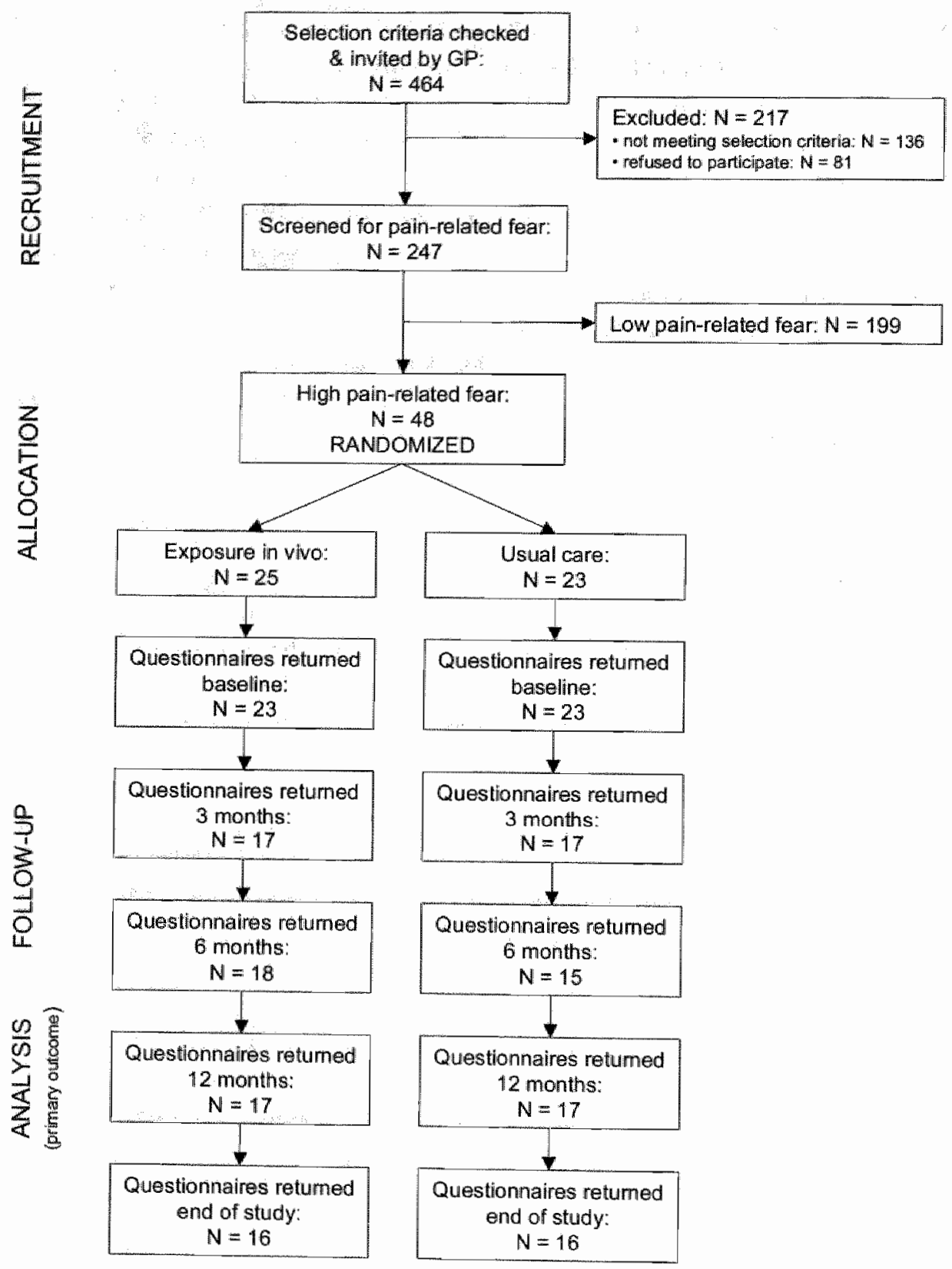




\section{RESULTS}

\section{Subject characteristics}

Patients were enrolled between January 2001 and April 2003 by 35 general practices, representing a total amount of 180,000 patient years eligible for recruitment. The GPs invited 464 of their patients to participate. Figure 6.1 shows the patients flow through the subsequent stages of the study. Of the 247 patients who were screened, 48 reported high pain-related fear and were randomised (25 $\mathrm{EV}$ and $23 \mathrm{UC}$ ). In total, $68 \%$ of the intervention group and $70 \%$ of the control group provided follow-up information useful for primary analysis. At baseline, demographic and clinical characteristics in both treatment groups were quite similar (table 6.1).

\section{Follow-up}

Regarding the follow-up measurements, non-responders tended to be younger than respondents. No differences were found between response rates in both treatment groups. The cross-sectional end of study data collection (primary outcome) resulted in a median follow-up time of 2.2 years (EV) and 2.1 years (UC); minimum and maximum were the same for both groups (1.2 years and 3.0 years respectively).

\section{Intervention}

Of the 25 patients within the EV group, 22 participants attended two EV sessions; treatment was subsequently terminated according to the preset criteria. One person needed a third and fourth session. Two patients dropped out of treatment (reasons: (1) LBP appeared to be caused by a herniated disc problem and surgery was needed; (2) severe psychiatric and social problems were far more important than the current LBP episode). In the control group (UC) data on treatment dropout were unavailable because no pre-described additional treatment was given.

Co-interventions provided by the GP (as part of usual care) were equal in both groups; no large differences were found with respect to numbers of follow-up consultations ( $\mathrm{EV}$ median $=1.5$, UC median $=1.0$ ), drug prescriptions (in 11 cases EV vs. 13 cases UC) and referrals to physical therapists (in 6 cases EV vs. 5 cases UC) or medical specialists (in 3 cases EV vs. 5 cases UC).

\section{Primary outcome}

GCPS distributions for both treatment groups during follow-up are shown in figure 6.2. The Mann-Whitney test for differences between EV and UC groups at 
12 months revealed no difference between both interventions ( $p=0.28$ ). Between baseline and 12 months, participants in both groups showed a median overall improvement by two grades (GCPS), from high disability/moderately limiting to low disability/low pain intensity.

Table 6.1a \& 6.1b Chatacteristics of exposure in vivo and usual care groups

\begin{tabular}{lcccc}
\hline A & \multicolumn{2}{c}{$\begin{array}{c}\text { Exposure in vivo } \\
\text { median (Q1-Q3) }\end{array}$} & \multicolumn{2}{c}{$\begin{array}{c}\text { Usual care } \\
\text { median }\end{array}$} \\
\hline Ag1-Q3) (years) & 48 & $(39-54)$ & 45 & $(32-54)$ \\
Time since LBP onset (days) & 7 & $(4-10)$ & 4 & $(3-10)$ \\
Pain-related fear (TSK) at consultation & 47 & $(43-49)$ & 46 & $(44-50)$ \\
\hline B & Exposure in vivo $n$ & Usual care $n$ \\
& (group $\mathbf{n}=25)$ & (group $\mathbf{n}=23$ ) \\
\hline
\end{tabular}

\section{Gender}

male

female

\section{Education}

primary/lower rocational

intermediate/higher vocational

university

missing

Employment statws

working

housekeeping

long-term sick leave/disability retirement ${ }^{1}$

Siche leave due to LBP at time of consultation

no
yes
missing

$18-19$

54

20

Pyudous LBP treatment

no

$6-6$

yes

16

missing

$3-1$

Radiating symptoms

$\begin{array}{lrr}\text { no } & 6 & 7 \\ \text { yes } & 17 & 16 \\ \text { missing } & 2 & 0\end{array}$

Q1-Q3 = interquartile range. 1long-term sick leave/disability retirement not necessarily due to LBP. 


\section{Secondary outconie}

A summary of secondary outcome and intermediate variables is presented in table 6.2. Despite randomisation, baseline levels of 'somatic focus' and 'activity awoidance' differed between treatment groups $\left(p=0.034\right.$ for 'somatic focus ${ }^{x}$ and $p$ $=0.002$ for 'activity avoidance'; however the size of the differences may be judged more relevant than statistical significance). EV participants also seemed to be somewhat more depressed during follow-up, and they reported lower pain intensity levels at 12-months compared to the control group. Change scores at 12 months, as defined by change from baseline, ate also presented. Participants in the $\mathbb{E V}$ group showed more improvement on disability.

Figure 6.2 Distribution of Graded Chronic Pain Scale scores during follow-up for both treatment groups

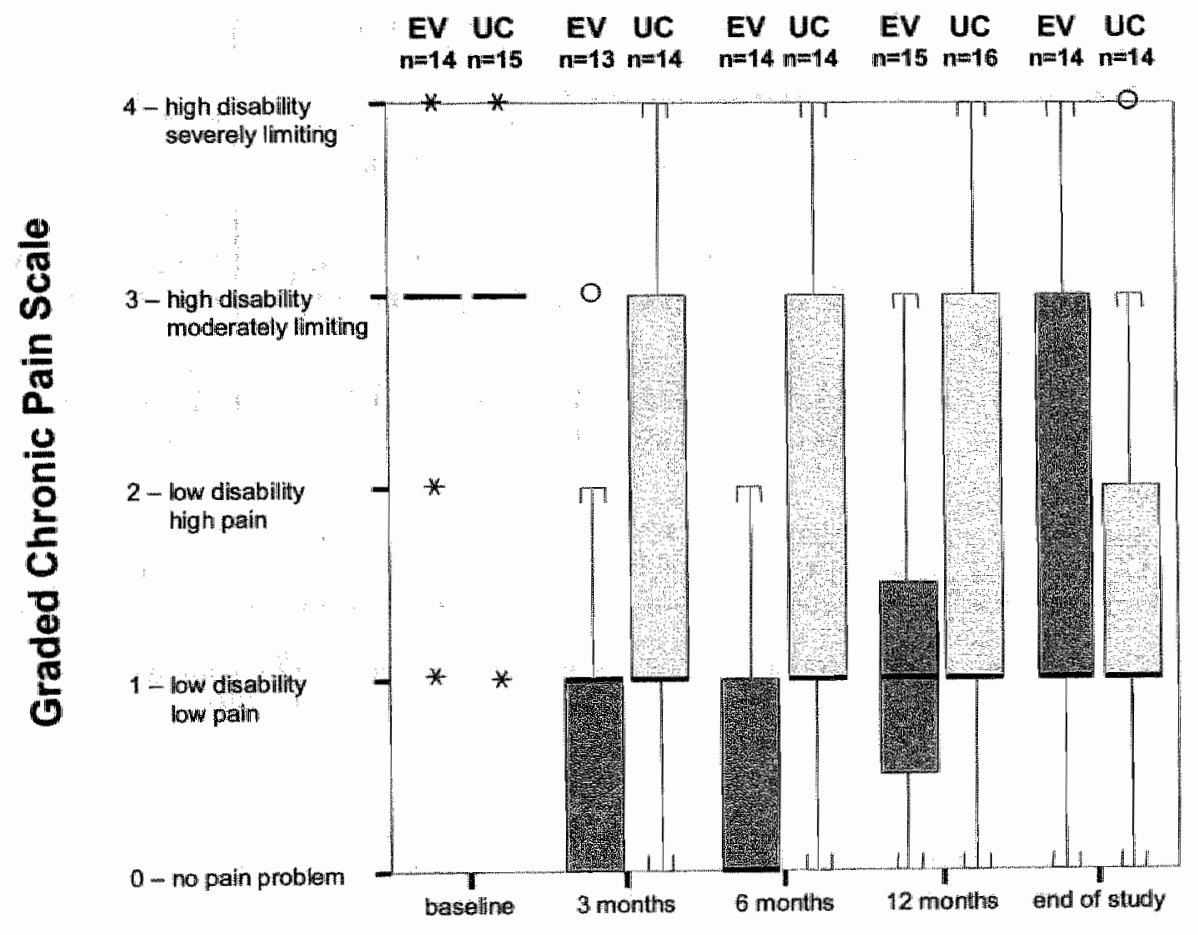

Boxplots: horizontal lines mark medians, boxes display 25-75 percentile ( $=$ interquartille rànge IQR), whiskers mark lowest/highest value within $1.5 \mathrm{IQR}$ from box, tounds matk outliers $(1.5-3.0 \mathrm{IQR})$, asterisks mark extremes ( $>3.0 \mathrm{IQR}$ ). 
Table 6.2 Secondary outcome: median scores (interquartile ranges) and change scotes for both treatment groups

\begin{tabular}{|c|c|c|c|c|c|}
\hline & & Out & atcome & & \\
\hline & Baseline & 3 months & 66 months & 12 moniths & 12 months \\
\hline $\begin{array}{l}\text { Vuld N } \\
\text { exposure in vivo } \\
\text { usual care }\end{array}$ & $\begin{array}{l}23 \\
23\end{array}$ & $\begin{array}{l}17 \\
17 \\
\end{array}$ & $\begin{array}{l}18 \\
15\end{array}$ & $\begin{array}{l}17 \\
17 \\
\end{array}$ & \\
\hline $\begin{array}{l}\text { Pain atostrophioging (PCS) } \\
\text { exposure in vivo } \\
\text { usual care }\end{array}$ & $\begin{array}{l}21(19-28) \\
22(13-29)\end{array}$ & $\begin{array}{l}17(6-29) \\
16(12-28)\end{array}$ & $\begin{array}{l}16(8-25) \\
13(8-23)\end{array}$ & $\begin{array}{l}16(7-24) \\
14(7-24)\end{array}$ & $\begin{array}{l}4.0(-3.0-17.0) \\
6.0(-2.0-14.0)\end{array}$ \\
\hline $\begin{array}{l}\text { Somatio forts (TSK) } \\
\text { exposure in vivo } \\
\text { usual care }\end{array}$ & $\begin{array}{l}12(11-14) \\
10(8-12)\end{array}$ & $\begin{array}{l}9(7-13) \\
9(6-12)\end{array}$ & $\begin{array}{l}9(7-13) \\
9(6-11)\end{array}$ & $\begin{array}{l}11(6-13) \\
10(7-12)\end{array}$ & $\begin{array}{l}2.0(0.0-5.2) \\
1.0(-1.0-3.0)\end{array}$ \\
\hline $\begin{array}{l}\text { Aativity alotance (TSK) } \\
\text { exposure in vivo } \\
\text { usual care }\end{array}$ & $\begin{array}{l}22(20-24) \\
19(17-21)\end{array}$ & $\begin{array}{l}19(13-24) \\
16(13-22)\end{array}$ & $\begin{array}{l}20(15-21) \\
17(13-20)\end{array}$ & $\begin{array}{l}19(13-23) \\
19(15-23)\end{array}$ & $\begin{array}{l}4.5(-1.3-7.0) \\
1.0(-0.5-4.5)\end{array}$ \\
\hline $\begin{array}{l}\text { Awodance bebawoun } \\
\text { exposure in wivo } \\
\text { ustual care }\end{array}$ & $\begin{array}{l}6(3-11) \\
7(4-13)\end{array}$ & $\begin{array}{l}1(0-6) \\
1(0-8)\end{array}$ & $\begin{array}{l}0(0-1) \\
0(0-4)\end{array}$ & $\begin{array}{l}0(0-4) \\
1(0-6)\end{array}$ & $\begin{array}{l}2.5(0.0-9.0) \\
2.5(0.0-5.3)\end{array}$ \\
\hline $\begin{array}{l}\text { Disability (OBPDS) } \\
\text { exposure in vivo } \\
\text { usual cart }\end{array}$ & $\begin{array}{l}54(36-63) \\
46(38-60)\end{array}$ & $\begin{array}{l}19(5-35) \\
18(1-35)\end{array}$ & $\begin{array}{l}15(2-25) \\
11(0-43)\end{array}$ & $\begin{array}{l}16(3-36) \\
20(7-51)\end{array}$ & $\begin{array}{l}33.0(15.0-40.0) \\
17.0(2.3-28.5)\end{array}$ \\
\hline $\begin{array}{l}\text { Pat intensity }(V / A S) \\
\text { exposute in wivo } \\
\text { usual care }\end{array}$ & $\begin{array}{l}39(16-71) \\
38(24-67)\end{array}$ & $\begin{array}{l}3(0-24) \\
3(0-43)\end{array}$ & $\begin{array}{l}1(0-17) \\
11(0-42)\end{array}$ & $\begin{array}{l}2(0-41) \\
19(2-43)\end{array}$ & $\begin{array}{l}15.0(0.8 \text {. } 64.5) \\
17.0(3.5-29.5)\end{array}$ \\
\hline $\begin{array}{l}\text { Depnessen }(B D D) \\
\text { exposure in vivo } \\
\text { uscul care }\end{array}$ & $\begin{array}{l}9(6-12) \\
9(3-13)\end{array}$ & $\begin{array}{l}7(3-11) \\
4(1-8)\end{array}$ & $\begin{array}{l}10(4-11) \\
5(1-8)\end{array}$ & $\begin{array}{l}7(4-11) \\
7(2-12)\end{array}$ & $\begin{array}{l}1.5(-2.5-4.5) \\
1.0(-3.0-2.5)\end{array}$ \\
\hline
\end{tabular}

1 Change scote = difference between baseline and follow-up measures: 12-months vs. baseline. Posilive values represent recovery; negative values tepresent worsening of symproms.

Analysis conrected for baseline pain-related fear (primary outcome)

An ordinal regression analysis was carried out to test EV versus $U C$ differences on the primary outcome variable while controlling for the level of baseline painrelated fear. Scores on TSK subscales 'somatic focus' and 'activity avoidance' were added to construct a single fear-avoidance variable. As shown in table 6.3, the interaction between pain-related fear and treatment condition was significant $(\mathrm{p}=0.050)$. The interaction between baseline level of pain-related fear and treatment condition is illustrated by figure 6.3. As is shown in the figure, for the 
lower levels of pain-related fear UC was as effective as $\mathrm{EV}$, but with higher levels of pain-related fear UC became less effective, whereas EV remains as effective as in the lower levels. In other words: the interaction suggests that EV is superior to UC only in patients with higher (and persistent) levels of pain-related fear. In patients with subsiding and relatively lower levels of pain-related fear, UC is as effective as EV. This conclusion is supported by a post hoc analysis of subgroups of relatively high versus relatively low fearful patients (median split on baseline pain-related fear). In the higher pain-related fear group EV was significantly more effective than UC $(p=0.02 ; \mathrm{Mann}$-Whitney test). In the lower pain-related fear group the conditions did not differ at all $(p=0.95$; Mann-Whitney test). In conclusion, in this secondary analysis the condition effect turned out to be modified by baseline pain-related fear.

Table 6.3 Results of ordinal logistic regression analysis regarding interaction between baseline pain-related fear and treatment allocation (dependent $=12$ months' GCPS)

\begin{tabular}{|c|c|c|}
\hline Predictor & Parameter estimate & p-value \\
\hline Group (EV vs. UC) & -1.277 & 0.137 \\
\hline Pain-related fear (baseline) & 0.376 & 0.009 \\
\hline Group ${ }^{*}$ pain-related fear & -0.384 & 0.050 \\
\hline
\end{tabular}

Model fitting information: Nagelkerke Pseudo R-square $=0.287$; final model significance $=0.021$.

${ }^{1}$ Pain-related fear = "TSK 'somatic focus' + TSK 'activity avoidance'.

\section{Analysis corrected for baseline pain-related fear (secondany outtome)}

Similat ordinal regression analyses, again post-hoc, were performed on 12 months $^{3}$ fear-avoidance variables (table 6.4). Conclusions concerning the role of individual variables within the fear-avoidance model can hardly be drawn from these data, but the overall direction of results is in line with the model.

\section{Early course of pain-related fear}

As the results suggest that EV may be more effective in relatively highly fearful patients than in low fearful patients, we performed some additional post hoc analyses to explore whether we could further describe pain-related fear groups (median split on baseline pain-related fear) by other variables. No differences regarding age, gender, LBP history and episode characteristics were found. Remarkably, the groups also did not differ on TSK-scores as measured during the 
selection procedure (TSK-1). Remember that the TSK scores as measured by the baseline questioninaire (TSK-2) appeared to differ between EV and UC groups and gave rise to stratification. The median interval between both measurements was 7 days (interquartile range $3-13$ days). Our analysis showed that in the "high painrelated fear" group, median "TSK total scores changed within a few days from 48 to 38, while in the "very high pain-related fear" group median TSK total scores remained invariably high ( 46 and 47 respectively).

Table 6.4 Secondary outcome variable at 12 months: effect of group (EV versus UC) corrected for pain-related fear ${ }^{1}$

\begin{tabular}{|c|c|c|}
\hline & Parameter estimate & p-value \\
\hline Pain catastrophizing (PCS) & -0.742 & 0.291 \\
\hline Somatic focus ( $1 \mathrm{SK}$ ) & -0.606 & 0.390 \\
\hline Activity avoidance (TSK) & -1.052 & 0.150 \\
\hline Avoidance behaviour & -0.554 & 0.457 \\
\hline Disability $(\mathrm{QBPDS})^{2}$ & see below & see below \\
\hline Pain intensity (VAS) & -1.087 & 0.120 \\
\hline Depression (BDI) & -0.111 & 0.873 \\
\hline
\end{tabular}

1 Results are from ordinal regression analysis widh secondary variable (12 months) as a dependent variable and pain-related fear (baseline) as a covariate. 2 For all variables in this table interaction. (group * pain-related fear) was not significant, except for disability. For disability the final model was: -1.845 group +0.552 pain-selated feat -0.477 (group * pain-related fear) with $p=0.052$ for group, $p=0.007$ for pain-related fear and $p=0.045$ for group * pain-related fear.

\section{Discussion}

Aim of the present study was to test the effectiveness of an exposure in vivo treatment in addition to usual care for patients with acute LBP and elevated levels of pain-related fear. We encountered major problems in patient recruitment, which reduced the sample size and therefore power of statistical tests. The planned direct comparison of $\mathrm{UC}$ and $\mathrm{EV}$ revealed no evidence for an additional effect of EV above UC. Secondary analyses with baseline pain-related fear level as a covariate revealed however an interaction between treatment condition and covariate, suggesting that EV compared to $\mathrm{UC}$ might have a therapeutic effect in the persistently highly fearful patients. Interestingly, the results suggest that UC was as effective as EV in patients with relatively lower and subsiding levels of pain-related fear, whereas in those with persistently high pain-related fear levels, UC did not lead to a reduction of the pain problem. In contrast, EV seems to be as effective in 
reducing the pain problem in the persistently highly fearful patients as in the subsiding/lower fearful patients: the median effect of EV appeated to be a low disability/low pain level as outcome, independent of baseline level of pain-related fear. It should be noted however, that this finding was based on secondary analysis (as baseline differences between conditions on pain-related fear had not been expected, nor an interaction of this type was hypothesised), so that replication by new studies is needed. Our results also suggest that persistence of high pain-related fear is the essential factor in increasing the risk for the pain-problem to become chronic without fear-reducing treatment, and not an initially high level of painrelated fear. In other words, if pain-related fear reduces during the early stages of LBP, chances are high that the pain problem will disappear spontaneously or with usual care. If, on the other hand, pain-telated fear remains high, EV might be indicated as an additional treatment.

Figure 6.3 Interaction between pain-related fear and treatment allocation: effects on 12-months' GCPS

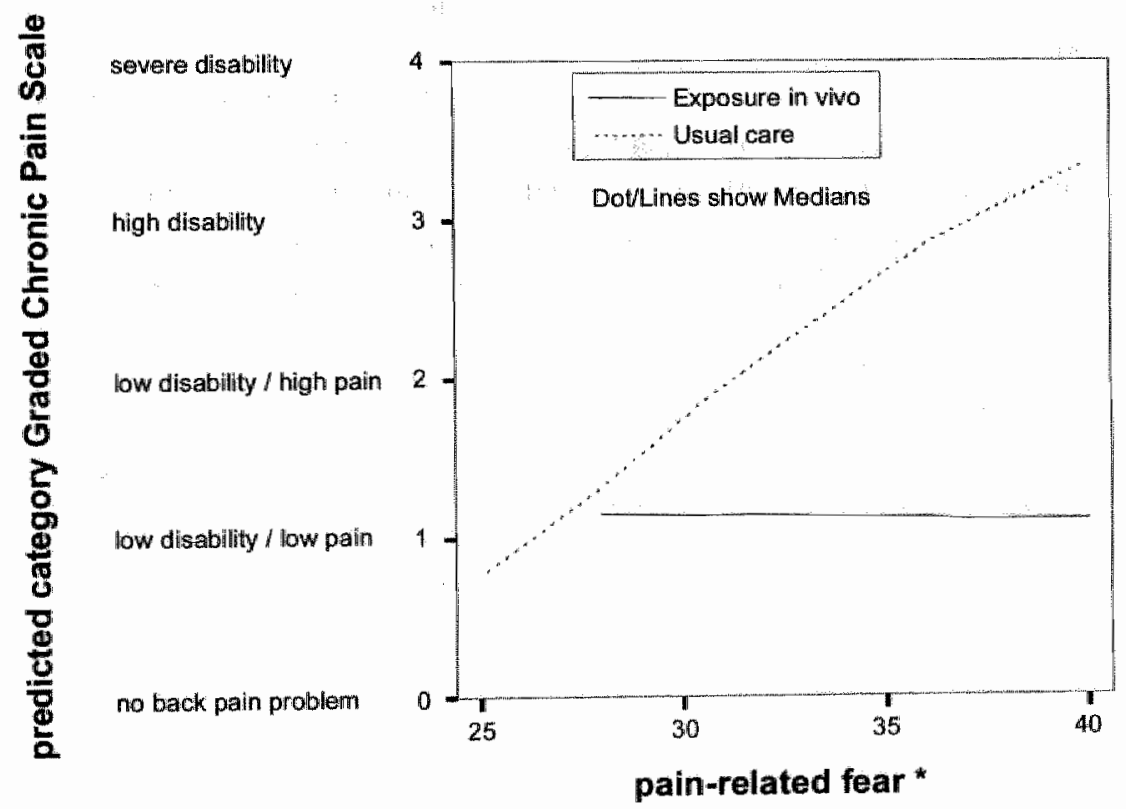

* pain-related fear: scores displayed are sums of TSK 'somatic focus' and 'TSK 'activity avoidance'. NB: The original 17-item TSK total score is about 10 points higher (mean difference $=10.00 \pm 1.86$ ). 


\section{Methodological considerations}

Sasple size It is obvious that in this study the number of participants who were randomised to each condition is too small (only $20 \%$ of expected). As a result only very large differences between groups will reach statistical significance levels, and imbalances between groups are likely to occur. Recruiting acute patients during consultation appeared to highly interfere with normal general practice routine (affecting invitation rate) and patient interest (affecting refusal and exclusion tates). Finally, patient motivation to complete follow-up questionnaires (after their LBP episode was resolved) turned out to be a problem. The results of this trial should be regarded with caution as they might easily have been subject to selective response bias.

Intervention quantity: The $\mathrm{EV}$ treatment was not conclusively found to be effective beyond the 12-months follow-up. Although the results suggested that the majority of the patients indeed showed a sufficient response after two sessions, the quantity of the intervention might still not have been enough to generalize and consolidate this initial rapid response over a longer period of time. EV seemed to improve prognosis to some extent, but recurrences are still likely to happen. Perhaps a booster session offered whenever a new episode occurs may enhance long-term effectiveness.

Co-interventions: Another concern of this study is the possible influence of effective co-interventions. The design of the study implies that the experimental treatment was tested as an addition to usual care conform clinical guidelines (Faas et al., 1996). As GPs were not limited by the study protocol with respect to the care that they provided, they were free to prescribe drugs or tefer to other disciplines when indicated. Since the amount of co-interventions was equal in both groups, it seems unlikely that the results were biased as such. Unfortunately the numbers eligible are too small for an explorative adjusted analysis, so we cannot get an idea about the masking of the treatment effect by co-interventions.

\section{Theoretical and stinical comments}

Pain-related fear cat-off point: At the start of this study no information was available about a clinically relevant TSK cut-off score above which patients were likely to benefit from fear-reducing treatment, so we arbitrarily chose a subgroup with TSK total scores $\geq 42$. Post hoc analysis of the strata in the present study suggests that not only the absolute TSK-score is relevant; an elevated level of pain-related fear immediately after a new LBP injury might even be obvious and common. It can be argued that the cowrse of pain-related fear during early stages of a LBP episode may be more important. If, together with the rapid physical recovery that is usually seen in most episodes, pain-related fear also spontaneously decreases to acceptable 
levels, treatment might not be needed. In contrast, patients whose pain-related fear levels remain disturbingly high after the first few days might benefit from $\mathrm{EV}$. Within this context, the strata in this study should better be renamed "tapidly fading pain-telated fear" and "sustained high pain-related fear". This argumentation is in line with findings from our previous study (Sieben et al., 2002), in which a subgtoup of patients was identified in which acute stage rising levels of pain-related fear wete associated with poor outcome, while an early decrease of pain-related fear was associated with good prognosis.

Exposure in acute LBP: A complication of EV we encountered during this study is that it appeared not to be suitable for all varieties of pain-related fear that were presented by acute patients. The format of a behavioural experiment is a useful tool in correcting irrational cognitions that can be falsified instantaneously ("If I jump down this step, my spine will fracture immediately'). However, many acute LBP patients are not afraid of the immediate consequences of movement, but they are worried about long-term damage caused by back straining activities (If I have to lift $10 \mathrm{~kg}$. boxes 50 times a day for the next 10 years, then I will be unable to walk by the time I am $50^{\prime}$ ). We noticed that many fearful patients in our sample were heavy-duty workers (construction workers, production workers, nurses, cleaning personnel), and the typical worries that they express cannot be challenged by EV experiments as described.

\section{Directions for future research}

We strongly emphasize the need for replication of this RCT. Our findings are interesting but inconclusive, and a larger sample is badly needed to test the effectiveness of EV as a preventive strategy. Our first experiences with EV in acute LBP could help improve the design. We recommend prestratification on pain-related fear, a placebo condition and strict guidance with respect to cointerventions. Furthermore, special attention should be paid to alternative recruitment methods. Replication of this study (with an improved design) is urgently needed to come to clinical applicable empirical evidence.

\section{ACKNOWLEDGMENTS}

The authors want to thank the staff of the general practices participating in this study for recruiting patients. We are also grateful to Sita van Riet, Eric Bousema and Jeanine Verbunt for their help in study management. Special thanks to the colleagues from the Centre for Health Studies, Group Health Cooperative, Seattle (USA) for their hospitality and contribution to the implementation of the exposure in vivo intervention in primary care. 


\section{REFERENCES}

- Al-Obatid, S.M, Nelson, R.M., Al-Awadhi, S., Al-Shuwaie, N. (2000). The role of anticipation and fear of pain in the persistence of avoidance behavior in patients with chronic low back pain. Spinte, 25 (9), 1126-1131.

- Asmundson, G.J, Norton, G.R, Allerdings, M.D. (1997). Fear and avoidance in dysfunctional chronic back pain patients Pain, 69 (3), 231-236.

- Beck, A.T, Ward, C.H., Mendelson, M., Mock, J., Erbaugh, J. (1961). An inventory for measuring depression. Areb Gen Psyebatatry, 4, 561-571.

- Boersma, K, Linton, S, Overmeer, T., Jansson, M., Vlaeyen, J., de Jong, J. (2004). Lowering feat-avoidance and enhancing function through exposure in vivo. A multiple baseline study across sitx patients with back pain. Pain, 108 (1-2), 8-16.

- Bosscher, R.J., Koning, H., Van Meurs, R. (1986). Reliability and validity of the Beck Depression Inventory in a Dutch college population. Psycbol Rep, 58 (3), 696-698.

- Buchbinder, R., Jolley, D., Wyatt, M. (2001). 2001 Volvo Award Winner in Clinical Studies: Effects of a media campaign on back pain beliefs and its potential influence on management of low back pain in general practice. Spine, 26 (23), 2535-2542.

- Buer, N., Linton, S.J. (2002). Fear-avoidance beliefs and catastrophizing: occurrence and risk factor in back pain and ADL in the general population. Pain, 99 (3), 485-491.

- Burton, A.K., Waddell, G., Tillotson, K.M., Summerton, N. (1999). Information and advice to patients with back pain can have a positive effect. A randomized controlled trial of a novel educational booklet in primary care. Spine, 24 (23), 2484-2491.

- Butler, G. (1989). Phobic disorders. In K. Hawton, P. M. Salkovskis, J. Kirk \& D. M. Clark (Eds.), Cognitive bebatiour therapy for psycbiatric problems" a practical guide (pp. 97-128). Oxford: Oxford University Press.

- Crombez, G., Vlaeyen, J.W.S., Heuts, P.H., Lysens, R. (1999). Pain-related fear is more disabling than pain itself: evidence on the role of pain-related fear in chronic back pain disability. Pain, 80 (1-2), 329-339.

- Elliott, A.M., Smith, B.H., Smith, W.C., Chambers, W.A. (2000). Changes in chronic pain severity over time: the Chronic Pain Grade as a valid measure. Pain, 88 (3), 303-308.

- Engel, C.C., von Korff, M., Katon, W.J. (1996). Back pain in primary care: predictors of high health-care costs. Pain, 65 (2-3), 197-204.

- Faas, A., Chavannes, A.W., Koes, A.W., Van den Hoogen, J.M.M., Mens, J.M.A., Smeele, IJ.M., Romeijnders, A.C.M., Van der Laan, J.R. (1996). Practice Guideline Lou Back Pain' (translation). Utrecht: Dutch College of General Practitioners (NHG).

- Fritz, J.M., George, S.Z., Delitto, A. (2001). The role of fear-avoidance beliefs in acute low back pain: relationships with current and future disability and work status. Pain, 94 (1), $7-15$.

- Goubert, L., Crombez, G., Van Damme, S., Vlaeyen, J.W.S., Bijttebier, P., Roelofs, J. (2004). Confirmatory factor analysis of the Tampa Scale for Kinesiophobia invariant twofactor model across low back pain patients and fibromyalgia patients. Clin I Pain, 20 (2), $103-110$.

- Jensen, M.P., Karoly, P. (1992). Self-report scales and procedures for assessing pain in adults. In D. C. Turk \& R. Melzack (Eds.), Handbook of pain assessment (pp. 135-151). New York: Guilford Press. 
- Kopec, JA., Esdaile, JM., Abrahamowicz; M., Abenhain, L, Wood-Dauphinee, S, Lamping, D.L., Williams, J.I. (1996). The Quebec Back Pain Disability Scalle: conceptralization and development J Ch Epudemiol, 49 (2), 151-161.

- Kort, S.H., Miller, R.P., Todd, D.D. (1990). Kinisophobia: a new view of chronic pain behavios. Pain Masuagenent, jantuav/febratary, 35 43.

- Kuglet, K, Win, J., Geilen, M., de Jong, J., Heuts, P.H.T.G., Vlaeyen, JW.S. (1999). The Pbotograph Series of Daily Activities (PHODA) CD-ROM version. Institute for Rehabilitation Research Hoensbroek, School for Physiotherapy Heerlen, and Maastricht University, The Netherlands.

- Linton, S.J. (2002). A cognitive-behavioral approach to the prevention of chronic back pain. In D. C. Turk \& R. J. Gatchel (Eds.), Psydological approacher to puin matragement. A prattitioner's bandbook. Second edition (pp. 317-333). New York: The Guilford Press.

- Metsemakers, J.F., Hoppener, P., Knottnerus, J.A., Kocken, R.J., Limonard, C.B: (1992). Computerized health information in The Netherlands: a tegistration network of family practices. BrJ Gen Prat; 42 (356), 102-106.

- Miller, R.P., Kori, S.H. Todd, D.D. (1991). The Tampa Seale for Kunestophobia. Unpublished report.

- Moore, J.E., Von Korff, M., Cherkin, D., Saunders, K., Lorig, K. (2000). A randomized trial of a cognitive-behavioral program for enhancing back pain self care in a primary care setting. Pain, $88(2), 145-153$.

- Osmar, A., Barrios, F.X., Kopper, B.A., Hauptmann, W., Jones, J., O'Neill, F. (1997). Factor structure, reliability, and validity of the Pain Catastrophizing Scale. I Behav Med, 20 (6), 589-605.

- Penny, K.I., Purves, A.M., Smith, B.H., Chambers, W.A., Smith, W.C. (1999). Relationship between the chronic pain grade and measures of physical, social and psychological well-being. Pain, 79 (2-3), 275-279.

- Philips, H.C. (1987). Avoidance behaviour and its role in sustaining chronic pain. Bebav Res Ther, 25 (4), 273-279.

- Picavet, H.S., Vaeyen, J.W.S., Schouten, J.S. (2002). Pain catastrophizing and kinesiophobia: predictors of chronic low back pain. Am / Epidewiols 156 (1.1), 1028-1034.

- Pincus, T., Vlaeyen, J.W.S., Kendall, N.A., Von Korff, M.R., Kalauokalani, D.A., Reis, S. (2002). Cognitive-behawioral therapy and psychosocial factors in low back pain: ditections for the future. $S p i n t, 27(5), \mathrm{E}$ 133-138.

- Roelofs, I., Goubert, L., Peters, M.I., Vlaeyen, J.W.S., Crombez, G. (2004). The Tampa Scale for Kinesiophobia: further examination of psychometric properties in patients with chronic low back pain and fibromyalgia. Emr $J$ Paws, \& (5), 495-502.

- Schoppink, L.E., van Tulder, M.W., Koes, B.W., Beurskens, S.A., de Bie, R.A. (1996). Reliability and walidity of the Dutch adaptation of the Quebec Back Pain Disability Scale. Pbys Ther 76 (3), 268-275.

- Schouten, H.J. (1995). Adaptive biased um randomization in small strata when blinding is impossible. Biometrics, 51 (4), 1529-1535.

- Sieben, J.M., Vlaeyen, J.W.S., Pottegijs, P.J.M., Verbunt, J.A., van Riet - Rutgers, S., Kester, A.D.M., Von Korff, M., Antz, A., Knottnerus, J.A. (2005). A longitudinal study on the predictive validity of the fear-avoidance model in low back pain. Pain, 117, 162-170. 
- Sieben, JM., Vlaeyen, J.W.S., Tueflinckx, S, Portegiis, P.J.M. (2002). Pain-related fear in acute low back pain: the first two weeks of a new episode. Exty Pan, 6 (3), 229-237.

- Smith, B.H., Penny, KI., Purves, A.M., Munro, C., Wilson, B., Grimshaw, J., Chambers, W.A, Smith, W.C. (1997). The Chronic Pain Grade questionnaire: validation and reliability in postal research. Pan, 71 (2), 141147 .

- Sullivan, MJI, Bishop, SR, Pivik, J (1995). The Pain Catastrophizing Scale: development and validation. Psycbological Assessment, 7 (4), 524-532.

- Van Damme, S., Crombez, G, Bijttebier, P., Goubert, L, Van Houdenhove, B. (2002). A confirmatory factor analysis of the Pain Catastrophizing $5 \mathrm{cale}$ invariant factor structure across clinical and non-clinical populations. Pain, 96 (3), 319-324.

- Vercoulen, J.H., Bazelmans, E, Swanink, C.M., Galama, JM., Jongen, P.J., Hommes, O., Wan der Meer, JW., Bleijenberg, G. (1997). Physical activity in chronic fatigue syndrome: assessment and its role in fatigue. J Psycbiatr Res, 31 (6), 661-673.

- Vlaeyen, J.W.S., de Jong, J., Gellen, M., Heuts, P.H., van Bteukelen, G. (2001). Graded exposure in vivo in the treatment of pain-related fear: at replicated single-case experimental desigh in four patients with chronic low back pain. Behaw Res Tber, 39 (2), 151-166.

- Vlaeyen, J.W.S., de Jong, J., Geilen, M., Heuts, P.H., van Breukelen, G. (2002a). The treatment of fear of movement/(re)injury in chronic low back pain: further evidence on the effectiveness of exposure in vivo. Clix f Pain, 18 (4), 251-261.

- Vlaeyen, J.W.S., de Jong, J., Sieben, J., Crombez, G. (2002b). Graded exposure in vivo for pain-related fear. In D. C. Turk \& R. J. Gatchel (Eds.), Psycbological approaches to pain managetnent: practitioner's bandbook (second edition) (pp. 210-233). New York: The Guilford Press.

- Vlaeyen, J.W.S., Kole-Snijders, A.M., Boeren, R.G., wan Eek, H. (1995a). Fear of movement/(re)injury in chronic low back pain and its relation to behavioral performance. Paix, 62 (3), 363-372.

- Vlaeyen, J.W.S., Kole-Snijders, A.M.J., Rotteveel, A., Ruesink, R. Heuts, P.H.T.G. (1995b). The role of fear of movement/(re)injury in pain disability. J Ocap Rebals, 5 (4), $235-252$

- Vaeyen, J.W.S., Linton, S.J. (2000). Fear-avoidance and its consequences in chronic musculoskeletal pain: a state of the art Pais, 85 (3), 317.332.

- Von Korff, M., Ormel, J., Keefe, F.J., Dworkin, S.F. (1992). Grading the severity of chronic pain. Pain, 50 (2), 133-149. 


\section{Chapter 7}

\section{General practitioners' treatment orientations towards low back pain: influence on treatment behaviour and patient outcome}

Judith M. Sieben, Johan W.S. Vlaeyen, Piet J.M. Portegijs,

Franca C. Warmenhoven, Ageeth G. Sint, Nadine Dautzenberg, Arnold Romeijnders, Arnoud Arntz, J. André Knottnerus 


\section{Abstract}

In low back pain (LBP) treatment and research attention has shifted from a biomedical towards a biopsychosocial approach. Patients' LBP beliefs and attitudes were found to predict long-term outcome, and recently it has been suggested that the health care providers' ideas about LBP are also important predictors of treatment behaviour and outcome. In the present study we examined whether (1) differences in General Practitioners' (GP) LBP treatment orientation are associated with differences in actual treatment behaviour and (2) whether treatment orientation is related to LBP outcome in patients.

Two hundred twenty two patients consulting their GP with a new episode of LBP were recruited and completed questionnaites on (among others) LBP outcome (graded chronic pain scale) at baseline, during 12 months of follow-up and at the end of the study. Data on treatment were collected from the GPs. The GPs also completed a set of questionnaires on LBP treatment orientation. Associations between measures of treatment otientation, treatment recommendations, treatment behaviour and LBP outcome were analysed.

A biomedical treatment orientation was found to be associated with mote concern about tissue damage and the effect of physical activity on pain and recovery in vignettes. No associations were found between treatment orientation measures, actual treatment behaviour and LBP outcome.

We offer several explanations for not finding associations as expected, address methodological aspects and clinical and theoretical implications of this study. 


\section{INTRODUCTION}

Current clinical guidelines on non-specific low back pain (LBP) do not only address the diagnosis and treatment of physical "red flags" (symptoms that might indicate a serious medical condition) (AHCPR, 1994; Waddell, 1998), they also increasingly acknowledge the influence of psychological factors on both the onset and the development of LBP (Faas et al., 1996; Kendail et al., 1997; Waddell et al, 1999; ACC, 2003). Negative affect, low self-efficacy, catastrophizing thoughts and fear-avoidance beliefs have been shown to be predictors of chronic disability (ALObaidi et al., 2000; van den Hout et al., 2001; Fritz and George, 2002; Janssen; 2002; Picavet et al., 2002; Denison et al., 2004). Interventions aimed at adjusting these cognitive and behavioural factors were found effective in improving longterm outcome (Moore et al., 2000; Buchbinder et al., 2001; Linton and Ryberg, 2001; Pincus et al., 2002; Vlaeyen et al., 2002).

This shift towards a more psychosocial approach to LBP has its consequences for clinical practice. If we assume that a patient's behaviour and the way he/she deals with LBP is guided by his/her orientation and beliefs about pain, and that these beliefs are possibly shaped by the health care provider ( $\mathrm{HCP}$ ), then the HCP's own ideas and orientation become important, too. After all, why should HCPs differ from other people? The advice given and actions undertaken as part of treatment will (explicitly or implicitly) reflect the HCP's own ideas and treatment orientation.

Two treatment orientations regarding LBP are common (Ostelo et al., 2003). One orientation is based upon the biomedical model of disease, in which pain and functional limitations are explained by physical pathology. Pain is viewed as a signal of tissue damage, and treatment is aimed at finding and subsequently curing the cause of the pain. A second orientation considers (chronic) pain problems a result of biomedical, psychological and social factors. Health care providers holding this biopsychosocial orientation consider LBP disability is not (only) related to pain intensity, and view improvement of function despite pain as an important goal of treatment. They also pay attention to factors like occupational demands, stress, cognitive errors and reinforcement issues.

Previous research has shown orientation and beliefs of health care providers to be important in the management of LBP. Cherkin and colleagues (1995) demonstrated within a sample of US physicians a wide variety of views on how LBP should be treated. A study done by Rainville et al. (2000) confirmed that physicians' recommendations are highly variable and often testrictive. These recommendations were based on both treatment orientation and the clinical symptoms presented. Linton et al. (2002) examined the fear-avoidance beliefs of GPs and physical therapists (PTs) and concluded that some of them held beliefs reflecting pain-related fear, which influenced advice concerning sick leave and 
awoidance of activities. Similar results were found by Houben et al. (in press), who showed among PTs that two factors on a treatment orientation questionnaire ('biomedical' and 'biopsychosocial') were associated with perceived harmfulness of physical activities and recommendations for return to work. Almost all of these previous studies only investigated HCP self-report measures on treatment of fictive patients (e.g. case presentations); to our knowledge, onlly one study (Von Korff et al., 1994) also involved actual patient outcome. This study showed that a primary care practice style consistent with $L B P$ self-care yielded similar long-term pain and functional outcomes, but with lower health care costs and higher patient satisfaction compared to a practice style associated with more frequent prescription of pain medication and bed rest.

The setting of the present study, which is performed within a sample of Dutch general practitioners (GPs) who participated in a longitudinal study on acute LBP in primary care patients (Sieben et al., submitted Pain, manuscript nr. D-04-00599), offers a unique opportunity to study associations between GP orientation and patient data. We examined (1) whether differences in LBP treatment orientation are associated with differences in actual treatment behaviour and (2) whether GP treatment orientation is related to LBP outcome in patients. Based on theory and previous findings, we hypothesize that the GPs' treatment orientations will influence their treatment choices and thereby influence their patients' LBP careers.

\section{METHODS}

\section{Subjects}

The research presented in this paper is embedded within a longitudinal cohort study on the role of pain-related fear in the development of chronic LBP. In summary, patients consulting their GP with a new episode of non-specific LBP (within 3 weeks of pain onset) were invited to participate in the study and completed postal questionnaires at baseline, 3 months, 6 months and 12 months follow-up and at the end of the study. Data on treatment during the follow-up period were collected from the GPs. Details on patient selection criteria etc. are reported elsewhere (Sieben et al., submitted Pain, manuscript nr. D-04-00599). The GPs involved in the recruitment of acute LBP patients for this study also participated in a survey on GP treatment orientation. The study protocol was approved by the medical ethics review committees of Maastricht University Hospital \& Maastricht University (Maastricht, the Netherlands) and the Institute for Rehabilitation Research (Hoensbroek, the Netherlands). 


\section{Survey on GP treatment onientation}

Destriptive characteristics: Information was gathered about the GP's age, gender and years of working experience, together with details on practice situation like (a) group or solo practice (b) full-time or part-time assignment and (c) estimated frequency of LBP in own practice. Additionally, fields of special interest and interest in LBP as a primary care problem were explored. Also the level of physical activity and back pain history of the GP were measured.

$L B P$ orientation: The Health Care Providers' Pain and Impaiment Relationship Scale (HC-PAIRS) (Rainville et al., 1995) was designed to assess the orientation and beliefs of health care providers about functional expectations for chronic LBP. patients. The questionnaire consists of 15 statements with a 6-point Likert-scale ("totally disagree" to "totally agree"). A high score on the HC-PAIRS reflects a more biomedical treatment orientation. Reliability and validity of the Dutch version of the HC-PAIRS has been shown good (Houben et al., 2004).

Fear of movement/(re)injtry: The Tampa Scale for Kinesiophobia (TSK) was originally designed to measure fear of movement and/or (re)injury in LBP patients (Miller et al., 1991; Vlaeyen et al., 1995). An adaptation of this scale (TSK-HC) was developed by Houben et al. (2004) to determine to what extent HCPs believe that movement and physical activity is harmful for their LBP patients. The TSK-HC consists of 17 statements, which have to be rated on a 6-point Likert scale ranging from "totally agree" to "totally disagree". As an example, the original TSK-item "If I were to try to overcome it, my pain would increase" was converted to "If a low back pain patient was to try to overcome his or her pain, it would increase" (TSKHC).

Threat value of physical activity: The Photograph Series of Daily Activities (PHODA) (Kugler et al., 1999) was initially developed to obtain hierarchies of specific fear-eliciting movements for treatment purposes in patients with high levels of fear of movement. The PHODA consists of 98 photographs of people carrying out daily activities. For this study, 8 pictures were selected based on high ratings (reflecting fear for and an unge to avoid the specific activity) in patients in a previous study (Vlaeyen et al., 2001). With each picture the GP is asked to answer two questions: (1) To what extent do you think this activity is harmful for a low back pain patient?; (2) To what extent would you advise a low back pain patient to avoid this activity? GPs rate their answers on an 11-point Likert scale, varying from "certainly not harmful" to "certainly harmful" and "no restrictions" to "strongly advised against" respectively. For both sets of 8 items an average score is calculated (representing "perceived harmfulness" and "advise to activity avoidance").

Treatment recommendations: Three patient vignettes constructed by Rainville (2000) were used to explore physicians' recommendations on activity and work for 
patients with chronic LBP. The vignettes present different levels of pathology, symptoms and work requirements. In each vignette details of work situation, symptoms, relewant physical findings, diagnostics and previous treatment are described. All rignettes purposely lack diagnostic evidence of comptession of neurological structures that would require surgery. For each vignette GPs are asked to rate (a) the severity of symptoms, (b) the severity of pathology, (c) appropriate level of activities and (d) appropriate level of work. Ratings are made by selecting one of five graded response options for each topic.

\section{Measures from the longitudinal study}

Patient questionnaines: Patients completed questionnaires on LBP outcome, fearavoidance variables, pain and disability at baseline and at 3 months, 6 months and 12 months follow-up and at the end of the study (LBP outcome only). Key measures were the graded chronic pain scale (GCPS), pain intensity (measured by a Visual Analogue Scale), pain-related fear (measured by Tampa Scale of Kinesiophobia, TSK) and back pain disability (measured by Quelbec Back Pain Disability Scale, QBPDS). Details on the questionnaires used are reported elsewhere (Sieben et al., submitted Pain, manuscript nr. D-04-00599). We used the GCPS (Von Korff et al., 1992) as a primary outcome variable. The GCPS accounts for levels of pain, disability and social interference due to LBP. The patient's LBP situation is graded on a 5 -point scale ranging from 0 ("no pain problem") to 4 ("high disability/ severely limiting").

Treatment: Twelve months after the initial LBP-consultation GPs completed a report for each patient on treatment, drug prescription, and referrals during the follow-up period.

\section{Analysis}

SPSS 11.5 was used for all statistical analyses (SPSS, Chicago, USA). Unless reported otherwise, all statistical tests are two-sided and $p$-values $\leq 0.05$ are judged significant.

Associations between measures of treatment orientation aspects (HC-PAIRS, TSK-HC) and measures reflecting treatment recommendations (PHODA, vignettes), treatment behaviour (patient follow-up reports) and LBP outcome (chronic pain grade) were analysed using Spearman's tho correlation coefficients.

Regarding the relation between treatment orientation (GP) and LBP outcome (patient), multi-level analysis is indicated if the observations in one level (patient) are dependent upon the other level (GP). We explored the dependency between the levels of measurement using intra-class correlation coefficients (ICC). In case of high ICC, the next step would be to perform a multi-level analysis. In case of 
low ICC, we would instead perform a regression analysis with GCPS as a dependent variable and HC-PAIRS as an independent variable while controlling for known patient variables.

\section{RESULTS}

\section{Subject characteristics}

Betwieen January 2001 and April 2003, 35 general practices (56 GPs) located in the southern part of the Netherlands were involved in this study.

(a) Response rates: Two hundred twenty two patients were recruited by 36 of the 56 GPs. The cross-sectional survey on treatment orientation was completed by 42 GPs $(75 \%)$. Both patient data and GP-survey data were available from 27 GPs $(48 \%)$. In these, the median number of patients per GP was 3 (interquartile range 2-7).

Table 7.1 Baseline chatacteristics of the general practitioners sample

\begin{tabular}{|c|c|c|c|}
\hline & $\%(N=42)$ & & $\%(N=42)$ \\
\hline Age (years) & & Working experience as GP (jears) & \\
\hline $25 \cdot 34$ & 5 & $<5$ & 7 \\
\hline $35-44$ & 38 & $5-10$ & 26 \\
\hline $45-54$ & 47 & $11-20$ & 36 \\
\hline $55-64$ & 10 & $>20$ & 31 \\
\hline Pant-time / fulltime jobs & & Nof LBP patients in onn practice & \\
\hline fulltime $(1.0$ fte $)$ & 66 & 0-2 patients/month & 9 \\
\hline part-time $(>0.5$ fte $)$ & 17 & 2-5 patients/month & 45 \\
\hline \multirow[t]{2}{*}{ part-time $(\leq 0.5$ fte $)$} & 17 & 5-10 patients/month & 34 \\
\hline & & $>10$ patients $/$ month & 12 \\
\hline Gender & & Treatwent arienation measmes" & \\
\hline male & 81 & HC-PAIRS (6-point scale) & $45.5(6.5)$ \\
\hline female & 19 & TSK-HC & $35.8(8.3)$ \\
\hline
\end{tabular}

1 mean scores (SD) are presented.

(b) General practitioners: Descriptives of the GPs are presented in table 7.1. The majority of participants were male, fulltime working and experienced physicians. On a $0-10$ scale, mean interest in LBP in general practice was $5.5(\mathrm{SD}=1.9)$. One GP reported to have LBP himself at the time he completed the questionnaire. 
(c) LBP patients: Extensive details on the LBP patients are described in Sieben et at (submited Pain, manuscript nr. D-0400599). Highlights are briefly summarized in table 7.2 .

Table 7.2 Baseline characteristics of LBP patients ${ }^{1}$

\begin{tabular}{lc}
\hline & $\mathbf{N}=222$ \\
\hline $\begin{array}{l}\text { Gender } \\
\text { male }(\%) \\
\text { female }(\%)\end{array}$ & 56.3 \\
\hline Age years) & 43.7 \\
Duration of complains (days) & $44(34-50)$ \\
Pain inrensity $(0-100)^{2}$ & $5(2-10)$ \\
LBP disability $(0-100)^{3}$ & $48(27-64)$ \\
\hline
\end{tabular}

1 Median scores with interquartile ranges are presented unless otherwise stated. ${ }^{2}$ Measured by $10 \mathrm{~cm}$. Visual. Analogue Scale with anchors representing "no pain" $(0)$ and "unbearable pain" (100). ${ }^{3}$ Measured by Quebec Back Pain Disability Sale.

\section{Trealment orientation, treatment recommendations and actual treatment bebaviour}

Correlations between measures of treatment orientation and self-reported treatment recommendations (table 7.3) show a biomedical approach to be associated with a more severe judgement of pathology, more restrictive recommendations about activities, and more hatmful appraisals of movements. In general, biomedically oriented GPs seemed to be more concerned about tissue damage and the effects of physical activities on pain and recovery.

Table 7.3 also shows correlations between treatment orientation and actual treatment behaviour. Data from the patient follow-up reports ( 12 months) are used in this analysis. All additional diagnostic tests, referrals to therapy and referrals to specialist treatment that were ordered by the GPs were labelled "biomedical" or "psychosocial" interventions (detailed coding list available from corresponding author). For each GP, we calculated the percentage of his/her patients in which each type of intervention was applied. No significant associations were found between treatment orientation scores, numbers of diagnostic tests ordered and referral tates. 
Table 7.3 Associations of treatment orientation measures with treatinent intentions, treatment behaviour and low back pain outcome

Treatment orientation

HC-PAIRS TSK-HC

\section{Treatment intentions}

\section{Vignethes}

symptoms

$-0.047$

$-0.183$

pathology

$0.426 *$

$0.590 * *$

activities

0.278

0.373 *

work

$0.339 *$

0.232

PHODA

perceived harmfulness

$0.361 *$

$0.447 *$

advise to activity avoidance

0.129

0.217

\section{Actual treatment behaviour}

N follow-sp consultations

$-0.261 \quad-0.057$

$\%$ of patients in whom nedication prescribed

0.023

0.155

$\%$ of patients in whom additional diagnostics ondered

biomedical diagnostics

psychosocial diagnostics

$\begin{array}{ll}-0.130 & -0.239 \\ -0.096 & -0.256\end{array}$

$\%$ of patients referred to therapists

biomedical therapist

psychosocial therapist

$-0.243 \quad 0.013$

$0.277 \quad 0.194$

$\%$ of patients referred to specialists
biomedical specialist
$-0.017$
0.136
psychosocial specialist
$-0.284$
$-0.293$

$\%$ of patuents in whoms specific strensors awere diagnosed

biomedical stressots

psychosocial stressors

$-0.125$

$-0.261$

$-0.202$

0.064

\section{Low back pain outcome (patients)}

Chronic part grade (GCPS)

baseline

3 months

$-0.061$

$-0.035$

$-0.027$

0.072

6 months

12 months

end of study

0.067

0.014

$-0.015$

0.005

0.018

$-0.004$

Spearman's rho correlation coefficients are presented; correlations with $p$ - $\mathrm{xalues} \leq 0.05$ are marked *; correlations with $\mathrm{p}$-values $\leq 0.01$ are marked **; $\%$ : percentage of patients per GP. 
Table 7.4 Associations between measures of treatment orientation and LBP outconne

Treatment orientation

HC-PAIRS

TSK-HC

\begin{tabular}{|c|c|c|}
\hline Intorediate owhomel & & 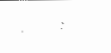 \\
\hline mean $G C P^{4}$ & 0.032 & -0.062 \\
\hline mean residuals & 0.073 & 0.280 \\
\hline \multicolumn{3}{|l|}{ Sbart-term outcome } \\
\hline mear $G C P S^{4}$ & 0.046 & 0.023 \\
\hline mean residual ${ }^{5}$ & -0.111 & -0.081 \\
\hline \multicolumn{3}{|l|}{ Long-fermy ownomes } \\
\hline noean $\mathrm{GCPS}^{4}$ & -0.044 & 0.045 \\
\hline mean residual ${ }^{5}$ & 0.139 & 0.030 \\
\hline
\end{tabular}

Spcarman's tho correlation coefficients are presented. Correlations with $\mathrm{p}$-values $\leq 0.05$ are marked *. Correlations with p-walues $\leq 0.01$ are marked **. 1 Immediate outcome: GCPS scote baseline questionnaite (after GP consultation). ${ }^{2}$ Short-term outcome: GCPS score at 3 months. ${ }^{3}$ Long-term outcome: GCPS at end of study (median follow-up = 1.9 years). "Mean GCPS score for all patients (per GP). ${ }^{5}$ Mean residual not explained by patient predictor variables (per GP).

\section{Treatment orientation and autcome of $L B P$}

Treatment orientation measures did not seem to correlated with LBP outcome (graded chronic pain scale) (table 7.3). Intra-class correlation coefficients for GCPS scores by GP were all zero or $<0.10$ throughout the study, which implied that multi-level analysis was not indicated. However, the small ICCs might have been due to the small numbers of patients per GP. In order to rule out any masked association between treatment orientation and patient outcome, we proceeded upon previous analyses within the patient cohort study. We assumed that patient outcome can be explained by both patient variables (demographics, episode characteristics and LBP beliefs) and GP variables (treatment orientation). In Sieben et al. (submitted Pain, manuscript nr. D-04-00599) we systematically derived an ordinal regression model explaining LBP outcome (GCPS) using patient variables. The final model contained age, number of previous episodes, level of education and baseline pain intensity as predictor variables. For the present study, GCPS-scores were predicted for each patient, using this model. Differences between actual GCPS-scores and predicted scores were calculated, representing the residual variance not explained by the patient predictor variables. These residuals were then averaged per GP. No significant associations were found between the GPs' treatment orientation measures and residual variance in their patients (table 
7.4); which suggests that the variance not explained by patient predictors could not be explained by GP orientation either.

\section{Discussion}

Within the context of a cohort study on fear-avoidance beliefs in primary care LBP patients, we explored the role of GP orientation on treatment behaviour and LBP outcome. Like in previous studies, trearment orientation was found to be associated with "virtual" treatment recommendations as teported by the GPs using vignettes on fictive patients. However, we could not demonstrate any significant association between treatment orientation and actual treatment behaviour in the study's patient population. Also no association was found between treatment orientation and LBP outcome in patients as measured by the Graded Chronic Pain Scale.

\section{Explanation 1: existing association ivas not detected}

We may well have overlooked an association between GP treatment orientation and patient LBP outcome for several reasons. The self-report instruments we used to measure treatment orientation (HC-PAIRS, TSK-HC) reflect explicit (conscious) aspects of treatment attitude, which are vulnerable to biases like social desirability and the influence of acquired knowledge, for example from clinical guidelines. In contrast, the underlying implicit (automatic) attitudes are not consciously controlled and may bettet predict treatment behaviour, because they are less vulnerable for strategy and demand influences. Future research should focus on developing methods to properly measure these implicit attitudes with respect to medical treatment (Houben et al., 2004).

Second, the answers to written vignettes on hypothetical patients suggest that GPs intend to act in line with their biomedical or biopsychosocial treatment orientation. On the other hand, no association was found between treatment otientation and actual treatment of patients. This apparent discrepancy may be explained by arguing that actual treatment behaviour; more than trentment intention as measured by the vignettes, is typically influenced by case-related specific factors (e.g. the patient's particular symptoms and treatment preferences, pressure of time, insurance issues), which are likely to mask the effect of treatment orientation.

Furthermore, the variance in treatment orientation and treatment behaviour may have been too small in the present sample of GPs, which may well have been a too homogenous group regarding e.g. education, L.BP beliefs and interest in behavioural research. Finally, the numbers of patients recruited per GP wete much lower than we had expected based on incidence rates. Data could not be 
aggregated for those GPs without any accompanying patients, resulting in a significant loss of statistical power.

In summary, we cannot exclude any of these explanations and together they may well explain our data.

\section{Explanation 2: associations do not exist as bypothesised}

Current biopsychosocial approaches to LBP and other pain problems presume an important influence of HCPs in changing patients" attitudes and beliefs about health. In our present study we could not confirm this role. If the GP treatment orientation indeed does not influence LBP outcome in patients, the implications may be serious. These findings may indicate that GPs treat their patients exactly according to protocols and guidelines, apart from their own private ideas about LBP. This would be a hard to believe conclusion, as it is in contradiction with research findings on guideline adherence (Lipman, 2004; Overmeer et al., 2005). On the other hand, however many patients will value their GP's opinion, it's influence will probably hardly exceed the much more frequent impact of ideas ventilated by relevant others (family, relatives, friends) and media.

It is also possible that most commonly used interventions aimed at changing the prognosis of LBP are hardly effective in daily practice, so differences in treatment orientation do not matter. As Von Korff et al. (1994) demonstrated, even clear differences in actual treatment behaviour may not influence long-term pain and functional outcome. Regarding LBP, indeed only few strategies are conclusively supported by evidence ("Cochrane Library,").

These explanations are disturbing and deserve much more attention in the debate than they have received until now. For it is unlikely that the influence of the GP (even if future research would show a weak association after all) is much stronger in other diagnoses than LBP, and regarding many aspects of health (smoling, exercise, dietary habits), improvement of prognosis depends largely on changing cognitions and behaviour (instead of technical/somatic interventions).

\section{Conthing renartes}

Despite some methodological shortcomings, to our knowledge this study is unique for its' combination of information on both GP treatment orientation and patient outcome. Unfortunately (and remarkably) we found no literature reporting on analogous studies in other disorders to compare with. Therefore our findings give rise to some relevant questions concerning widely accepted and clinically applied assumptions on behavioural medicine and the role of the HCP in influencing patients health attitudes and behaviour in general. Future studies should employ 
experimental designs if possible, and extend exidence on the role of treatment orientation to a broader spectrum of diseases.

\section{ACKNOWLEDGMENTS}

The authors are grateful to the GPs and patients who participated in this research. Special thanks to Sita van Riet for her help in study management. 


\section{RETERENCES}

- ACC. (2003). Nexy Zealowd Acute Low Back Pain Grade (June 2003 edition). Wellington, NZ.: Accident Compensation Corporation and the New Zealand Guidelines Group.

- AHCPR. (1994). Clinical Pratice Guideline Number 14. Acute low back problems in adults. Rockville USA: Agency for Health Care Policy and Research, US Department of Health and Human Services.

- Al-Obaidi, S.M., Nelson, RM., Al-Awadhi, S., Al-Shuwaie, N. (2000). The role of anticipation and fear of pain in the persistence of avoidance behavior in patients with chronic low back pain. Spine, 25 (9), 1126-1131.

- Buchbinder, R. Jolley, D., Wyatt, M. (2001). Population based intervention to change back pain belliefs and disability: three part evaluation. Bmj, 322 (7301), 1516-1520.

- Cherkin, D.C., Deyo, R.A., Wheeler, K., Ciol, M.A. (1995). Physician views about treating low back pain. The results of a national survey. Spine, 20 (1), 1-9; discussion 9-10.

- Cochrane Library, www thecochranelibrary.com: Wiley InterScience.

- Denison, E., Asenlof, P., Lindberg, P. (2004). Self-efficacy, fear avoidance, and pain intensity as predictors of disability in subacute and chronic musculoskeletal pain patients in primary health care. Pain, $111(3), 245-252$.

- Faas, A., Chavannes, A.W., Koes, A.W., Van den Hoogen, J.M.M., Mens, J.M.A., Smeele, I.J.M., Romeijnders, A.C.M., Van der Laan, J.R. (1996). Practice Guidelinte Low Back Pain' [translation]. Utrecht: Dutch College of General Practitioners (NHG).

- Fritz, J.M., George, S.Z. (2002). Identifying psychosocial variables in patients with acute work-related low back pain: the importance of fear-awoidance beliefs. Phys Ther, $82(10)$, 973-983.

- Houben, R.M., Vlaeyen, J.W.S., Peters, M., Ostelo, R.W., Wolters, P.M., Stomp-van den Berg, S.G. (2004). Health care providers" attitudes and beliefs towards common low back pain: factor structure and psychometric properties of the HC-PAIRS. Clin J Pain, 20 (1), 3744.

- Houben, R.M.A., Ostelo, R.W.J.G., Vlaeyen, J.W.S., Wolters, P.M.J.C., Peters, M., Stomp-van den. Berg, S.G.M. (2005). Health care providers' orientation towards common low back pain predict perceived tharmfulness of physical activities and recommendations regarding return to normal activity. Eur J Pain, 9 (2), 173-183.

- Janssen, S.A. (2002). Negative affect and sensitization to pain. Scand / Psychol, 43 (2), $131-137$.

- Kendall, N.A.S., Linton, S.J., Main, C.J. (1997). Gwide to arsersing psychasacial yellow flags iw arat low brock pain: risk factors for long term disability and work lors. Wellington, NZ.: Accident Rehabilitation \& Compensation Insurance Corporation of New Zealand and National Health Commitree.

- Kugler, K., Wijn, J., Geillen, M., de Jong, J., Hents, P.H.T.G., Vlacyen, J.W.S. (1999). The Photograph Senter of Daily Activities (PHODA). CD-ROM version. Institute for Rehabilitation Research Hoensbroek, School for Physiotherapy Heerlen, and Maastricht University, The Netherlands. 
- Linton, S.J., Ryberg, M. (2001). A cognitive-behavional group intervention as prevention for persistent neck and back pain in a non-patient population: a randonized controlled trial. Pain, 90 (1-2), 83-90.

- Linton, S.J., Vlaeyen, J.W.S., Ostelo, R. (2002). The back pain beliefs of health care providers: are we fear-avoidant? J Octop Rababil, 12 (4), 223-232.

- Lipman, T. (2004). The doctor, his patient, and the computerized evidence-based guideline. J Eval Clin Pract, 10 (2), 163-176.

- Miller, R.P., Kori, S.H, Todd, D.D. (1991). Tho Tampa Sache for Kinesrophobia. Unpublished report.

- Moore, J. E., Von Korff, M. Cherkin, D., Saunders, K, Lorig, K. (2000). A randomized trial of a cognitive-behavioral program for enhancing back pain self care in a primary care setting. Pain, 88 (2), 145-153.

- Ostelo, R.W., Stomp-van den Berg, S.G., Vlaeyen, J.W.S, Wolters, P.M., de Vet, H.C. (2003). Health care provider's attitudes and beliefs towards chronic low back pain: the development of a questionnaire. Man Tber, 8 (4), 214-222.

- Overmeer, T., Linton, S.j., Holmquist, L., Eriksson, M., Engfeldt, P. (2005). Do evidence-based guidelines have an impact in primary care? A cross-sectional study of Swedish physicians and physiotherapists. Spive, 30 (1), 146-151.

- Picavet, H.S., Vlaeyen, J.W.S., Schouten, J.S. (2002). Pain catastrophizing and kinesiophobia: predictors of chronic low back pain. Am J Epidemiol, 156 (11), 1028-1034.

- Pincus, T., Vlaeyen, J.W.S., Kendall, N.A., Von Korff, M.R., Kalauokalani, D.A., Reis, S. (2002). Cognitive-behaviotal therapy and psychosocial factors in low back pain: directions for the future. Spine, 27 (5), $\mathbb{E} 133-138$.

- Rainville, J., Bagnall, D., Phalen, L. (1995). Health care providers' artitudes and beliefs about functional impairments and chronic back pain. Clin J Pain, 11 (4), 287-295.

- Rainville, J., Carlson, N., Polatin, P., Gatchel, R.J., Indahd, A. (2000). Exploration of physicians' recommendations for activities in chronic low back pain. Spine, 25 (17), 22102220.

- Sieben, J.M. Vlaeyen, J.W.S., Portegijs, P.J.M., Verbunt, J.A., Van Riet - Rutgers, S., Kester, A.D.M., Von Korff, M., Arntz, A., Knottnerus, J A. (2005). A longirudinal study on the predictive validity of the fear-avoidance model in low back pain. $P_{d i n,} 117,162-170$.

- van den Hout, J.H.C., Vlaeyen, JW.S., Heuts, P.H.T.G., Sillen, W.J.H., Willen, A.J.E.H.L. (2001). Functional disability in nonspecific low back pain: the role of painrelated fear and problem-solving skills. Interwational Jownal of Behawioral Medione, 8 (2), 149. 162.

- Vlaeyen, J.W.S., de Jong, J., Geilen, M., Heuts, P.H., van Breukelen, G. (2001). Graded exposure in wivo in the treatment of pain-related fear: a replicated single-case experimental design in four patients with chronic low back pain. Bebas Rer Ther, 39 (2), 151-166.

- Vlaeyen, J.W.S., de Jong, J., Geilen, M., Heuts, P.H., van Breuketen, G. (2002). "The treatment of fear of movement/(re)injury in chronic low back pain: further evidence on the effectiveness of exposure in vivo. Cin J Pait, 18 (4), 251-261.

- Vlaeyen, JW.S., Kole-Snijders, A.M.J, Rotteveel, A., Ruesink, R., Heuts, P.H.T.G. (1995). The role of fear of movement/(re)injury in pain disability. J Ocaty Rebab, 5 (4), 235 252. 
- Von Korff, M., Barlow, W, Cherkin, D., Deyo, R.A. (1994). Effects of practice style in managing back pain. Ann Intem Med, 121 (3), 187-195.

- Von Korf, M., Ormel, J, Keefe, F.J., Dworkin, S.F. (1992). Grading the severity of chronic pain: Pain, $50(2), 133-149$.

- Waddell, G. (1998). Diagnostic triage, The Back Pain Rewoutuon (pp. 9-25). Edinburgh: Churchill Liwingstone.

- Waddell, G., McIntosh, A, Hutchinson, A., Feder, G., Lewis, M. (1999). Lou back pain

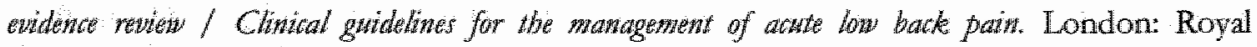
College of General Practitioners (RCGP). 


\section{Chapter 8}

General discussion 


\section{SUMMARY OF CONCLUSIONS}

The findings of the studies presented in this thesis led to mixed conclusions. In our first study, subgroups of acute LBP patients with rising, stable and decreasing courses of pain-related fear could be distinguished; the rising pain-related fear group showed higher disability during follow-up. Next, cross-sectional acute stage associations between fear-avoidance model variables in the cohort were found significant, but weaker and different from those in chtonic conditions (disability correlated with pain intensity instead of pain-related fear). So far, the featavoidance model seemed demonstrable in acute LBP, although the model as it was derived in chronic patients may not entirely apply.

Then, in longitudinal analyses within the cohort, acute stage pain-related fear did not predict long-tern LBP outcome in any way. The longitudinal validity of the fear-avoidance model could not be supported by our observational data as hypothesised. However, in the experimental study, although the overall test showed no significant effect, exposure in vivo treatment was found to improve prognosis in a subgroup of persistently highly fearful patients, but not in those with milder and subsiding levels of pain-related fear. In a secondary analysis, a significant interaction effect between pain-related fear and treatment condition was found. We concluded that usual care alone was as effective as exposure in vivo in lower fearful patients, and that adding exposure in vivo to usual care may be beneficial for the persisting highly fearful. Although these data should be interpreted with some caution, these findings suggest that reduction of fear indeed leads to a reduction of the pain problem, which again is in line with fear-avoidance theory.

\section{LONGITUDINAL VALIDITY OF THE FEAR-AVOIDANCE MODEL}

The equivocal results may imply that the fear-avoidance model is relevant to explain the further course of LBP only in a much smaller proportion of patients than expected. However a biopsychosocial approach implicitly presumes multiple possible risk factors, within this perspective we may have overestimated the importance of the fear-avoidance model in the present study to begin with. Beforehand we expected a clear confirmation, but in a longitudinal cohort study pain-related fear will only emerge as a strong predictor of long-term disability if fear-avoidance is a highly prevalent pathway to chronicity. It might be argued that in very acute LBP patients the warious pathways compete with each other (and with the needs of solving the acute situation), without one being most important yet. Maybe the samples used in previous studies on subacute and chronic patients were more homogeneous selections with regard to the most relevant risk factors, 
causing an overestimation of the overall influence of the fear-avoidance model for the general population.

In addition, the discrepancy between findings from the cohort study and the RCT may be due to a relatively low number of highly fearful patients in the cohort. The results from the RCT indicate that only a subgroup of very highly and persisting fearful patients are at risk. It is very likely that not enough of these patients were included in the cohort to detect any effect of pain-related fear on outcome. The exclusion of the EV-group (RCT) for the cohort analyses further lowered the range of pain-telated fear levels in the cohort.

The present results do not negate the longitudinal validity of the feat-avoidance model nor clearly support it; for the time being several options must be kept under consideration: (1) in acute low back pain multiple (unknown) factors obscure and/or dilute the influence of pain-related fear; (2) pain-related fear is a relevant risk factor only in a subgroup of very highly and persistently fearful patients (the size of this group remains largely unclear); (3) pain related fear and avoidance become relevant only at a later stage during an episode (or even only after multiple episodes); (3) the fear-avoidance model does not adequately explain the transition from acute to chronic low back pain.

\section{EXPosure IN VIVo}

The results of our trial study stimulated an intesesting discussion within our group on how to interpret the results. With a negative overall test, should a positive subgroup effect resulting from secondary amalysis be considered relevant? According to the methodologist, one should not put too much faith in results based on so few patients (although formally the tests used account for that). However, from a theoretical point of view, the tesults all together suggest a trend in favour of the experimentall treatment that is hard to ignore. It is difficult to imagine that a larger sample would not have yielded significant results.

Assuming that exposure in vivo may be beneficial (which at least was not disconfirmed by our data), the question remains what subgroup of patients should be targeted and when. Within our trial, benefiting and non-benefiting groups (roughly divided) seemed to differ on the acute stage baseline course of their painrelated fear (spontaneously decreasing versus invariably high). This difference may indeed indicate a relevant (but observational, not experimental) difference between subgroups, suggesting that the early course of pain-related fear may be a more important clue to efficient screening than absolute levels during the first consultation.

We achieved promising results using only a minimal exposure in vivo protocol. The effectiveness of exposure in vivo treatment may be further optimised by more closely monitoring its processes of habituation and extinguishing. We don't know 
yet whether our approach (1) elicited levels of fear during the exercises that were high enough for an effect to be expected; (2) whether the exposure was applied long enough for the fear to diminish; (3) whether the habituation generalised between exercises and exercise sessions. Our $2 / 4$ sessions stepped care protocol was just one option; further refinement will surely enhance effectiveness.

\section{METHODOLOGICAL ASPECTS OF THE TRANSITION FROM ACUTE TO CHRONIC LBP}

Without repeating all methodological considerations mentioned in the discussion sections of previous chapters, one topic deserves closer attention. Previous research on low back pain and the fear-avoidance model has been performed in chionic patient populations. With the present research we shifted focus to acute LBP in primary care. This change introduced difficulties in the definition and subsequent operationalisation concerning LBP course and outcome.

Chronic LBP is a relatively straightforwatd condition, as it is rather continuous with respect to pain and disability. But low back pain as seen in primary care typically runs an episodic course with ups and downs. We found ourselves challenged to adequately describe this recurrent nature in our studies. How to capture episodes (when do they start, and where do they end), for example? And how to measure outcome in terms of chronicity? For a simple measurement of pain and/or disability at any given moment in time may not properly reflect the situation (see figure 8.1).

Figure 8.1 Recurrent low back pain and measurement of outcome

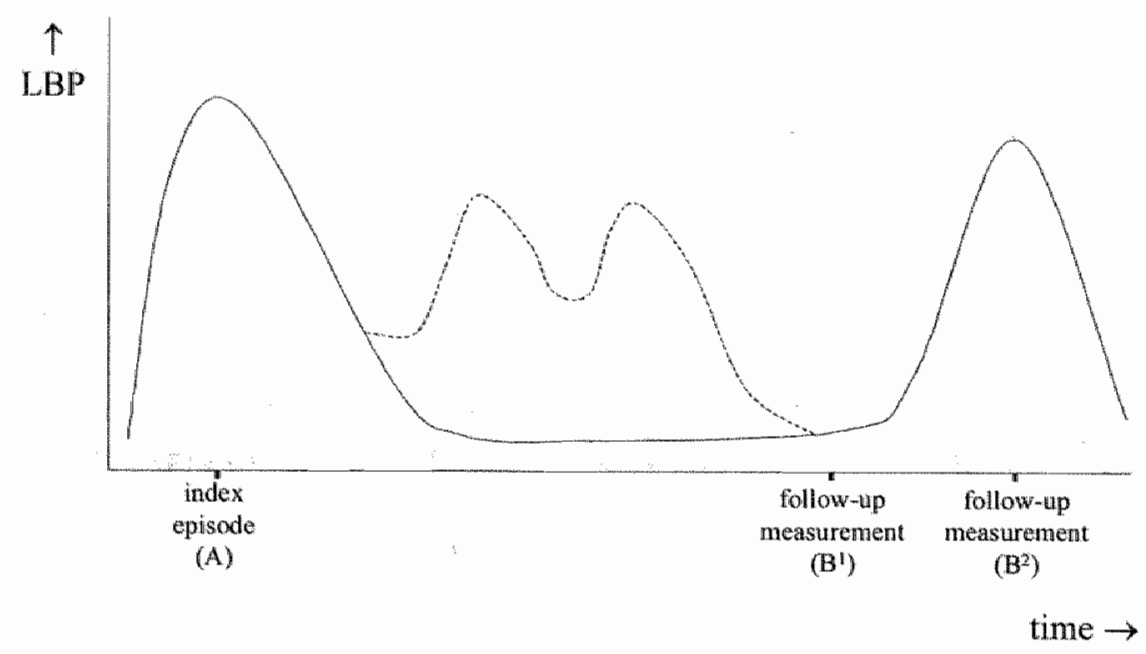


Given the index episode $A$, the value at follow-up measurement $B$ will depend on whether this measurement happens to coincide with a recurrence (B2) or not (B1). Moreover, follow-up measurement B does not include possible in-between relapses (dotted line). The typical LBP career as seen in primary care most often shows a recurrent pattern, with episodes occurring more frequently over time: However these flare-ups may already severely hamper the patient, a chronic condition in terms of persistent pain and disability (in which interpolation from $\mathrm{A}$ to $B$ is largely justified) usually only develops after many years. Within the limits of a realistically achievable study follow-up period, clearly definable chronic cases are rare in a case-mix like ours.

In summary, in our studies outcome could not be defined as prolonged disability from the indexed episode. Instead we chose to interpret the Graded Chronic Pain Scale score (covering the preceding 6 months) at the end of the study (the longest available follow-up) as a status report of the patient's LBP career, assuming that the most likely evolution is subsequently upwards through the stages distinguished by this instrument. Another option, in which cases that report poor outcome at consecutive follow-up measurements where considered "chronic" as opposed to all other "non-chronic" cases, yielded similar results in analysis. However, a drawback of this latter approach is that is requires very large numbers to attain sufficient statistical power.

Research on low back pain transition has gained interest only during recent years, and although in the recently published papers only Boersma and Linton (in press) briefly mention it in their discussion section, more researchers will encounter the same problem (and probably solve it one way or another). A debate on the available and best-preferred methods to tackle this is badly needed in addition to existing consensus on outcome measures in (chronic) LBP research (Deyo et al., 1998; Turk et al., 2003; Dworkin et al., 2005).

\section{CONTEXT OF RECENT EVIDENCE}

Previous research mainly focussed on chronic pain populations, but recently some mote studies on acute LBP have been published. Several cross-sectional studies were performed on the acute stage associations between fear-avoidance variables (Fritz et al., 2001; Swinkels-Meewisse et al., 2003; Grotle et al., 2004). Correlations between pain-related fear, disability and pain-intensity were comparable to the results of our analyses on the baseline data of the cohort sample, indicating rather weak but significant associations between pain-related fear and disability and a stronger association between pain-intensity and disability (see table 8.1) compared to findings in chronic samples.

Regarding research on the transition to chronicity, longitudinal studies including really acute patients are still scarce; Fritz et al. (2001) found work-related 
fear-avoidance beliefs to predict disability and return to work in an equally acute group ( $<3$ weeks duration; mean $=5.5$ days; $\mathrm{N}=69$ ). However, the follow-up lasted only 4 weeks. Picavet et al. (2002) furthermore showed pain catastrophizing and pain-related fear to predict disability at 6 months, however it is unclear how acute their sample was; from a population-based cohort subjects were selected for curtent low back pain, but pain duration at baseline was not reported. For this and other methodological differences (predictor and outcome variables used, strategy of analyses) findings are hard to compare. Three more recent studies on the fearavoidance model need to be addressed here for their creative design and interesting results. Linton et al. (2000) found in a sample of pain-free individuals baseline fearavoidance beliefs to be weakly to modestly related to the occurrence of LBP and levels of physical function during the next year. Buet and Linton (2002) replicated this finding in a cross-sectional mixed sample of pain-free subjects and patients with non-chronic spinal pain. Boersma and Linton (in press) cross-sectionally compared three groups with different stages of chronicity $(<1$ year; $1-3$ years; $>3$ years) and found that the association between TSK and disability/function differed across the stages; pain-related fear appeared a significant predictor only after more than one year of pain duration. This latter finding corresponds to the lack of finding any relationship between pain-related fear and LBP outcome in our cohort study.

Table 8.1 Acute stage associations between fear-avoidance variables

\begin{tabular}{lccc}
\hline & $\begin{array}{c}\text { Correlation } \\
\text { pain-related fear } \\
\text { and disability }\end{array}$ & $\begin{array}{c}\text { Correlation } \\
\text { pain intensity } \\
\text { and disability }\end{array}$ & $\begin{array}{c}\text { Correlation } \\
\text { pain-related fear } \\
\text { and pain intensity }\end{array}$ \\
\hline Fritz et al. $(2001)^{*}$ & $0.34^{*}-0.40^{*}$ & $0.58^{*}$ & $0.40^{*}-0.53^{*}$ \\
Grotle et al. $(2004)^{2}$ & $0.14-0.25^{*}$ & $0.45^{*}$ & $0.07-0.13$ \\
Swinkels-Meewisse et al. $(2003)^{3}$ & - & $0.45^{*}$ & $0.10-0.18^{*}$ \\
Sieben et al. $(2005)^{4}$ & $0.33^{*}$ & $0.57^{*}$ & $0.15^{*}$ \\
\hline
\end{tabular}

1) $\mathrm{N}=78$, acute $\mathrm{LBP}<3$ weeks; pain intensity: 0-10 ordinal rating scale; pain-related fear: $\mathrm{PABQ}$ work, PABQ-physical activity; disability: Oswestry; Pearson cortelations presented.

2) $\mathrm{N}=123$, acuite $\mathrm{LBP}<3$ weeks with furst $\mathrm{LBP}$ consultation; pain-intensity: 0-100 mm. VAS ; painrelated fear: FABQ-work, FABQ-physical activity; disability: Oswestry; Pearson correlations presented.

3) $\mathrm{N}=329$, acute $\mathrm{CBP} \leq 4$ weeks; pain-intensity: 0-100 mm. VAS; pain-related fear: TSK harm, TSK-activiry-avoidance; disability: RDQ; Pearson correlations presented.

4) $\mathrm{N}=247$, acute LBP $\leq 3$ weeks; pain-intensity: 0-100 mm VAS; pain-related fear: TSK; disability: QBPDS; Spearman rank cotrelations presented.

$\mathrm{FABQ}=$ Fear Awoidance Beliefs Questionnaire; Oswestry = Oswestry Disability Questionnaire; VAS = Visual Analogue Scale; RDQ = Roland Disability Questionnaire; QBPDS = Quebec Back Pain

Disability Scale, p-values $\leq 0.05$ are marked *. 
With respect to fear-reducing treatment, evidence is accumulating. An evidence based booklet, a cognitive-behavioural self-management ptogtam and ath activating intervention were found to reduce pain-related fear in primary care LBP patients (Burton et al., 1999; Moore et al., 2000; Von Korff et al., 2005), and a population based media-campaign improved beliefs about LBP in both patients and GPs (Buchbinder et al., 2001). Initial evidence from single-case experiments on the effectiveness of specific exposure in vivo treatment was extended to more settings and research designs (Boersma et al., 2004) and with objective measures of physical activity (Vlaeyen et al., 2002). A study done by de Jong et al (2005) showed the educational patt of the intervention to cause initial improvements, but further improvement occurred only after exposure in vivo was also applied (and not after graded activity, which was used as a control condition). Performance on relevant daily activities was not affected by education and improved only after exposure. No other studies testing exposure in vivo in acute patients could be traced in literature.

\section{WHAT THIS RESEARCH ADDS}

Our research will probably not yet change evidence-based primary care clinical guidelines; for that the results are too weak and the conclusions too ambiguous. On the other hand, from an epidemiological point of view it can be argued that if pain-related fear influences LBP course only a slightest bit, and if fear-reducing treatment is effective in even a small subgroup of patients, then implementation in daily practice may still make a large difference on the overall picture. Considering that LBP incidence rates are high and powerful treatment options are lacking, our findings, together with other evidence from recent literature, may deserve the benefit of the doubt (given its theoretical grounding) pending further research. However, implementation at this point is difficult also for practical reasons. Nomative data on the Tampa Scale for Kinesiophobia needed for efficient screening are still lacking. Furthermore, the exposure in vivo intervention as we tested was designed and applied by researchers; protocols and tools will have to be reconsidered for their usefulness in clinical practice and GPs will have to be trained in specific skills needed to derive a hierarchy of feared activities and to conduct behavioural experiments.

\section{RECOMMENDATIONS FOR FUTURE RESEARCH}

Regarding fear-avoidance processes during the acute stages of LBP, future research should further explore how the differences between acute and chronic conditions that were found in several studies can be explained. Single case designs with 
frequently repeated measurements may be helpful in studying these details, and are also useful in further refinement of exposure in viwo treatment protocols. Furthermote, additional large longitudinal studies on the influence of fearavoidance variables of LBP prognosis are badly needed, but consensus on preferable methods is a necessary tequirement for comparability.

Additionally, attention should be paid to the further development of screening procedures to identify patients at risk. Exposure in vivo treatment may be beneficial for a subgroup of patients, but this subgroup has to be defined more clearly. More research is needed on the properties of the TSK as a screening tool. Alternative instruments should also be considered, like the often-used Fear Avoidance Beliefs Questionnaire (FABQ) (Waddell et al., 1993) or the modified FABQ that Linton et al. (2000) developed specifically for application in pain-free individuals. As the four () items of this scale are formulated in more general phrasing, this instrument may also be useful in acute stages of a LBP episode. Many patients in our study mentioned having problems in the interpretation of the TSK items; they indicated that their acute stage answers according to the instructions were not in line with their general LBP beliefs. Although the theoretical constructs measured with TSK and FABQ largely overlap, they are not completely the same. While the TSK mainly measures fear of (re)injury, the FABQ is aimed at fear of pain caused by physical activities or work. It can be suggested that this latter operationalisation may better fit to the problems acute LBP patients experience; in the treatment reports from our trial (intervention gtoup) we noticed that many highly fearful patients reported heavy duty occupations, and many feared activities related to work and sports activities. It would be interesting to replicate out RCT with a concurrent assessment of multiple screening tools at baseline to see which one fits best with the treatment results.

A general concern in conducting research on acute patients is the difficulty to recruit patients. This type of research interferes with daily routine in general practice and with patient interest; alternative recruitment methods should be explored. Finally, future research will also have to focus on both further refinement of theoretical knowledge on the exposure in vivo treatment together with clinical implementation studies. 


\section{REFERENCES}

- Boersma, K, Linton, S, Ovemeer, T, Jansson, M, Vlaeyen, J, de Jong, J. (2004). Lowering fear-avodance and enhancing function through exposure in vivo A multiple baseline study across six patients with back parn. Pain, $108(1-2), 8-16$.

- Boersma, K. Einton, S.J. (in press). How does persistent pan develop? An andysis of the relationship between psychological trariables, pain and function across stages of chronicity. Behausur Reseamb and Therapy.

- Buchbinder, R. Jolley, D., Wyati, M. (2001). Popalation based intervention to change back pain beliefs and disability: three part evaluation. Bwy, 322 (7301), 1516-1520.

- Buer, N, Linton, S.J. (2002). Fear-avoidance beltefs and catastrophizing: occurrence and risk factor in back pain and ADL in the general population. Pain, 99 (3), 485-491.

- Burton, A.K., Waddell, G., Tillotson, K.M., Summerton, N. (1999). Intormation and advice to patients whth back pain can have a positive effect. A randomized controlled tral of a novel educational booklet in primary care. Spine, 24 (23), 2484-2491.

- de Jong, J.R., Vlaeyen, J.W.S., Onghena, P., Goossens, M.E., Geilen, M., Mulder, H. (2005). Fear of movement/(re)injury in chronic low back pain: education or exposure in vivo as mediator to fear teduction? Clin J Pañ, 21 (1), 9-17; discussion 69-72.

- Deyo, R.A., Battie, M., Beurskens, A.J., Bombardier, C., Croft, P., Koes, B., Malmivara, A., Roland, M., Von Korff, M., Waddell, G. (1998). Outcome measures for low back pain research. A proposal for standardized use. Spine, 23 (18), 2003-2013.

- Dworkin, R.H., Turk, D.C., Farrar, J.T., Haythornthwaite, J.A., Jensen, M.P., Katz, N.P., Kerns, R.D., Stucki, G., Allen, R.R., Bellamy, N., Carr, D.B., Chandler, J., Cowan, P., Dionne, R., Galer, B.S., Hertz, S., Jadad, A.R., Kramer, L.D., Manning, D.C., Martin, S., McCormick, C.G., McDermott, M.P., McGrath, P., Quessy, S., Rappaport, B.A., Robbins, W., Robinson, J.P., Rothman, M., Royal, M.A., Simon, L., Stauffer, J.W., Stein, W., Tollett, J., Wernicke, J., Witter, J. (2005). Core outcome measures for chronic pain clinical trials: IMMPACT recommendations. Pain, $113(1-2), 9-19$.

- Fritz, J.M., George, S.Z., Delitto, A. (2001). The role of fearavoidance beliefs in actute low back pain: relationships with current and future disability and work status. Parn, 94 (1), 7-15.

- Grotle, M., Vollestad, N.K., Veierod, M.B., Brox, J.I. (2004). Fear-avoidance beliefs and distress in relation to disability in acute and chronic low back pain. Pain, $112(3), 343-352$.

- Linton, S.J., Buer, N., Vlaeyen, J.W.S., Hellsing, A.L. (2000). Are fear-avoidance beliefs related to the inception of an episode of back pain? A prospective study. Psybology and Health, 14, 1051-1059.

- Moore, J.E., Von Korff, M., Cherkin, D., Saunders, K, Lorig, K. (2000). A randomized trial of a cognitive-behavioral program for enhancing back pain self care in a primary care setring. Patis, 88 (2), 145-153.

- Picavet, H.S., Vlaeyen, J.W.S., Schouten, J.S. (2002). Pain catastrophizing and kinesiophobia predictors of chronic low back pain. Ant Espiatmiol, 156 (11), 1028 1034.

- Swinkels-Meewisse, I.E., Roelofs, J, Verbeek, A.I., Oostendorp, R.A., Vlaryen, J.W.S. (2003). Fear of movement/(re)injury, disability and participation in acute low back pain. Pain, $105(1-2), 371-379$. 
- Turk, D.C., Dworkin, R.H., Allen, R.R., Bellarny, N., Brandenburg, N., Carr, D.B, Cleeland, C.s Dionne, R. Farrar, J.T., Galer, B.S., Hewitt, D.I., Jadad, A.R., Katz, N.P., Kramer, L.D., Manning, D.C., McCormick, C.G., McDermont, M.P., McGrath, P., Quessy, S., Rappaport, B.A., Robinson, J.P., Royal, M.A., Simon, L., Stauffer, J.W., Stein, W., Tollett, J., Witter, J. (2003). Core outcome domains for chronic pain clinical trials: TMMPACT recommendations. Pait, 106 (3), $337-345$.

- Vlaeyen, JW.S., de Jong, J., Geilen, M., Heuts, P.H, van Breukelen, G. (2002). The treatment of fear of movement/(re)injury in chronic low back pain: further evidence on the effectiveness of exposute in vivo. Clin J Pain, 18 (4), 251-261.

- Von Korff, M., Balderson, B.H., Saunders, K, Migliorett, D.L., Lin, E.H., Berry, S., Moore, JE., Turner, J A. (2005). A trial of an activaring intervention for chronic back pain in primary care and physical therapy settings. Pain, 113 (3), 323-330.

- Waddell, G, Newton, M., Henderson, I, Somerville, D., Main, C.I. (1993). A FearAvoidance Beliefs Questionnaire (FABQ) and the role of fear avoidance beliefs in chronic low back pain and disability. Pain, $52(2), 157-168$. 
Summary 


\section{CHAPTER 1 Introduction}

Low back pain (LBP) is a major health problem, especially in industrialised countries. Lifetime incidence rates are high (59-70\%), and although most patients recover within weeks, recurrences are common. Some even develop a chronic LBP condition, with severe disability and psychological problems. This minority also accounts for high health care and socio-economic costs.

Previous research mainly focussed on chronic conditions, but recent literature suggests that secondary prevention (preventing acute pain from becoming chronic) may be a more promising approach. The development of chronicity may be explained by the fear-avoidance model. However, this theoretical model was derived and validated in studies on chronic LBP patients. The overall aim of the reseatch reported in this thesis was to test the longitudinal validity of the fearavoidance model in explaining the transition from acute into chronic low back pain.

\section{CHAPTER 2 Theoretical backgrounds}

The fear-avoidance model was developed from a biopsychosocial perspective on chronic musculoskeletal pain, and postulates that LBP patients who are highly fearful of physical activity and movement (because they fear pain and/or reinjury) are more vulnerable to become chronically disabled. Most patients will resume their daily activities as soon as possible, and continuously confront and adjust their expectations about pain. In contrast, patients who report high levels of pain-related fear will instead avoid new pain experiences. They deprive themselves of the opportunity to calibrate their pain behaviour against the actual level of nociception, and are at risk of becoming trapped in a cycle of fear, inactivity, and consequent plyysical deconditioning, disability and depressive symptoms.

Recently, several screening instruments have been developed to measure painrelated fear. Also a fear-reducing exposure in vivo treatment was designed and applied in chronic LBP patients. By exposing the fearful patient to movements and activities that he or she tends to avoid, synchrony between pain sensation and pain cognitions is restored. This exposure treatment is analogous to the treatment of phobia, and results from the awareness of the strong similarities between phobia and pain-related fear in chronic pain.

\section{Chapter 3 Early stage pain-related fear}

Lacking any information on pain-related fear levels in acute LBP, we conducted a prospective case series to investigate the course of pain-related fear during the first two weeks of a new LBP episode. Forty-four general practice patients who 
consulted their physician because of a new episode of non-specific LBP $\quad \leq 3$ weeks) were recruited: "They completed diaries on pain-related fear, pain and pain catastrophizing for 14 days following the consultation. Follow-up questionnaires on disability were completed at 3 months and 12 months. Time series analyses produced subgroups of patients with descending ( $n=13$ ), stable $(n=12)$ and rising $(n=9)$ levels of pain-related fear over the 2 -week period: These groups differed on levels of disability at baseline and follow-up; patients who reported rising painrelated fear levels were more disabled after one year. This subgroup may benefit from early intervention.

Furthermore, although increases in pain intensity were accompanied by increases in pain-related fear and probably its precursor pain catastrophizing as well, any sequential relationship (time-shift) between these variables could not be demonstrated.

\section{CHAPTER 4 Acute stage fear-avoidance variables associations}

Another sample of general practice patients reporting new episodes of LBP was recruited to participate in a longitudinal cohort study (see chapter 5) and a tandomised controlled trial (see chapter 6). Prior to reporting on the longitudinal data, we focused on acute stage baseline associations between fear-avoidance variables. Two hundred and forty-seven patients (median duration of current episode was 5 days) completed questionnaires on (among others) pain-related fear, avoidance, pain and disability. Modest but significant associations were found between pain intensity, pain-telated fear, avoidance behaviour and disability. A strong association was found between pain intensity and disability.

In view of the need for early screening in primary care, we also tested whether pain-related fear was associated with other patient characteristics routinely asséssed by the general practitioner (GP). Pain-related fear was slightly higher in patients reporting low job satisfaction and in those taking bedrest.

These results suggest that the fear-avoidance model as it was developed and tested in chronic LBP, may not entirely apply to acute LBP patients.

\section{Chapter 5 Predictive value of acute stage pain-related fear}

In order to test the assumption that acute stage pain-related fear predicts future disability, the cohort of patients described in chapter 4 was prospectively followed up. The participants completed questionnaires on background variables, fearavoidance model variables and LBP outcome at baseline, 3 months, 6 months and 12 months follow-up and at the end of the study (median 1.9 years). Two hundred twenty-two patients could be included, of whom 174 provided full follow-up information (78.4\%). A backward ordinal regression analysis showed previous LBP 
history and pain intensity to be the most important predictors of end of study Graded Chronic Pain Scale. Of the fear-avoidance model variables, only negative affect added to this model.

Our results do not really support the longitudinal validity of the fear-avoidance model, but they do feed the discussion on the role of pain-related fear in early stages of LBP. The findings also give rise to some methodological considerations concening research on the transition from acute to chronic LBP (see also chapter 8).

\section{Chapter 6 Exposure in vivo treatment}

According to the fear-avoidance model, reduction of pain-related fear in acute stages of LBP will prevent long-term disability. A randomised controlled trial (RCT) was conducted to test the effectiveness of exposure in vivo treatment in addition to usual care for acute LBP patients with elevated levels of pain-telated fear.

Lacking any nomative data, we arbitrarily chose to target the upper quartile of acute stage pain-related fear scores for this experiment. From the sample collected for the study reported in chapter 3, we determined the distribution of Tampa Scale for Kinesiophobia (TSK) scores in acute LBP; the upper quartile of this distribution corresponded with TSK $\geq 42$.

In order to include patients for the RCT, the entire cohort sample (chapter 3) was screened for pain-related fear (as part of the overall recruitment protocol). Patients reporting TSK scores $\geq 42$ were randomised to either exposure in vivo treatment in addition to usual care (EV) or usual care only (UC). Primary outcome was 12-months' Graded Chronic Pain Scale score. (Please note that the EV-group was excluded for the analyses reported in chapter 5.)

Of 247 patients screened, 48 had TSK-scores $\geq 42$ and were randomised. Thirty-four provided full follow-up information at 12 months. The primary analysis (Mann-Whitney test) revealed no differences between treatment groups. However, despite randomisation the EV group showed higher baseline levels of pain-related fear than the UC group. A secondary ordinal regression analysis showed a significant interaction effect between pain-related fear and allocation $(p=0.05$ two-sided). These findings must be interpreted with great caution, as they are based on very small groups (however the statistical test accounts for that). Nevertheless, the results do support fear-avoidance theory and suggest that in a subgroup of very highly and persistently fearful patients exposure in vivo in addition to usual care might be helpful in reducing pain-related fear and improving outcome. However, these conclusions are based on secondary analysis, so replication by new studies is needed. 


\section{Chapter 7 Physicians" LBP orientations}

Assuming patients" L.BP beliefs and behaviour to be predictive of LBP outcome, clinicians should target these in their treatment. And, in line with a biopsychosocial perspective on LBP, it can be hypothesised that the treatinent behaviour of clinicians in turn will be influenced by their own LBP orientation. In this study we examined whether (1) differences in GP treatment orientations towards LBP are associated with differences in actual treatment behaviour and (2) whether treatment orientation is related to LBP outcome in patients.

The GPs who participated in patient recruitment for the cohort study (chapter 3 and 4) completed a set of questionnaires on LBP treatment orientation. These data were linked to the patient data from the cohort study. Associations between measures of treatment orientation, treatment recommendations, treattment behaviour and LBP outcome were analysed.

A biomedical treatment orientation was found to be associated with more concern about tissue damage and the effect of physical activity on pain and recovery in vignettes. No associations were found between treatment orientation measures, actual treatment behaviour and LBP outcome (Graded Chronic Pain Scale) in the cohort patients.

Several explanations were offered for not finding associations as expected, including both the possibilities that an existing association was not detected and/or that the hypotheses used are inaccurate.

\section{CHAPTER 8 General discussion}

The final chapter of this thesis provides an overwiew of conclusions and comments on the findings within the framework of other recent research. The present results do not clearly support nor negate the longitudinal walidity of the fear-avoldance model. The remarkable acute stage associations between fear-avoidance variables (in fact the lack of strong associations) were supported by several other studies. Methodological aspects concerning outcome measurement in recurrent L.BP are addressed, and recommendations are made for future research, including suggestions for longitudinal studies, the development of screening procedures and refinement of exposure treatment. 
Samenvatting 


\section{VOORAF}

Dit is de samenvatting van het proefschrift "Pijngerelateerde vrees bij acute lage rugpijn: op weg naar inzicht in en preventie wan chroniciteit". In dit hoofdstuk wordt het onderzoek beschreven en uitgelegd voor de geinteresseerde lezer zonder medische of wetenschappelijke achtergrond. Collega-onderzoekers en behandelaars die op zoek zijn naar specifieke vaktermen of inhoudelijke details kunnen deze vinden in de Engelstalige hoofdstukken en samenvatting (Summary).

\section{HoOFDSTUK 1 Inleiding}

In het eerste hoofdstuk wordt ingegaan op de relevantie en de voorgeschiedenis van dit onderzoek, "Gewone" lage rugpijn, dus zonder bijzondere oorzaak (zoals een hernia, wervelbreuk, tumor, etc.) komt zeer veel voor; geschat wordt dat 70$85 \%$ van alle volwassenen in westerse samenlevingen ooit rugpijn oploopt (door vertillen, verdraaien, of - vaker nog - zonder duidelijke aanleiding). Bij verreweg de meeste patiënten gaat zo'n rugpijnaanval (ook wel "episode" genoemd), net als een verkoudheid, zonder speciale zorg of behandeling binnen enkele dagen tot weken vanzelf weer over. Bij veel mensen komen de rugklachten echter met enige regelmaat terug, en met iedere nieuwe episode wordt de kans groter dat de pijn uiteindelijk chronisch wordt. Hoewel slechts een paar procent van alle patiënten dergelijke blijvende rugpijn heeft, zijin voor deze groep de problemen het grootst. De rugpijn veroorzaakt belangrijke lichamelijke en sociale beperkingen voor de persoon zelf, en daarnaast vormen het ziekteverzuim en de medische zorg een grote maatschappelijke kostenpost.

Het is nog steeds de vraag waarom rugpijn bij sommige mensen chronisch wordt, en bij al die anderen niet. Tot op heden heeft de medische wetenschap bij de meeste patiënten met chronische rugpijn geen duidelijke lichamelijke oorzaak kunnen aantonen. De laatste tientallen jaren hebben diverse onderzoeken wel aannemelijk gemaakt dat psychische en sociale factoren een rol spelen, zoals bijvoorbeeld de manier waarop iemand reageert op en omgaat met pijn. Een theoretisch model dat hierover gaat is het vrees-vermijdingsmodel (zie hst. 2). Aan de hand van dit model (dat een vicieuze cirkel beschrijft) kan worden uitgelegd hoe chronische rugpijn kan blijven voortduren. Maar kan dit model ook gebruikt worden als verklaring voor het ontstaan van de chroniciteit, dus het chronisch worden van een op zich onschuldige rugpijnaanval? Een antwoord vinden op deze vraag is het eerste doel van het onderzoek waarvan in dit proefschrift verslag gedaan wordt.

Een tweede onderzoekswraag is of een nieuwe behandeling, die gebaseerd is op de genoemde theorie, effectief is en perspectief biedt voor patienten met rugpijn in de huisartspraktijk. 


\section{HoofDSTUK 2 Theoretische achtergrond}

Het ligt wellicht voor de hand dat men, als men rugpijn heef, een beetje voorzichtig doet met die rug. Maar bij rugpijn zonder bijzondere oorzaak zijn de spieren na een paar dagen woldoende hersteld om weer normal hun werk te kunnen doen. Sterker nog: lichaamsbeweging bevordert het herstel van de rug: Sommige mensen zijn er echter zó van overtuigd dat er iets ernstigs aan de hand is, en zijn zó bang voor blijvende schade aan hun rug (dit wordt pijngerelateerce vxees genoemd), dat ze bewegingen zoals tillen, draaien en bukken "uit voorzorg" helemaal vermijden (ook na de eerste paar dagen). Mar een rug die niet beweegt en niet belast wordt, wordt gauw stijf en de spieren worden zwakker. Op den duur wordt het lichaam gevoeliger voor pijn, en kan de rug nergens meer tegen. Men raakt dan steeds meer beperkt in de gebruikelijke bezigheden zoals werk, sport en hobby's. De leuke bezigheden schieten er vaak het eerste bij in, en dat gaat weer ten koste van het humeur en het vermogen om de pijn te verdragen. Patiënten met veel pijngetelateerde vrees lopen zo het risico verzeild te raken in een cirkel van pijn, angst, vermijding, beperkingen en depressiviteit, waat ze zonder hulp niet uit kunnen komen.

\section{Hoofostuk 3 Pijngerelateerde vrees in het begin van een episode}

Hoofdstuk drie gaat over een voorstudie die is uitgevoerd als voorbereiding op de rest van het project. Toen dit project in 1999 van start ging, was er al het nodige onderzoek geclaan bij patiënten met chronische lage rugpijn, maar was er nog weinig tot niets bekend over de rol die pijngerelateerde vrees speelt bij acute rugpijn. Wij vroegen 44 patiënten die naar hun huisarts gingen vanwege een nieuwe episode van lage rugpijn, om gedurende de eerste twee weken na dit consult een dagboek bij te houden. Dat dagboek bestond uit vragen die onder andere te maken hadden met de emst van de pijn in de rug en met de pijngerelateerde vrees die men daarbij had. Drie maanden later en na een jaat vulden ze ook nog een vervolgvragenlijst in, waarin werd nagegaan hoe het op dat moment met de $\operatorname{rug}($ pijn) was.

Statistische analyses wan de gegevens in de dagboekjes lieten zien dat er verschillende groepen te onderscheiden waren: patiënten bij wie de pijngerelateerde vrees eerst hoog was, maar in de loop van de twee weken "vanzelp" afnam (13 personen); patiënten bij wie de pijngerelateercle vrees nagenoeg constant bleef (12 personen) en patiënten bij wie de pijngerelateerde vrees steeds erger werd ( 9 personen). Die laatstgenoemde gtoep had een jaar later meer last van de rug dan de andere twee groepen. Deze uitkomsten suggereren dat het goed kan zijn om al in een vroeg stadium in de gaten te houden hoe de pijngerelateerde vrees zich 
ontwikkelt en zo nodig in te grijpen; een laag beginniveau betekent niet per definitie een goed vooruitzicht (en omgekeerd).

\section{HoOFDsTUK 4 Het vrees-vermijdingsmodel bij acute rugpijn}

In dit hoofdstuk wordt de beginfase van de hoofdstudie van dit project beschreven. Een nieuwe, grote groep patienten met acute lage rugpijn werd via de huisarts benaderd on deel te nemen aan een langlopend vragenlijstonderzoek (hoofdstuk 5) en/of een behandelstudie (hoofdstuk 6). Aan deze oproep gaven 247 patienten gehoor. Nadat ze bij de huisarts waten geweest vanwege hun rugpijn (de meeste deden dat zo'n vijf dagen na het ontstaan wan de klachten), vulden deze patiënten een eerste uitgebreide vragenlijst in.

Al die vragenlijsten bij elkaar lieten zien, dat de intensiteit van de rugpijn, de hoogte van de pijngerelateerde vrees, de mate waarin activiteiten vermeden werden, en de hoeveelheid ervaren lichamelijke beperkingen enigszins met elkaar samenhingen. Op grond van de theorie van het vrees-vermijdingsmodel zou men deze verbanden ook mogen verwachten, maar dan wel in sterkere mate (zoals het geval is bij groepen met chronische patiënten). Hoewel de samenhang tussen de meeste van de genoemde kenmerken over het algemeen dus nogal zwak was, waren de uitkomsten wel statistisch significant. Dit betekent dat de gevonden verbanden niet mogen worden opgevat als louter toevallig. Het enige sterke verband werd gevonden tussen de intensiteit van de rugpijn en de mate waarin men zich beperkt voelde. In eerdete onderzoeken bij chronische patiënten was die laatste relatie juist telkens afwezig.

Hoewel onze resultaten niet heel duidelijk te interpreteren zijn, lijkt het erop dat het vrees-vermijdingsmodel zoals het is ontworpen voor de chronische fase wel herkenbaar is bij acute rugpijn, maar dat het toch niet helemaal precies past.

\section{HoofDSTUK 5 Voorspelt pijngerelateerde vrees latere rugklachten?}

In hoofdstuk vijf wordt verslag gedaan van het vervolg van het vragenlijstonderzoek. Om na te gaan of de mate waarin iemand pijngerelateerde vrees heeft in het beginstadium van rugpijn een voorspellende factor is voor toekomstige rugklachten, hebben we de groep patienten die beschreven is in hoofdstuk vier lange tijd gevolgd. De deelnemers vulden 3 maanden, 6 maanden en 12 maanden na het begin van hun rugpijn opnieuw viagenlijsten in. Aan het einde van het hele project (in april 2004) hebben we iedereen tegelijk nog een korte vragenlijst gestuurd; dat was gemiddeld bijna twee jaar na het (eerste) bezoek aan de huisarts.

Voor de analyses die nodig waren om de vraag die bij dit hoofdstuk hoort te kunnen beantwoorden, konden we de gegevens van 222 patiënten gebruiken. Van hen vulden er $174(78.4 \%)$ alle vervolgvragenlijsten in. Uit de analyses bleek, dat 
het antal eerdere rugpijnepisodes en de intensiteit van de pijn (gemeten na het bezoek aan de huisarts, dus tijdens de acute fase) de beste voorspellers waten voor de ernst van de klachten aan het eind van de vervolgperiode. Van alle kenmerken die te maken hebben met het vrees-vermijdingsmodel, voegden alleen negatieve emoties nog iets toe aan de voorspelling.

Tegen de verwachting in bleek pijngerelateerde vrees in deze studie dus geen voorspellende factor voor een negatieve ontwikkeling van nigklachten. Dit kan global twee dingen betekenen: (1) de overgang van acute naar chronische rugpijn kan niet afdoende verklaard worden aan de hand wan het vrees-vermijdingsmodel, of (2) de manier waarop dit onderzoek is uitgewoerd is niet helemaal geschikt geweest om een relatie tussen vroege pijngerelateerde vrees en het beloop op lange termijn van de rugklachten vast te stellen.

\section{HoOFDSTUK 6 Een vreesverlagende behandeling}

Een volgende deelstudie, een experiment met een vreesverlagende behandeling, wordt beschreven in hoofdstuk zes van dit proefschrift. Een experiment wordt beschouwd als de sterkste vorm van wetenschappelijk bewijs; het is de ideale methode om oorzaak-gevolg-relaties te onderzoeken. Door een groep patiënten die een "nieuwe" behandeling heeft gekregen te vergelijken met een andere groep die geen behandeling, een reeds bestaande behandeling of een nepbehandeling heeft gehad, kan worden nagegaan hoe effectief de nieuwe behandeling is geweest. Wij deelden patiënten met acute rugpijn en veel pijngerelateerde wrees door middel van loting in één van twee groepen in. De ene groep ontwing van ons, naast de gangbare behandeling door de eigen huisarts, een aanvullende vreesverlagende behandeling. De andere groep werd alleen door de huisarts behandeld zoals dat gebruikelijk is.

Die vreesverlagende behandeling leek nogal op de manier waarop ook fobieèn aangepakt worden. Angst voor spinnen bijvoorbeeld, wordt behandeld door de persoon stukje bij beetje te confronteren met steeds grotere spinnen, die steeds dichterbij komen. En hoogtevrees gaat vaak over als men begeleid wordt bij het beklimmen van steeds hogere trappen en ladders. Deze aanpak wordt "exposure in vivo" genoemd (letterlijk: blootstelling aan den lijve). In ons onderzoek hebben we een vergelijkbare werkwijze toegepast. Onze behandeling bestond uit drie opeenvolgende stappen. In de eerste stap werd voor iedere patiënt uitgebreid uitgezocht voor wellke bewegingen hij of zij het meest bang was en waatom (wat zou er mis kunnen gaan met de rug?). Dit gebeurde door middel van een gestructureerd gesprek aan de hand van foto's met voorbeelden van allerlei bewegingen en activiteiten. Vervolgens kreeg de patiënt in de tweede stap informatie over rugpijn in het algemeen (wat is het? hoe wordt ' $t$ behandeld?) en uitleg over het vrees-vermijdingsmodel in het bijzonder. Het eigen verhaal van de 
patiënt stond daarbij steeds centraal. Nadat de patiènt zich bewust was geworden van zijn of haar extreme voorzichtigheid, het vermijdingsgedrag en de risico's die daaraan kleven (namelijk dat het de klachten op den duur erger maakt in plaats van verbetert), gingen we verder met de derde en laatste stap van de behandeling. Daarin werden de bewegingen waar de patiënt het meest bang voor was, stukje bij beetje geoefend. Vaak waren dat bezigheden zoals tillen; bukken, draaien of springen, maar het kon woor iedereen iets anders zijn. Op die manier werd de patiënt in de gelegenheid gesteld om aan den lijve te ervaren dat deze bewegingen toch niet zo weel kwaad kunnen als hij of zij van tevoten had gedacht. Deze exposure-oefeningen werden gedaan volgens een bepaalde systematiek en net zo lang tordat de patiënt voldoende gerustgesteld was en vertrouwen had opgedaan on zelf in het dagelijks leven ook vaker de rug weer te durven belasten.

We veronderstelden dat met deze behandeling de vicieuze cirkel van her vreesvermijdingsmodel doorbroken kon worden. Als deze aanname klopt, dan zouden er in de behandelde groep in ons experiment op den duur minder patiënten chronische rugpijn moeten krijgen dan in de vergelijkingsgroep. We namen dus de proef op de som. Achtenveertig patiënten met veel pijngetelateerde vrees werden ingedeeld in de twee groepen. Vietendertig van hen vulden twaalf maanden later ook de vervolgvragenlijst weer in. Op het eerste gezicht vonden we geen verschillen tussen de twee behandelingen; na een jaar ging het met beide groepen even goed. Maar de situatie werd gecompliceend doordat de beide groepen, ondanks de loting, niet helemaal vergelijkbaar waren. De patiënten in de behandelgroep hadden ramelijk in het begin meer pijngerelateerde vrees dan de vergelijkingsgroep, en clat zou de uitkomsten vertekend kunnen hebben. Bij een tweede analyse, waarbij we corrigeerden voor dit verschil, leek het erop dat de exposure-in-vivo-behandeling wel werkte, maat dan voorall bij de patiënten bij wie de pijngerelateerde vrees aan het begin het hoogst was. Deze resultaten moeten echter met de nodige voorzichtigheid bekeken worden, omdat ze zijn gebaseerd op kleine aantallen patiënten, en dan is het niet geoorloofd om algemeen geldende uitsptaken te doen. Oorspronkelijk was het ook de bedoeling geweest om veel meer mensen aan deze deelstudie te laten meedoen (2 groepen van ieder 100 in plaats van 2 groepen van ieder 25), maar dat bleek uiteindelijk niet haalbaar te zijn.

Niettemin ondersteunen de bevindingen het vrees-vermijdingsmodel. Het lijkt erop dat patiënten met rugpijn en extreem hoge en langdurende pijngerelateerde vrees baat kunnen hebben bij de vreesverlagende exposure-in-vivo-behandeling. Voor patiënten met minder pijngerelateerde vrees en vrees die als de rugpijn minder wordt ook spontaan weer zakt, is het nut niet aangetoond. Deze conclusies zijn echter gebaseerd op analyses die in tweede instantie zijn gedaan (en die niet in het oorspronkelijke plan stonden), en dat betekent dat ze opnieuw onderzocht zullen moeten worden in nieuwe studies. 


\section{Hoofdstuk 7 De visie van de huisarts op rugpijn}

In het laatste onderdeel van het onderzoeksproject vormen nu eens niet de patiënten, maar de huisartsen die hen behandelen het onderwerp van studie. We vetonderstelden steeds, dat de ideeën en het gedrag van de patiënten de klachten beilnwloeden. Behandelaars, zoals huisartsen, moeten daar, in navolging van de huidige richtlijnen, in hun behandeling aandacht aan besteden en waar nodig de patiënt proberen bij te sturen ("op andere gedachten brengen"). Het is dan te verwachten dat die arts zich, bewust of onbewust, hierbij zal laten leiden door hoe hij of zij zelf denkt over rugpijn. Deze visie van de arts wordt de behandeloriëntatie genoemd. In deze deelstudie gingen we na of (1) verschillen in behandeloriëntaties tussen huisartsen samengaan met verschillen in behandeling en (2) of de behandeloriëntatie samenhangt met het beloop van de klachten bij de patiënten.

De huisartsen, die ons eerder hielpen bij het zoeken naar en uitnodigen van patiënten voor het project, vulden zelf ook vragenlijsten in. Met deze vragenlijsten werd hun behandeloriëntatie ten aanzien van rugpijn gemeten. Deze gegevens werden gecombineerd met de gegevens die we hadden van de patiënten.

De analyses lieten zien dat artsen die meer biomedisch georiënteerd zijn, bij rugpijn eerder het idee hebben dat er sprake is van beschadigingen, en meer bezorgd zijn over de invloed die lichamelijke activiteit kan hebben op pijn en herstel. We vonden geen verband tussen de behandeloriëntatie van de huisarts, de behandeling die de patiënten kregen, en het beloop van de rugpijn bij de patiënten.

Wellicht waren onze veronderstellingen over het verband tussen behandeloriëntatie, werkelijke behandeling en het beloop van rugpijn op langere termijn toch niet juist. Maar het kan ook zijn dat we een samenhang die wel degelijk bestaat niet gevonden hebben, aangezien het om concepten gaat die heel moeilijk praktisch te omschrijven en te meten zijn.

\section{Hoofdstuk 8 . Algemene discussie}

In de algemene discussie worden alle bevindingen uit dit proefschrift nog eens op een rijtje gezet en besproken in het kader van andere recente onderzoeken. Alles bij elkaar vormen onze resultaten geen duidelijke ondersteuning voor het vreesvermijdingsmodel als verklaring voor de ontwikkeling van chronische tugpijn, maar ze ontkrachten de theorie ook niet. Misschien komt dat, doordat pijngerelateerde vrees wel een rol speelt, maar slechts bij een veel kleiner deel van alle patiënten dan wij vooraf dachten. Als ook andere factoren hun steentje bijdragen (en dat is zeer aannemelijk), dan "verdunt" dat het zichtbare effect van pijngerelateerde vrees. Het kan ook zijn, dat pijngerelateerde vrees niet meteen aan 
het begin van een rugpijnepisode, maar pas later, als de pijn langer duurt of vaker tertugkomt, belangrijk wordt.

Het is al even moeilijk om een uitspraak te doen over de effectiviteit van de exposure-in-vivo-behandeling bij patiènten met acute rugpijn. Vanwege het beperkte aantal patiënten dat wij konden bestuderen, mogen we uit ons experiment geen "harde", algemeen geldende, conclusies trekken. Maar van de andere kant wekken de tesultaten wel de suggestie dat een deel van de patiënten baat kan hebben bij exposure in vivo. Vervolgonderzoek in een grotere groep is zeker nodig on dit verder uit te zoeken. Ook de manier waarop de behandeling gegeven wordt, kan in de toekomst nog verder verbeterd worden.

Waat we in ieder geval achter gekomen zijn, is dat het niet eenvoudig is om het verloop van rugpijn in de tijd te meten. Want bij de meeste mensen kent tugpijn een grillig patroon, met pieken van ernstige pijn, periodes van lichtere, "zeurende" pijn en pijnvrije momenten. Het ligt er dus maar nét aan, op welk moment iemand de vragenlijsten ingevuld heeft. De eerdere studies die gedaan zijn bij patiënten met ernstige, chronische rugpijn hadden hier niet zoveel last van, omdat die voornamelijk deelnemers hadden bij wie de pijn een constanter karakter had. In onze studiepopulatie zijn dergelijke écht chronische gevallen echter zeldzaam. Ook. hier kunnen we weer van leren voor toekomstig onderzoek.

In de tijd waarin dit onderzoeksproject is uitgevoerd (1999-2005), zijn ook enkele andere onderzoekers in binnen- en buitenland bezig geweest met studies naar acute lage rugpijn. De opvallende verbanden die wij enigszins onverwacht in hoofdstuk vier vonden, werden ook door andere onderzoekers gerapporteerd. De weinige andere studies die er zijn gedaan op het gebied van de ontwikkeling van. chroniciteit zijn moeilijk met elkaar te vergelijken, maar ze ondersteunen nagenoeg allemaal het vrees-vermijdingsmodel. Er zijn echter nauwelijks studies te vinden die net als wij heel acute patiënten in het onderzoek hebben betrokken. Hetzelfde geldt voor onderzoek naar vreesverlagende behandelingen.

Wat voegt dit proefschrift nu toe aan de medische wetenschap? Het zal, gezien de dubbelzinnige uitkomsten, op dit moment weinig veranderen aan de manier wararop rugpijn behandeld wordt. Van de andere kant, zelfs als we de conclusies uiterst voorzichtig interpreteren, kan dat belangxijk zijn voor de dagelijkse praktijk. Want zelfs al zou pijngerelateerde vrees maar een heel klein beetje invloed hebben op de ontwikkeling van rugpijn, en ook al zou exposure-in-vivo-behandeling effect hebben in slechts een kleine groep patiënten, dan kan dat nog een groot verschil betekenen voor het grote geheel, aangezien rugpijn zo ontzettend vaak voorkomt, en er nog weinig goed werkende behandelingen bekend zijn. Maar... verder onderzoek is zeker noodzakelijk om wat professor Waddell (een autoriteit in dit vakgebied) ooit "het grootste gezondheidszorgraadsel van de twintigste eeuw" noemde, op te lossen! 
Dankwoord 


\section{DANKWOORD}

Het laatste hoofdstuk van dit proefschrift is aangebroken. Dat betekent dat het werk erop zit, hetgeen ik uiteraard fijn maar tegelijkertijd ook best jammer vind. Het markeert het einde van een bijzondere periode. Zes jaar promotietraject zijn voorbij gevlogen; het is voor mij een leerzame en vooral plezierige tijd geweest. En daar hebben zeer velen aan bijgedragen.

Op de eerste plaats wil ik me richten tot Piet Portegijs. Een enthousiaster dagelijks begeleider kan ik me niet voorstellen. Ook al zaten we wel eens in de knoop met elkaars gebruiksaanwijzing (eerlijk is eerlijk, en het gold vast voor ons beiden), gaandeweg konden we blindelings van elkaar op aan. De samenwerking groeide uit tot een goed geoliede machine (of was het een windmolen, Piet?). Ik heb veel opgestoken van jouw methodologisch en statistisch inzicht. Jouw niet aflatende betrokkenheid bij het project, het proefschrift én mijn persoonlijk welbevinden was bijzonder en heb ik zeer gewaardeerd. Ik zal in de toekomst vast nog wel eens bij je te rade komen, als dat mag.

Hartelijk dank ook aan de andere (co-)promotoren: Johan Vlaeyen, André Knottnerus, Annoud Arntz en eerder ook Marcel van den Hout. Jullie stonden steeds klaar met raad en daad wanneer dat nodig was. Ieders inbreng was uniek en onmisbaar. Johan, jij stond als geestelijk vader aan de wieg van dit project en gaf door de jaren heen de nodige theoretische richting aan het geheel. Bedankt voor je coaching en hulp in het algemeen, en in het bijzonder bij het aanleren van de interventie. En natuurlijk ook voor de talrijke uitstapjes naar congressen en collegaonderzoeksgroepen. André, als eerste promotor stuurde jii op een zeer prettige manier - rustig en duidelijk - het geheel aan. Bedankt voor de diplomatieke wijze waarop jij menige knoop hielp doorhakken, wanneer alle goede ideeën uit de diverse disciplines even niet met elkaar te verenigen leken te zijn. Marcel, bedankt. voor je hulp bij het denkwerk in de beginfase. Arnoud, jii werkte je na het vertrek van Marcel van den Hout in korte tijd in het project in. Bedankt voor je tauchtere, kritische blik, statistische lessen en aanstekelijke gedrevenheid.

En dan was er natuurlijk het Back Use team. In Back. Use (zo luidde de werktitel. waaronder het project in de praktijk werd uitgevoerd) werden verschillende deelstudies, niet zonder pijn en moeite, maar met groot succes verenigd. Back Use was niet alleen mijn project - het was vooral ook óns project. Met z'n allen brachten we op onnavolgbare wijze (ja, echt!) het project tot leven.

"Soulmate" Jeanine, het was fijn om met jou in hetzelfde schuitje te zitten. "Samen sterk" klinkt afgezaagd, maar geldt zeker in dit geval. Bedlankt voor je geduld in de beginfase van het project en woor het delen wan een bed in San Diego. 
Sita en Eric, zonder jullie werk was het allemaal niet gelukt. Al die telefoontjes naat patiënten en ritjes naar praktijken; stel je toch eens voor dat we duizend patiënten gehad hadden! (lk moet er niet aan denken....) En zonder de stagiaires Sandrine, Franca, Ageeth en Nadine was een aantal studies die deel uitmaken van dit proefschrift niet mogelijk geweest. Bedankt voor jullie inzet, frisse ideeèn en lef?

De dinsdagochtend is in ieder geval nooit meer hetzelfde geworden. Weet er iemand al een goede smoes voor de volgende borrel?

Ook wil ik de FADIS-programmagtoep (ooit door een buitenlandse collega op een congres liefkozend "The Maastricht Maffia" genoemd) bedanken. Ruud, Jeffrey, Madelon, Claudine, Marielle, Jeroen, Anja en later ook Maaike en Caroline, dank jullie wel voor de vele inspirerende bijeenkomsten en gezellige trips naar congressen. Alle andere onderzoekers van "de pijnclub" in brede zin: llse, Rob, Jacques, Camiel, het was telkens weer fijn om met jullie van gedachten te wisselen.

De EPP AiO-cursussen zijn een belangrijk element geweest in het promotietraject. De bijeenkomsten in Soesterberg leverden niet alleen nuttige kennis op, maar ook een paar goede vriendschappen. "Slapies" Jannet en Mieke, ik mag de rij sluiten. Dadelijk zijn we alle drie doctor, dat staat sjiek! Laten we ons driemanschap (drievrouwschap?) blijven koesteren...

Bij de capaciteitsgroep Huisartsgeneeskunde, die als mijn thuisbasis fungeerde, heb ilk een prima tijd gehad. Bedankt allemaal! Vooral de bewoners van de tweede verdieping (Marjolein, Roelf, Barbara, Lisette, Maaike, Janneke, Arjan, Jochen) dank ik voor de prettige werksfeer en onderlinge betrokkenheid.

Welgemeende dank ook aan de nog niet genoemde mede-auteurs van de verschillende hoofdstukken in dit proefschrift: Arnold Kester, voor zijn objectieve statistische adviezen; Arnold Romeijnders, voor zijn gastvrijheid in de beginfase én het leveren van het cruciale idee dat ten grondslag lag aan hoofdstuk 7; Paul Knipschild voor een immer kritische blik en uitdagende discussies.

Dear Michael Von Korff, you played an important role throughout the entire project. Thank you for having me stay at your home. I had an unforgettable time in Seattle! Not only because of the tainforest, mountains and baseball; the lessons I learned from your expertise about back pain research and cognitive behavioural interventions have been crucial to this study. Thank you also for your cooperation on and critical remarks to chapter $5-I$ am very pleased having you as a co-author!

Noor van Nierop, bedankt voor het beschikbaar stellen van Hanna voor het omslag van dit boekje. Het is prachtig geworden! 
Zonder deelnemers geen onderzoek. Ik wil alle huisartsen en assistentes bedanken die zo hun best gedaan hebben om ons aan (schijnbar onvindbare?) acute rugpijnpatiënten te helpen. Excuses voor al het gezeur en gebedel dat jullie $2 \frac{1}{2}$ jaar lang hebben moeten ondergaan. Natuurlijk dank ook aan de patiënten, die al die dikke vragenlijsten telkens weer invulden, ook al hadden ze daar zelf helemaal niets aan. Een speciaal woord van dank wil ik kwijt aan de deelnemers in de interventiegroep, die de tijd namen voor mij, mijn verhaal en mijn krat met oefenattributen. Het moet jullie soms vreemd zijn voorgekomen!

Er zijn ook een heleboel mensen buiten het onderzoek en de universiteit die, misschien zonder het zelf te weten, bijgedragen hebben aan mijn "algemeen welbevinden" in de afgelopen jaren.

Op vrijdag vond ik de nodige afwisseling bij Corio Sports \& Health Club. Jacqueline en collega's, bedankt voor alle begrip en vervangingen als ik er vanwege het onderzoek of de AiO-opleiding weer eens niet was. En natuurlijk de leden, mijn leden, van de aquatrainingen en herenfit-groep, het was heerlijk om aan jullie les te geven. Het spijt me dat ik jullie inmiddels heb moeten verlaten.

De dames van het eerste team van handbalvereniging Marsna verdienen hier ook een eervolle vermelding. Samen met jullie kon ik me uitleven en affeageren. Meiden, op naar weer een gezellig en succesvol seizoen!

Nu weer terng naar de dag van vandaag. Jan Wertz, helaas kun jij er, uitgerekend op jouw verjaardag, niet meer bij zijn. Je zou het vast een mooie vertoning hebben gevonden voor de elfde van de elfde! Toke en Ine, bij jullie voel ik me altijd welkom. Fijn dat jullie vandaag meevieren.

Lieve Elise en Tanja, ik ben blij dat jullie vandaag als paranimfen nastst mij staan. Tanja, kamergenote vanaf het eerste uur, we hebben samen zo veel lief en leed gedeeld. Ook al zitten er nu een vijver en een zebrapad tussen onze werkplekken, we blijven elkaar in de gaten houden (daar zorgen onze mannen anders wel voorl). Elise, mijn grote zus, altijd mijn steun en toevetlaat. Jij en ik, bijna tegelijk allebei een titel erbij...... Ik ben best trots op ons! Frans, Marijn en Joost, als "mannelijke tak" van de familie zijn jullie onmisbaar, zeker bij dit soort aangelegenheden.

Lieve papa en mama, in zekere zin hebben jullie de basis gelegd voor dit boekje en alles wat eraan voorafgegaan is. Jullie lieten me de wereld zien, en stimuleerden me om overal op af te gaan, zowel op sociaal gebied als wat studie betreft. Bedankt voor een warm nest, liefdevolle opvoeding en onvoorwaardelijke steun!

En dan het laatste wootd. Lieve Raymond, je blijft liever op de achtergrond, maar ook iij hebt je steentje bijgedragen. Jij was degene die "dweilde" als bij mij de 
emmet even overliep. Jouw relativeringsvermogen hield mij op het juiste spoor. Alles wat ik nu kan verzinnen is cliché, maar toch.... Bedankt dlat je er altijd voor me bent. Eén ding weet ik zeker: liefde gaat voor wetenschap. Vandaag is het feest, óns feest, want er is nog zo veel te vieren: Leve de liefde! 
About the Author 


\section{ABOUT THE AUTHOR}

Judith Sieben was born on september 17, 1973 in Geleen, the Netherlands. She grew up in Elsloo. From 1985 she attended secondary education at the Scholengemeenschap Sint Michiel in Geleen; she obtained her Gymnasium diploma in 1991. She then started her study in Health Sciences at Maastricht University. She specialised in Movement Sciences and graduated in 1996 . Her master's thesis focused on exercise counseling in individuals with health problems. She worked as a medical fitness instructor and management assistant at Q-life Centrum voor Beweging en Gezondheid (1995-1998) and Corio Sports \& Heall th Club (1998-sept. 2005), both in Heerlen. In 1999 she started as a PhD-student at the department of General Practice of Maastricht University and continued her job in sports business on a part-time basis. The studies presented in this thesis are part of the FADIS ("Fear-avoidance beliefs, physical disuse and pain disability in low back pain") research program, which is incorporated within the Experimental Psychopathology Research Institute (EPP). Currently, Judith is working as a lecturer in the department of Anatomy and Embryology of Maastricht University. Besides teaching she is involved in the "Epidemiology of Musculoskeletal Disorders" research program of the Care and Public Health Research Institute (CAPHRI). She is happily married to Raymond Wertz. 
Publications 


\section{PUblications}

Sieben, J.M., Portegijs, P.J.M., Vlaeyen, J.W.S., Knottnerus, J.A. Pain-related fear at the start of a new low back pain episode. Exyropean Jourval of Pain. In press.

Sieben, J.M., Verbunt, J.A., de Jong, J., Vlaeyen, J.W.S. Fear of movement / (re)injury in musculoskeletal pain disorders. In: Simmonds, M. (ed): Measwring and managing patients. In press.

Sieben, J.M., Vlaeyen, J.W.S., Portegijs, P.J.M., Verbunt, J.A., van Riet, S., Kester, A.D.M., Von Korf, M., Arntz, A., Knottnerus, J.A. (2005). A longitudinal study on the predictive validity of the fear-avoidance model in low back pain. Paim, 117, 162170 .

Sieben, J.M. Een bewegingsvrees-verlagende interventie bij acute lage rugpijn. In: van Burken, P., Dijkstra, P.U., Marinus, HJ., Nijs, J., van Wilgen, P. Jaarboek. Fysiotherapie Kinesitherapie 2005. Houten: Bohn Stafleu Van Loghum (2005). pp. 232245.

Verbunt, J.A., Sieben, J.M., Seelen, H.A., Vlaeyen, J.W.S., Bousema, E.J., van der Heijden, G.J., Knottnerus, J.A. (2005). Decline in physical activity, disability and pain-related fear in sub-acute low back pain. European Journal of Pain, 9 (4), 417-425.

Hendriks, D.C.H.J., Sieben, J.M., Tuerlinckx, S., Portegijs, P.J.M., Vlaeyen, J.W.S. (2003) Psychosociale risicofactoren en chronische rugpijn: bruikbare voorspellers in de huisartspraktijk? Huisarts $N$ H, 32(5), 238-247.

Vlaeyen, J.W.S., Peters, M.L., Roelofs, J., de Jong, J.R., Sieben, J., Houben, R., Verbunt, J., Lamoth, C. (2002) Serie onderzoek en psychotherapie: catastrofale misinterpretaties. Vrees voor beweging, letsel en pijn bij lage rugpijn. Tijdscbrift woor Psychotherapie, 28, 205-222.

Vlaeyen, J.W.S., de Jong, J., Sieben, J., Crombez, G. Graded exposure in vivo for pain-telated fear. In: Turk, D.C., Gatchel, R.J. (eds): Psychological approaclses to pain management - a practitioners handbook (second edition). The Guilford Press, New York, 2002, pp. 210-233.

Sieben, J.M., Vlaeyen, J.W.S., Tuerlinckx, S., Portegijs, P.J.M. (2002) Pain-related fear in acute low back pain: the first two weeks of a new episode. European Joumal of Pain, 6 (3), 229-237. 